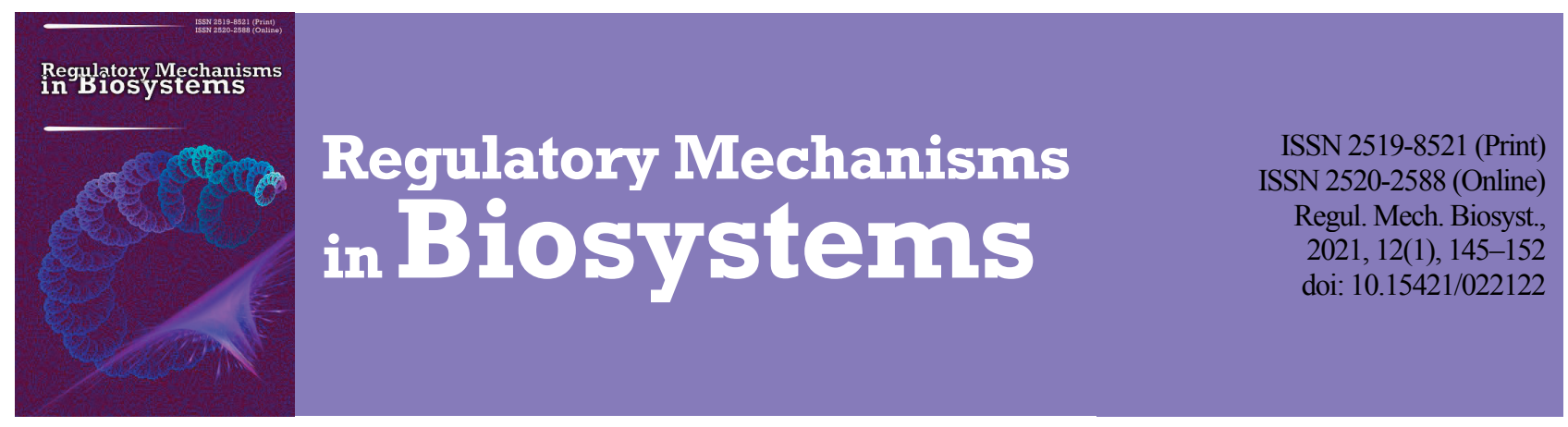

\title{
Hematological parameters and protein metabolism in the blood of pregnant rats under the effect of vanadium citrate
}

\author{
H. V. Klymets*, R. Y. Iskra*, O. Z. Svarchevska** \\ *Institute of Animal Biology NAAS, Lviv, Ukraine \\ **Stepan Gzhytskyi National University of Veterinary Medicine and Biotechnologies Lviv, Lviv, Ukraine
}

Article info

Received 01.02.2021

Received in revised form 04.03.2021

Accepted 06.03.2021

Institute of Animal Biolog

NAAS, Vasyl Stus st., 38,

Lviv, 79034, Ukraine.

Tel.: +38-032-260-07-95.

E-mail:

klimets.halyna@gmail.com

Stepan Gzhytskyi National

University of Veterinary

Medicine and Biotechnolo-

gies Lviv, Pekarska st., 50,

Lviv, 79010, Ukraine.

Tel.: +38-032-239-26-93.

E-mail:

oksanasvarchevska@ukr.net

Klymets, H. V., Iskra, R. Y., \& Svarchevska, O. Z. (2021). Hematological parameters and protein metabolism in the blood of pregnant rats under the effect of vanadium citrate. Regulatory Mechanisms in Biosystems, 12(1), 145-152. doi:10.15421/022122

Dose-dependent changes in protein metabolism in the blood and hematological parameters of pregnant rats under the effect of vanadium citrate are presented in the article. The animals were divided into five groups: group I - non-pregnant females, II - pregnant females consuming pure water without additives, III, IV, V - females which during the mating and pregnancy period received the solution of vanadium citrate at concentrations of $0.03,0.125$ and $0.50 \mu \mathrm{g} \mathrm{V} / \mathrm{mL}$ water. The research findings show that in pregnant animals of group II, the level of urea and alkaline phosphatase activity increased, meanwhile aspartate aminotransferase activity decreased, as compared to the non-pregnant females of group I. The levels of total protein and albumin decreased; however, the content of $\beta$-globulins increased in the pregnant animals of group II, as compared with that in group I. Also, in the rats of group II, there was a decrease in hemolysis time, total content of erythrocytes and hemoglobin, the content of old and mature erythrocytes, while the content of young erythrocytes increased, as compared to group I. The platelet content and thrombocrit in rats of group II increased in comparison with group I. The content of leukocytes and lymphocytes in pregnant animals of group II decreased, while the content of granulocytes increased, in contrast to non-pregnant rats. Under the effect of vanadium citrate at concentrations of $0.03-0.50 \mu \mathrm{g} \mathrm{V} / \mathrm{mL}$, there was a significant increase in the maximum number of prohemolized erythrocytes, the time of maximum hemolysis was delayed by 0.4-0.6 min, as compared with the pregnant rats of group II. This did not affect the time of total hemolysis in rats of groups III and $\mathrm{V}$, as compared with the pregnant animals in group II. Under the effect of vanadium citrate, an increase in the content of young erythrocytes was observed, as compared with group II. The hemoglobin content decreased at the concentration of $0.125 \mu \mathrm{g} \mathrm{V} / \mathrm{mL}$, while at the concentration of $0.50 \mu \mathrm{g} \mathrm{V} / \mathrm{mL}$ it increased, as compared to the pregnant animals of group II. Also, under the effect of vanadium citrate there was a decrease in the mean hemoglobin concentration in the erythrocyte. In pregnant animals fed with vanadium citrate solutions, the platelet content and thrombocrit, the relative width of platelet distribution by volume decreased, as compared with the pregnant rats of group II. The content of leukocytes, lymphocytes and granulocytes under the effect of vanadium citrate increased, as compared with the pregnant animals in group II. Under the effect of vanadium citrate at the concentration of $0.03 \mu \mathrm{g}$ $\mathrm{V} / \mathrm{mL}$, the level of albumin, creatinine and aspartate aminotransferase activity increased in blood plasma in comparison with group II. Meanwhile, at the concentration of $0.125 \mu \mathrm{g} \mathrm{V} / \mathrm{mL}$, the relative content of $\gamma$-globulins and aspartate aminotransferase activity increased, alkaline phosphatase activity and urea level decreased in comparison with group II. However at the concentration of $0.50 \mu \mathrm{g}$ $\mathrm{V} / \mathrm{mL}$, the relative $\alpha$ - and $\gamma$-globulins content and aspartate aminotransferase activity increased, at the same time, the relative $\beta$ globulins content and urea level decreased in comparison with group II. Therefore, vanadium citrate normalizes the indicators of protein metabolism during pregnancy, thus it can be considered as a potential dietary drug for the pregnant.

Keywords: rats; pregnancy; hematology; protein metabolism; vanadium citrate.

\section{Introduction}

To ensure the growth and development of the fetus, the mother's body undergoes compensatory changes in almost all systems, which leads to a state of unstable stress balance in homeostasis. In particular, pregnant women have anatomical, biochemical, physiological and endocrine changes that are necessary to support and regulate embryonic development (Salisu, 2009). Some authors point to certain changes in the protein and lipid profile of blood, kidney and liver dysfunction, and carbohydrate metabolism disorder in the body of pregnant women (Sánchez, 2011; Kolla et al., 2012). Also, during pregnancy many hematological changes take place (Sanci et al., 2017). In particular, erythrocytes change shape and size more often, and are more prone to abnormalities, in contrast to their condition in non-pregnant animals. These changes occur independently of the content of iron, folic acid and vitamin $\mathrm{B}_{12}$ (Lesesve, et al., 2019). An increase in mean corpuscular volume is common during pregnancy. This may be due to an increase in the content of reticulocytes in the blood ( $\mathrm{Lu}-$ rie, 1993). It is important to establish and maintain a positive pregnancy outcome, which implies the state of selective immune tolerance, immunosuppression and immunomodulation in the presence of strong antimicrobial immunity. The mammalian immune system is adapted to these needs. It regulates the reduction of potentially dangerous T-cell-mediated immune responses activating some components of the innate immune system, including monocytes and neutrophils. This unique dysregulation between different components of the immune system plays a central role in the mother's adaptation to pregnancy (Luppi et al., 2003). The proper functioning of the monocyte-macrophage system, an important unit of innate immunity, ensures the normal course of pregnancy. Normal pregnancy is also associated with phenotypic and metabolic changes in granulocytes. However, the innate immune response is not maximally activated during normal pregnancy (Naccasha et al., 2001). Therefore, the use of dietary drugs, based on trace elements that will strengthen the immune system in pregnant women, is necessary and will stop the occurrence of complications. It is known that trace elements act by participating in the 
transmembrane transport of immunocompetent cells. Since vanadium and its derivatives have antioxidant properties, their use results in an increase in antioxidant enzymes activity, reduces the side effects of statins on the heart tissues, liver and kidneys, as well as on the function of these organs (Crans et al., 2018). Due to the ability of vanadium to pass through the placental barrier, it can affect the development of the fetus and accumulate in its skeleton (Aureliano et al., 2014). In animal experiments, the deficiency of vanadium caused deformation of the skeleton extremities and their edema (Haenlein \& Anke, 2011; Aureliano et al., 2018), disorders of protein metabolism and hematological indicators, occurrence of fermentopathies, impairment of reproduction, growth and development of the organism. In the body, vanadium compounds act as cofactors that modulate enzyme activity, play an important role in metabolic processes, including glucose metabolism in the liver, glycogen, cholesterol, and triacylglycerols metabolism (Gunasinghe \& Kim, 2018). They interact with amino acids, in particular with L-cysteine, L-histidine and L-glycine (Levina et al., 2015). Vanadium simulates some effects of insulin in adipocytes due to staurosporin-susceptible cytosolic protein tyrosine kinase (CytPTK) (Mohammadi \& Yazdanparast, 2010; Aureliano \& Ohlin, 2014; Gunasinghe \& Kim, 2018). The studied element is involved in numerous physiological responses, particularly as an inhibitor of phosphate-mobilizing enzymes, such as tyrosine phosphatase, ribonuclease, ATPase (Crans et al., 2018). Vanadium enhances phosphorylation of proteins, inhibits intracellular protein tyrosine phosphatase, which causes dephosphorylation of the insulin receptor $\beta$-subunit, which contributes to the growth of numerous metabolic effects of insulin (Gunasinghe \& Kim, 2018). This element is able to form complexes with proteins. The protein compounds with vanadium have similar properties to compounds with ferum. In particular, hemoglobin is a protein that binds the cytoplasmic ions of vanadyl (Cantley \& Aisen, 1979). According to the literature, vanadium is associated with transferrin and albumin in the incubation serum at low concentrations (Sánchez et al., 2011). The ability of transferrin and albumin to coordinate $\mathrm{VO}_{2}{ }^{+}$-ion (Gunasinghe \& Kim, 2018) is known. In the form of vanadate, decavanadate-ion also interacts with proteins such as actin, myosin, and $\mathrm{Ca}^{2+}$-ATPase, thus affecting mitochondrial functions, including modification of certain cellular antioxidant markers (Aureliano et al., 2014). The effect of methavanadate on erythrocytes is due to the interaction with proteins located on the outer part of the membrane and may still involve other minor lipid components. In addition, partially unsaturated lipids can interact differently with fully saturated chains in model systems (Suwalsky et al., 2013).

Therefore, the purpose of our research was to clarify the effect of the vanadium citrate organic compound on the total protein content and its fraction, as well as the activity of aspartate aminotransferase (ASAT), alanine aminotransferase (ALAT), alkaline phosphatase (AP), urea and creatinine in the blood plasma of pregnant female rats, the resistance of erythrocytes to the acid hemolytic, the age population distribution of erythrocytes and hematological parameters in general.

\section{Material and methods}

All manipulations with animals were carried out in accordance with the "European convention for the protection of vertebrate animals used for research and scientific purposes" (Strasbourg, 1986) and "General ethical principles of animal experiments" adopted by the First National Congress on Bioethics (Kyiv, 2001). Protocol of the Bioethics Committee meeting at the Institute of Animal Biology No. 70 dated July 11, 2018.

The studies were performed on white female laboratory rats with the bodyweight of 140-160 g, which were divided into five groups: Group Inon-pregnant females, II - pregnant females which consumed pure water without additives, rats in groups III, IV, V consumed the solution of vanadium citrate at the concentrations of $0.03,0.125$ and $0.50 \mu \mathrm{g} \mathrm{V} / \mathrm{mL}$, respectively, in the period of mating and pregnancy. The rats were kept under vivarium conditions with a standard diet for laboratory animals. Water (in groups I and II) and the solution of vanadium citrate (in groups III, IV, V) were provided in the volume of $20 \mathrm{~mL}$ per animal. The study material was blood plasma of rats, in which the content of total protein was determined after the Lowry method (Vlizlo et al., 2012) and its spectrum by the method of vertical electrophoresis (Table 1) (Vlizlo et al., 2012), the activi- ty of ASAT, ALAT, AP, the content of urea and creatinine were determined using Humalyzer 2000 biochemical analyzer (Germany), applying the kits produced by "Biola". Acid erythrograms were determined after Terskov and Gitelzon in the whole blood (Terskov \& Gitelzon, 1959), hematological parameters were determined on a hematology analyzer (Orphèe Mythic 18, Switzerland), and blood samples were put in tubes (Terumo Europe N. V., Belgium) containing the anticoagulant EDTA-K . Age population distribution of erythrocytes was carried out in a sucrose gradient.

Polyacrylamide gel electrophoresis are given in Table 1. Materials and reagents: acrylamide (AA); methylene bisacrylamide (MBA); persulfate ammonium (PSA); tetramethylenediamine (TEMED) (standard, ready to use); $\mathrm{HCl}$ concentrated; glycine; tris; glycerin; bromophenol blue; amido black 10B; distilled water. Sample preparation: dilute $0.10 \mathrm{~mL}$ of blood plasma (serum) with electrode buffer in a ratio of 1:10-12 and add a drop of pre-prepared phenol blue solution. Soluble tissue proteins: grind $0.10 \mathrm{~g}$ of tissue with $0.10 \mathrm{~cm}^{3}$ of electrode buffer or saline and add a drop of pre-prepared phenol blue solution. Preparation of phenol blue solution add a drop of bromophenol blue to a drop of glycerin. Preparation of electrode buffer $\left(1 \mathrm{dm}^{3}\right)$ - add $\mathrm{HCl}$ concentrated $\left(0.60 \mathrm{~cm}^{3}\right)$ to glycine $(2.88 \mathrm{~g})$ and make it up to $1 \mathrm{dm}^{3}$ with distilled water.

\section{Table 1}

Preparation of gel for electrophoresis

\begin{tabular}{lcc}
\hline \multicolumn{1}{c}{ Component } & $7.5 \%$ separating gel, $\mathrm{cm}^{3}$ & Concentrating gel, $\mathrm{cm}^{3}$ \\
\hline Solution of acrylamide & 4.130 & 0.500 \\
1.5 M Tris & 4.125 & 0.500 \\
Water & 13.600 & 3.800 \\
Persulfate ammonium, $10 \%$ & 0.136 & 0.100 \\
Tetramethylenediamine, ready to use & 0.014 & 0.005 \\
HCl concentrated & 0.000 & 0.030 \\
\hline
\end{tabular}

Solution $\left(25 \mathrm{~cm}^{3}\right)-\operatorname{add} \mathrm{MBA}(0.35 \mathrm{~g})$ to AA $(9.65 \mathrm{~g})$ and make it up to $25 \mathrm{~cm}^{3}$ with distilled water. $1.5 \mathrm{M}$ tris $\left(25 \mathrm{~cm}^{3}\right)$ - add $\mathrm{HCl}$ concentrated $\left(0.60 \mathrm{~cm}^{3}\right)$ to tris $(4.54 \mathrm{~g})$ make it up to $25 \mathrm{~cm}^{3}$ with distilled water $(\mathrm{pH}=$ 8.8). PSA is prepared on the day of the study. PSA (10\%) - make up PSA $(0.10 \mathrm{~g})$ to $1 \mathrm{~cm}^{3}$ with distilled water.

Preparation of the separating gel: according to the table, add AA solution + 1.5 M Tris and water to the flask, stir well, then add PSA (10\%) and TEMED, stir again and pour between the cassettes. Pour a little distilled water on the top to level the surface. The polymerization time is 30 45 minutes. After polymerization, remove water with filter paper.

Preparation of the concentrating gel: prepare quickly to prevent polymerization; according to the table, add AA solution + $1.5 \mathrm{M}$ tris + water to the flask, stir well, quickly add PSA $(10 \%)$ and TEMED, stir again and pour over the separating gel. Put a comb with an appropriate number of holes for samples on the top. The polymerization time is 20-30 minutes. After polymerization of the concentrating gel, remove the comb. Put $0.04 \mathrm{~cm}^{3}$ of prepared samples in the formed holes. Add a little electrode buffer on the top of the samples. Put the cassette with the gel in the chamber. Fill the chamber with electrode buffer so that the buffer covers the sample holes. Connect the electrodes to the power device (UVIP) to supply current. The example for a cassette for 20 samples: for the concentrating gel $20-30 \mathrm{~mA}$ at $220 \mathrm{~V}$, for the separating gel $40-50 \mathrm{~mA}$ at $220 \mathrm{~V}$. When the front of the samples reaches the separating gel (visually visible), switch to $50 \mathrm{~mA}$. When the front of the samples reachesd the bottom of the cassette, turn off the UVIP. Carefully peel the gel from the glass cassettes and transfer it to the baths for painting. Staining: preparation of stain for fixation: dilute amido black 10B $(0.01 \mathrm{~g})$ in $6 \%$ acetic acid $\left(100 \mathrm{~cm}^{3}\right)$. Stain for 20-30 minutes. Washing: wash the gel in 6\% acetic acid until complete discoloration of the gel. The gel is ready for further work.

Resistance of erythrocytes to the action of acid hemolytic (Gitelzon \& Terskov, 1959). The principle of the method is based on the use of a direct relationship between the time of hemolysis of erythrocytes and the action of hemolytic used for their hemolysis. The analysis of hemolytic erythrograms was performed according to such parameters as: time of maximum hemolysis (min); the percentage of hemolyzed erythrocytes at the time of maximum hemolysis ( $\%$ max); duration of total hemolysis ( $\mathrm{min}$ ). Washed erythrocytes were diluted with $0.150 \mathrm{mmol} \mathrm{NaCl}$ in a ratio of 1:1000. The received suspension was diluted to achieve extinction in the range of 
$0.700-0.750$ at a wavelength of $630 \mathrm{~nm}$. The studies were performed in a thermostatted cuvette to maintain a constant temperature of the samples, as the hemolysis kinetics depends on the temperature of the solution. The optimal temperature for the study is $+24^{\circ} \mathrm{C}$. Erythrocyte suspension $2 \mathrm{~mL}$ was put to the cuvette, and a similar volume of hemolyzing solution $0.004 \mathrm{n} \mathrm{HCl}$ prepared in $0.150 \mathrm{mmol} \mathrm{NaCl}$ solution was added. From the moment the hemolytic was added, changes in extinction at a wavelength of $630 \mathrm{~nm}$ were recorded every $30 \mathrm{~s}$. Monitoring was performed until the complete cessation of changes in extinction values. Saline $2 \mathrm{~mL}$ was placed in the control cuvette, and $2 \mathrm{~mL} 0.004 \mathrm{~N} \mathrm{HCl}$ solution prepared on $0.150 \mathrm{~mm} \mathrm{NaCl}$ was added. The percentage distribution of erythrocytes by resistance was expressed as an erythrogram, a curve of the relationship between the percentage of hemolyzed erythrocytes and the time of hemolysis.

Population distribution of erythrocytes in the density gradient of sucrose (Table 2). Firstly, erythrocytes were washed by $0.9 \%$. NaCl solution. The obtained erythrocytes were diluted with the saline in a ratio of 1:10. Erythrocytes from different age populations were separated by the cell fractionation method in a seven-step density gradient of sucrose. Then, $0.5 \mathrm{~mL}$ of erythrocytes diluted in a sucrose gradient were applied to the column.

Table 2

Preparation of sucrose gradients

\begin{tabular}{ccc}
\hline $\begin{array}{c}\text { Concentration } \\
\text { of sucrose gradients, } \%\end{array}$ & \multicolumn{2}{c}{ Content of sucrose gradients } \\
\cline { 2 - 3 } 30 & sucrose, $\mathrm{g}$ & saline, $\mathrm{mL}$ \\
26 & 15 & 50 \\
22 & 13 & 50 \\
18 & 11 & 50 \\
14 & 9 & 50 \\
10 & 7 & 50 \\
6 & 5 & 50 \\
\hline
\end{tabular}

After applying erythrocytes to the column, it was rotated by $75^{\circ}$, and $2 \mathrm{~mL}$ of each sucrose solution, starting with the solution with the highest density of $30 \%$ and then respectively: $26,22,18,14,10$ and $6 \%$, was slowly applied to the wall of the column. The column was again fixed vertically. Thus, seven cell fractions were obtained. Each fraction of erythrocytes was collected in a separate tube and diluted with the saline to $10 \mathrm{~mL}$. Fractions of old erythrocytes (1-3) were obtained first, mature erythrocytes (4-5) followed, and fractions of young erythrocytes (6-7) went last. Photometer measurement was performed at $520 \mathrm{~nm}$. All extinctions were put together to get $100 \%$. To calculate the percentage of each fraction, they were related to $\mathrm{E}$.

Statistical processing of the survey results was performed using the computer software package Statistica 8 (StatSoft Inc., USA, 2014). The arithmetic mean value and the standard deviation of the arithmetic mean $(\mathrm{x} \pm \mathrm{SD})$ were determined. The differences between the values in the control and experimental groups were determined using the ANOVA, where the differences were considered significant as P-value less than 0.05 (with Bonferroni correction).

\section{Results}

Our results showed that the total protein in the blood plasma of the pregnant females in group II decreased by $9.7 \%$, as compared to group I (Table 3). The studies showed an increase in the mean levels of $\beta$-globulins in pregnant females of group II (10.7\%), as compared to non-pregnant rats, which may be due to their physiological state. Also, in the females of group II, there were no changes in the $\alpha$ - and $\gamma$-globulins fraction. The total protein reduction in group III by $8.3 \%$ was observed, as compared to group I. Stimulation of the body immune system by the vanadium compound is caused by the $\gamma$-globulins level growth in the animals of group IV by $4.7 \%$ and in those of group V by $9.7 \%$, as compared to the animals of group II. The fraction of $\alpha$-globulins in the blood plasma of the females in group $\mathrm{V}$ increased by $15.9 \%$ as compared to the animals of group II.

The performed studies showed that in the pregnant females of group II, the growth of urea content reached $27.3 \%$, as compared to the nonpregnant females in group I (Table 4).

Table 3

Protein plasma spectrum of blood of pregnant female rats under the effect of vanadium citrate $(x \pm S D, n=7)$

\begin{tabular}{|c|c|c|c|c|c|c|}
\hline \multirow{2}{*}{$\begin{array}{l}\text { Number } \\
\text { of group }\end{array}$} & \multirow{2}{*}{ Animal groups } & \multirow{2}{*}{ Total protein, $\mathrm{g} / \mathrm{L}$} & \multirow{2}{*}{ Albumins, $\%$} & \multicolumn{3}{|c|}{ Globulins, $\%$} \\
\hline & & & & $\alpha$ & $\beta$ & $\gamma$ \\
\hline I & Non-pregnant & $60.24 \pm 1.00$ & $26.17 \pm 0.63$ & $24.60 \pm 0.44$ & $26.10 \pm 0.93$ & $23.14 \pm 0.69$ \\
\hline II & Pregnant & $54.36 \pm 0.72^{*}$ & $23.73 \pm 0.78$ & $23.93 \pm 1.13$ & $28.90 \pm 0.48^{*}$ & $23.40 \pm 0.23^{*}$ \\
\hline III & Pregnant $+0.03 \mu \mathrm{gV} / \mathrm{mL}$ & $55.26 \pm 1.59^{*}$ & $26.61 \pm 0.32$ & $21.80 \pm 0.32^{*}$ & $27.44 \pm 0.49^{\#}$ & $24.16 \pm 0.57^{* *}$ \\
\hline IV & Pregnant $+0.125 \mu \mathrm{gVV} / \mathrm{mL}$ & $61.20 \pm 3.53$ & $23.90 \pm 1.71$ & $23.88 \pm 0.99$ & $28.24 \pm 0.53^{*}$ & $24.50 \pm 0.34^{* * *}$ \\
\hline $\mathrm{V}$ & Pregnant $+0.50 \mu \mathrm{gV} / \mathrm{mL}$ & $65.59 \pm 5.48$ & $23.12 \pm 1.35$ & $27.74 \pm 0.47^{* *}$ & $24.15 \pm 0.82^{\mathrm{m}}$ & $25.67 \pm 0.27^{\text {*\# }}$ \\
\hline
\end{tabular}

Note: ${ }_{-}-\mathrm{P}<0.05 ;{ }^{* *}-\mathrm{P}<0.01 ; * * *-\mathrm{P}<0.001$, reliable for group I; ${ }_{-}-\mathrm{P}<0.05 ;{ }^{\#}-\mathrm{P}<0.01 ;{ }^{\# \#}-\mathrm{P}<0.001$, reliable for group II.

Table 4

Biochemical parameters of blood plasma in pregnant female rats which consumed vanadium citrate $(x \pm S D, n=7)$

\begin{tabular}{|c|c|c|c|c|c|c|}
\hline $\begin{array}{l}\text { Number } \\
\text { of group }\end{array}$ & Animal groups & Creatinine, $\mathrm{kmol} / \mathrm{L}$ & Urea, $\mathrm{mmol} / \mathrm{L}$ & $\begin{array}{c}\text { Aspartate } \\
\text { aminotransferase, Units/L }\end{array}$ & $\begin{array}{c}\text { Alanine amino- } \\
\text { transferase, Units/L }\end{array}$ & $\begin{array}{c}\text { Alkaline } \\
\text { phosphatase, Units/L }\end{array}$ \\
\hline $\mathrm{I}$ & Non-pregnant & $56.25 \pm 1.54$ & $0.216 \pm 0.005$ & $178.19 \pm 0.78$ & $83.40 \pm 0.77$ & $313.4 \pm 11.0$ \\
\hline II & Pregnant & $51.35 \pm 1.69$ & $0.275 \pm 0.005^{*}$ & $140.00 \pm 1.28^{* * *}$ & $76.60 \pm 4.17^{*}$ & $509.4 \pm 17.7^{*}$ \\
\hline III & Pregnant $+0.03 \mu \mathrm{gV} / \mathrm{mL}$ & $56.61 \pm 0.87$ & $0.288 \pm 0.017^{* * * *}$ & $146.80 \pm 0.66^{* * * *}$ & $74.93 \pm 0.32^{*}$ & $460.2 \pm 20.3^{* \#}$ \\
\hline IV & Pregnant $+0.125 \mu \mathrm{gV} / \mathrm{mL}$ & $54.63 \pm 2.30$ & $0.229 \pm 0.002^{\#}$ & $163.20 \pm 1.03^{* * \ldots \#}$ & $83.50 \pm 2.43^{\#}$ & $394.2 \pm 39.8^{* \#}$ \\
\hline $\mathrm{V}$ & Pregnant $+0.50 \mu \mathrm{gV} / \mathrm{mL}$ & $53.08 \pm 1.03$ & $0.211 \pm 0.004^{\ldots \ldots}$ & $172.81 \pm 3.42^{\ldots \#}$ & $77.90 \pm 4.75$ & $379.4 \pm 81.7^{\#}$ \\
\hline
\end{tabular}

Note: see Table 3.

A decrease in ASAT and ALAT activity by $21.4 \%$ and $8.2 \%$ respectively was observed in the blood plasma of animals in group II in comparison with group I. As a result of the study, it was found that in the rats of group II the AP activity increased by $62.5 \%$, as compared to that in group I. Under the condition of feeding rats in experimental groups with vanadium citrate, the level of creatinine in the animals of group III increased by $10.3 \%$, while the level of urea decreased in the blood plasma of the animals in groups IV and V by $16.7 \%$ and $23.3 \%$, respectively, as compared to the pregnant females of group II which consumed water only. It was found that ASAT activity increased in rats of groups III, IV and V by $4.8 \%, 16.6 \%$ and $23.4 \%$, respectively, as compared to group I.

A significant $9.0 \%$, increase in ALAT activity was seen in the IV group compared with non-pregnant animals in group I. At the same time, the AP activity decreased in animals of group IV by $22.6 \%$, as compared to the pregnant females of group II which consumed water only. The studies did not show significant differences in hemolysis of erythrocytes in non-pregnant and pregnant rats (groups I and II), but the time of hemolysis in pregnant rats decreased by $0.4 \mathrm{~min}$, as compared with non-pregnant, and was $8.4 \mathrm{~min}$ (Fig. 1, Table 5).

In groups III and IV of pregnant animals fed with vanadium citrate, there was a significant increase in the maximum number of prohemolized erythrocytes by $5.6 \%$ and $4.8 \%$, as compared with the pregnant rats in group II. In the animals of group IV, there was a decrease in the total hemolysis time as compared with non-pregnant rats (group I) and pregnant animals (group II). And in groups III, IV and V, the time of maximum hemolysis was delayed by $0.4,0.5$ and $0.6 \mathrm{~min}$, respectively, compared with group II of pregnant rats, and was 3.4, 3.5 and 3.6 minutes. This did not affect the time of total hemolysis in the rats of groups IV and 
$\mathrm{V}$, as compared with the pregnant animals in group II. Besides, this indicates that vanadium citrate at a concentration of 0.03 and $0.50 \mu \mathrm{g} \mathrm{V} / \mathrm{mL}$ has the most favourable effect on the resistance of erythrocyte membranes to acid hemolytic. The erythrograms obtained as a result of the experiment are single-vertex, which indicates the normal erythropoiesis and the ab- sence of pathologies in the formation of red blood cells. Erythrograms of the animals of experimental groups III, IV and V are slightly shifted to the right (Fig. 1), as compared with groups I and II, which indicates the regenerative effect of vanadium citrate on erythropoiesis and the appearance of young erythrocytes in pregnant animals consuming sample solutions.

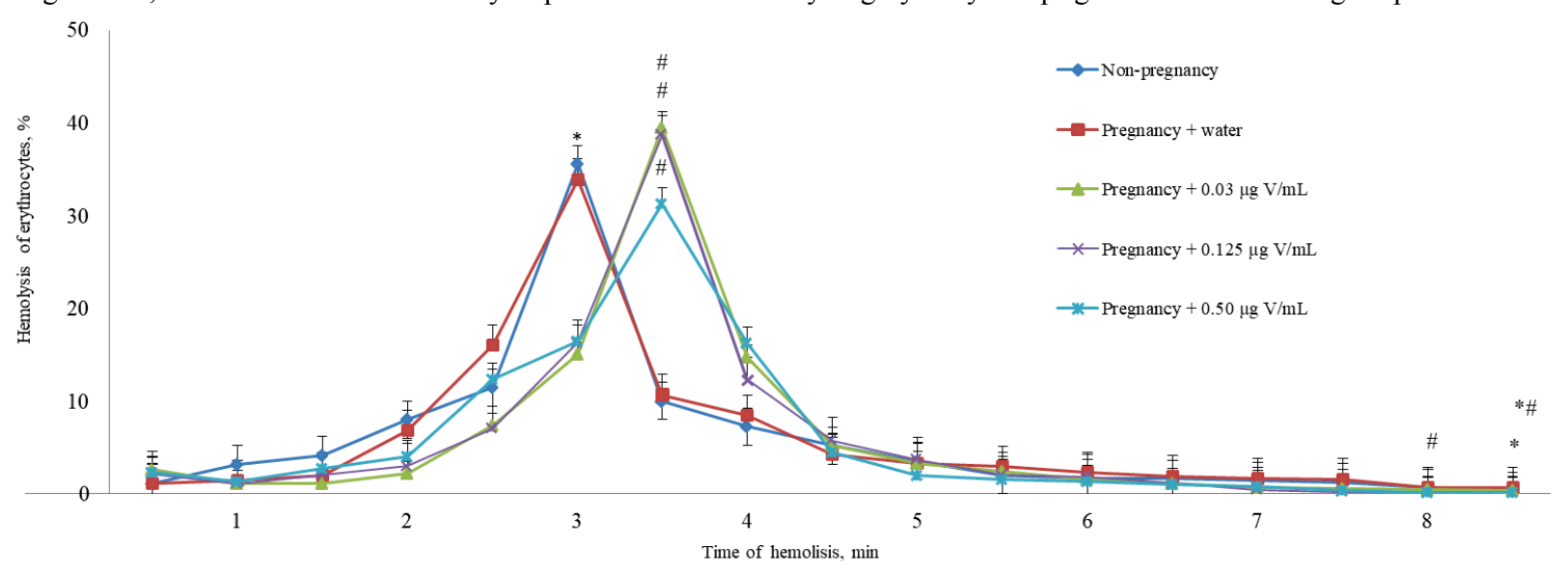

Fig. 1. Acid erythrograms (after Gitelzon) in the blood of pregnant female rats under the effect of vanadium citrate $(x \pm S D, n=7)$

Table 5

Acid erythrograms (after Gitelzon) in the blood of pregnant female rats under the effect of vanadium citrate $(x \pm S D, n=7)$

\begin{tabular}{clccc}
\hline $\begin{array}{c}\text { Number } \\
\text { of group }\end{array}$ & \multicolumn{1}{c}{ Animal group } & $\begin{array}{c}\text { Maximum } \\
\text { hemolysis, min }\end{array}$ & $\begin{array}{c}\text { Hemolysis } \\
\text { time, min }\end{array}$ & $\begin{array}{c}\text { Maximum } \\
\text { hemolysis, \% }\end{array}$ \\
\hline I & Non-pregnant & $3.10 \pm 0.10$ & $8.80 \pm 0.12$ & $35.55 \pm 1.83$ \\
II & Pregnant & $3.00 \pm 0.12$ & $8.40 \pm 0.10^{*}$ & $33.89 \pm 0.45^{*}$ \\
III & Pregnant $+0.030 \mu \mathrm{gV} / \mathrm{mL}$ & $3.40 \pm 0.40^{\#}$ & $8.40 \pm 0.44$ & $39.47 \pm 2.28^{\#}$ \\
IV & Pregnant $+0.125 \mu \mathrm{gV} / \mathrm{mL}$ & $3.50 \pm 0.21^{* \#}$ & $8.10 \pm 0.14^{* \#}$ & $38.74 \pm 3.42^{\#}$ \\
V & Pregnant $+0.500 \mu \mathrm{gV} / \mathrm{mL}$ & $3.60 \pm 0.13^{* \#}$ & $8.30 \pm 0.36^{* \#}$ & $31.30 \pm 3.70^{\#}$ \\
\hline
\end{tabular}

Note: see Table 3.

In pregnant animals of group II, there was a decrease in the content of old and mature erythrocytes by $10.6 \%$ and $3.8 \%$, respectively, while the content of young erythrocytes increased by $14.5 \%$, as compared with the non-pregnant animals of group I (Table 6).

\section{Table 6}

The age population distribution of erythrocytes in the density gradient of sucrose under the action of vanadium citrate $(x \pm S D, n=7)$

\begin{tabular}{clccc}
\hline \multirow{2}{*}{$\begin{array}{c}\text { Number } \\
\text { of group }\end{array}$} & \multirow{2}{*}{ Animal groups } & \multicolumn{3}{c}{ Percentage of erythrocyte populations } \\
\cline { 3 - 5 } & & old, \% & \multicolumn{1}{c}{ mature, \% } & \multicolumn{1}{c}{ young, \% } \\
\hline I & Non-pregnant & $17.52 \pm 0.34$ & $68.17 \pm 3.56$ & $14.30 \pm 0.87$ \\
II & Pregnant & $6.90 \pm 0.16^{* * * *}$ & $64.31 \pm 2.67^{*}$ & $28.85 \pm 2.10^{* * * *}$ \\
III & Pregnant $+0.03 \mu \mathrm{gV} / \mathrm{mL}$ & $8.70 \pm 0.25^{* * * * *}$ & $65.36 \pm 3.37^{* *}$ & $25.96 \pm 1.70^{* * * * *}$ \\
IV & Pregnant $+0.125 \mu \mathrm{gV} / \mathrm{mL}$ & $8.42 \pm 0.20^{* * * *}$ & $66.62 \pm 2.13^{\#}$ & $24.04 \pm 1.60^{* * * * *}$ \\
V & Pregnant $+0.500 \mu \mathrm{gV} / \mathrm{mL}$ & $9.50 \pm 0.21^{* * * * *}$ & $56.65 \pm 2.23^{* * * *}$ & $28.81 \pm 1.52^{* * * *}$ \\
\hline
\end{tabular}

Note: see Table 3 .

Under the effect of vanadium citrate, there was a slight increase in the content of old and mature erythrocytes, but a slight decrease in the content of young erythrocytes in almost all groups fed with vanadium citrate solution, as compared with the pregnant animals in group II. The content of young erythrocytes in animals fed with vanadium citrate solutions in- creased in group III by $11.7 \%$, IV $-9.7 \%$ and V $-14.5 \%$, as compared with the non-pregnant animals in group I.

In particular, we found a decrease in erythrocyte content in the pregnant rats of group II by $14.5 \%$, as compared with the non-pregnant animals of group I. The concentration of hemoglobin in the blood of the animals of group II decreased by $9.0 \%$, as compared with the nonpregnant animals of group I (Table 7). The mean hemoglobin concentration in the erythrocytes of the animals of group II increased slightly by $3.1 \%$, as compared with the non-pregnant animals of group I. The content of erythrocytes increased by $5.1 \%$ and $6.1 \%$ in the animals of groups III and IV, respectively, which consumed vanadium citrate, whereas the changes in the study group $\mathrm{V}$ were insignificant, as compared with the group II of pregnant animals. The concentration of hemoglobin in group IV decreased by $5.1 \%$, in group V it increased by $5.8 \%$, as compared with the pregnant animals of group II. Also, under the effect of vanadium citrate there was a decrease in the mean hemoglobin concentration in the erythrocytes in group III by $6.4 \%, \mathrm{IV}-3.3 \%$, while in group V there was a slight increase, as compared with the pregnant rats of group II.

In pregnant animals of group II, there was an increase in platelet count by $14.3 \%$, as compared with the control (Table 8 ). The value of thrombocrit in the rats of group II increased by $88.8 \%$, as compared with nonpregnant animals of group I. This is due to an increase in platelet count in the pregnant rats of group II. The relative platelet distribution width by volume in the pregnant animals of group II decreased by $4.0 \%$, as compared with the non-pregnant females of group I.

In the pregnant animals, fed with vanadium citrate solutions, the platelet content decreased, in group III - by $25.7 \%$, IV - by $37.9 \%$ and $\mathrm{V}$ - by $21.3 \%$, respectively, as compared with the pregnant rats in group II. Platelets also decreased in three experimental groups: III - by $28.0 \%$, IV - by $43.7 \%$ and V - by $21.0 \%$, as compared with the pregnant females in group II. In group III, the relative platelet distribution width by volume decreased by $3.2 \%$, and in group $\mathrm{V}$ increased by $1.3 \%$, as compared with group II.

Table 7

The quantity of erythrocytes and their functional properties in the peripheral blood of pregnant rats under the effect of vanadium citrate $(x \pm S D, n=7)$

\begin{tabular}{clcccccc}
\hline $\begin{array}{c}\text { Number } \\
\text { of group }\end{array}$ & \multicolumn{1}{c}{ Animal groups } & $\begin{array}{c}\text { Erythrocytes, } \\
1 \times 10^{12} / \mathrm{L}\end{array}$ & $\begin{array}{c}\text { Hemoglobin, } \\
\mathrm{g} / \mathrm{L}\end{array}$ & $\begin{array}{c}\text { Hematocrit, } \\
\%\end{array}$ & $\begin{array}{c}\text { Mean corpuscular } \\
\text { volume, } \mu \mathrm{m}^{3}\end{array}$ & $\begin{array}{c}\text { Mean corpuscular hemoglobin } \\
\text { in absolute quantities, } \mathrm{pg}\end{array}$ & $\begin{array}{c}\text { Mean corpuscular hemoglobin } \\
\text { concentration, } \mathrm{mg} \times \text { mol/L }\end{array}$ \\
\hline I & Non-pregnant & $7.34 \pm 0.25$ & $150.5 \pm 3.2$ & $0.34 \pm 0.023$ & $46.40 \pm 3.14$ & $20.50 \pm 2.27$ & $442.00 \pm 5.22$ \\
II & Pregnant & $6.27 \pm 0.30^{*}$ & $140.3 \pm 1.3^{*}$ & $0.31 \pm 0.014$ & $49.10 \pm 2.52$ & $22.37 \pm 1.37$ & $455.50 \pm 1.72^{*}$ \\
III & Pregnant $+0.03 \mu \mathrm{gV} / \mathrm{mL}$ & $6.59 \pm 0.16^{\#}$ & $137.5 \pm 2.4^{* *}$ & $0.32 \pm 0.010$ & $48.95 \pm 2.57$ & $20.85 \pm 1.75$ & $426.50 \pm 2.70^{\#}$ \\
IV & Pregnant $+0.125 \mu \mathrm{gVV} / \mathrm{mL}$ & $6.65 \pm 0.16^{\#}$ & $133.2 \pm 6.1^{* \#}$ & $0.33 \pm 0.024$ & $47.15 \pm 1.76$ & $21.97 \pm 1.64$ & $440.50 \pm 7.06^{\#}$ \\
V & Pregnant $+0.50 \mu \mathrm{gV} / \mathrm{mL}$ & $6.15 \pm 0.28^{* \#}$ & $147.0 \pm 4.6^{* \#}$ & $0.32 \pm 0.017$ & $52.00 \pm 3.64$ & $23.93 \pm 2.00$ & $460.75 \pm 3.31^{\#}$ \\
\hline
\end{tabular}

Note: see Table 3. 
Table 8

Platelet content and platelet indices of peripheral blood of pregnant rats under the action of vanadium citrate $(x \pm S D, n=7)$

\begin{tabular}{|c|c|c|c|c|c|}
\hline Number of group & Animal groups & Platelets, $10^{9} / \mathrm{L}$ & Mean platelet volume, $\mathrm{fL}$ & Thrombocrit, \% & $\begin{array}{c}\text { Relative platelet distribution } \\
\text { width by volume, } \%\end{array}$ \\
\hline I & Non-pregnant & $253.00 \pm 4.01$ & $6.00 \pm 0.44$ & $0.152 \pm 0.010$ & $19.25 \pm 1.40$ \\
\hline II & Pregnant & $289.20 \pm 4.50^{* * *}$ & $6.70 \pm 0.30$ & $0.286 \pm 0.014^{* * *}$ & $15.29 \pm 0.73^{*}$ \\
\hline III & Pregnant $+0.03 \mu \mathrm{gVV} / \mathrm{mL}$ & $215.00 \pm 6.78^{* * \ldots \# \#}$ & $6.40 \pm 0.46$ & $0.206 \pm 0.015^{* \ldots \#}$ & $12.15 \pm 0.89^{\text {***\# }}$ \\
\hline IV & Pregnant $+0.125 \mu \mathrm{gV} / \mathrm{mL}$ & $179.50 \pm 5.18^{* * \ldots \ldots}$ & $6.33 \pm 0.22$ & $0.161 \pm 0.008^{\#}$ & $15.56 \pm 0.78^{\#}$ \\
\hline $\mathrm{V}$ & Pregnant $+0.50 \mu \mathrm{gV} / \mathrm{mL}$ & $227.50 \pm 4.52^{* \ldots \#}$ & $6.51 \pm 0.28$ & $0.226 \pm 0.007^{* * *+}$ & $16.62 \pm 1.42^{\#}$ \\
\hline
\end{tabular}

Note: see Table 3.

Table 9

The concentration of leukocytes and their fractions in the peripheral blood of the pregnant rats under the effect of vanadium citrate $(x \pm S D, n=7)$

\begin{tabular}{|c|c|c|c|c|c|}
\hline Number of group & Animal groups & Leukocytes, $1 \times 10^{9} / \mathrm{L}$ & Lymphocytes, $1 \times 10^{9} / \mathrm{L}$ & Monocytes, $1 \times 10^{9} / \mathrm{L}$ & Granulocytes, $1 \times 10^{9} / \mathrm{L}$ \\
\hline I & Non-pregnant & $19.20 \pm 0.77$ & $14.10 \pm 0.19$ & $2.40 \pm 0.27$ & $2.75 \pm 0.21$ \\
\hline II & Pregnant & $13.95 \pm 0.33^{* * *}$ & $9.10 \pm 0.13^{* * *}$ & $1.77 \pm 0.18$ & $4.39 \pm 0.35^{* *}$ \\
\hline III & Pregnant $+0.03 \mu \mathrm{gV} / \mathrm{mL}$ & $15.20 \pm 0.25^{* * * \#}$ & $9.75 \pm 0.26 * * \#$ & $2.15 \pm 0.16$ & $3.30 \pm 0.24^{\#}$ \\
\hline IV & Pregnant $+0.125 \mu \mathrm{gV} / \mathrm{mL}$ & $16.45 \pm 0.57^{\#}$ & $11.25 \pm 0.21 * * \#$ & $2.35 \pm 0.26$ & $1.85 \pm 0.20^{\#}$ \\
\hline V & Pregnant $+0.50 \mu \mathrm{gV} / \mathrm{mL}$ & $15.00 \pm 0.54^{* * * \#}$ & $11.57 \pm 0.65^{* * * \ldots}$ & $1.98 \pm 0.14$ & $2.30 \pm 0.23^{\# \#}$ \\
\hline
\end{tabular}

Note: see Table 3.

The content of total leukocytes and lymphocytes, including in the pregnant animals of group II decreased by $27.3 \%$ and $35.5 \%$, respectively, while the content of granulocytes increased by $59.6 \%$, as compared with the control group I (Table 9). Under the action of vanadium citrate, the content of leukocytes increased in group III by $9.0 \%$, in group IV - by $18.0 \%$ and in group $\mathrm{V}$ - by $7.5 \%$; the content of lymphocytes also increased in the experimental groups: in III - 7.1\%, IV - 23.6\% and in Vby $27.2 \%$, as compared with the pregnant animals of group II. The content of granulocytes in the pregnant animals consuming vanadium citrate solutions decreased in group III by $25.8 \%$, IV $-57.9 \%$ and in V - by $47.6 \%$, as compared with the pregnant animals of group II.

\section{Discussion}

Blood plasma proteins carry out important functions: nutrition, $\mathrm{pH}$ maintenance, osmotic balance, regulation of cellular functions, transport of substances, reserve of amino acids (Dai et al., 2017). Pregnancy affects the expression of protein in the maternal plasma of blood and urine, manifested by quantitative differences in its content (Kolla et al., 2012; Gloria et al., 2018). The total protein in the blood plasma of the pregnant rats (Table 3) decreased, which is related to a physiological adaptation to pregnancy (Faught et al., 1995). Quantitative determination of albumins and globulins is essential for the diagnosis of diseases, including the problems of the liver and the immune system functioning (Alberghina et al., 2010). Synthesis of albumin, which is the most osmotically active plasma protein, is carried out in the liver. It is involved into the transport of free fatty acids, bile acids, bilirubin, calcium, hormones and drugs (Alberghina et al., 2010). According to the literature, reduced albumin concentration during pregnancy is a common phenomenon and may be due to an increase in blood plasma volume in females during pregnancy, $\alpha$-fetoprotein growth, as well as hormonal changes, namely, progesterone and estradiol concentration increase (Dai et al., 2017). The studies showed an increase in the mean levels of $\beta$-globulins in pregnant females of group II, as compared to non-pregnant rats, which may be due to their physiological state since the $\beta$-fraction contains such important protein-like components as haemopexin, transferrin, ferritin, C-reactive protein, as well as some immunoglobulins IgA and IgM, located between the $\beta 2$ and $\gamma$ sites (Gloria et al., 2018). It is known that $\alpha$-globulins are synthesized in the liver and any deviations in their synthesis are signals of the state of this organ (Alberghina et al., 2010; Gloria et al., 2018). The $\gamma$-fraction includes all types of immunoglobulins produced by the lymphoid tissue in response to antigenic stimulation. In the females of group II, there were no changes in the $\alpha$ - and $\gamma$ globulins fraction, which indicates the normal course of pregnancy. The tendency to increase in albumin levels in the animals which consume vanadium citrate at the concentration of $0.03 \mu \mathrm{g} \mathrm{V} / \mathrm{mL}$ is probably due to the stabilizing properties of vanadium at this concentration, affecting the synthesizing liver function (Mohammadi \& Yazdanparast, 2010). Stimulation of the body immune system by the vanadium compound is caused by the $\gamma$-globulins level growth at concentrations $0.125-0.50 \mu \mathrm{g} \mathrm{V} / \mathrm{mL}$. The frac- tion of $\alpha$-globulins in the blood plasma of the females at concentrations $0.50 \mu \mathrm{g} \mathrm{V} / \mathrm{mL}$ increased. Its content growth in the blood may be a sign of increased activity of kininogen and plasmin, the normalizing effect of vanadium on the antioxidant defense system, the ability of this microelement to reduce the number of free radicals in the blood and to inhibit the lipids' peroxide oxidation processes (Gloria et al., 2018). At the concentration of $0.50 \mu \mathrm{g} \mathrm{V} / \mathrm{mL}$, a reduction of the $\beta$-globulin fraction was observed, which probably indicates the ability of vanadium to affect ferrum transport in iron proteins and possibly delay the onset of iron deficiency anemia (Sánchez et al., 2010).

The level of urea and creatinine in the blood is important for the diagnosis and understanding of the intensity of the pathological processes in the body, as well as for the assessment of the applied corrective therapy efficacy (Table 4). The level of urea in the pregnant rats' blood performs a marker function and may indicate kidney disorder. The observed increase in the level of urea in the blood plasma of pregnant females is often due to the changes in renal function caused by the increase in urine production and its excretion (Mohammadi \& Yazdanparast, 2010). Creatinine, as a urea metabolite, is an intermediate of muscle metabolism, and the direct correlation between the level of this metabolite and muscle mass is indicated by Baba et al. (2017). In the females of group II, there is a tendency to the decreased level of creatinine, compared to group I, which is also a result of the increased kidney function and the total blood volume growth in females during pregnancy. This intensifies urination and the increased excretion of creatinine with urine, which results in an inverse correlation between the content of urea and creatinine.

Studies of the ASAT and ALAT activity in pregnant females permit one to detect possible heart and liver complications. A decrease in ASAT and ALAT activity in the blood plasma of pregnant animals in group II may be caused by the reduced levels of B6 vitamin in pregnant animals. Grown of the AP activity in pregnant animals may be due to the intensified synthesis of its isoenzymes in the fetal tissues, the growth of bone tissue and the placenta development (Crans et al., 2018; Gloria et al., 2018). It is known that vanadium has hepatoprotective effect (Mohammadi \& Yazdanparast, 2010), it causes stabilization of the ASAT and ALAT activity, normalizes the urea and creatinine levels. Alkaline phosphatase is a vanadium-sensitive phospho-hydrolyzase. According to the literature data, vanadium has the ability to inhibit enzymes-phosphatases, which are important for the phosphorylation of proteins in the process of osteoblasts differentiation (Haenlein \& Anke, 2011; Crans et al., 2018).

The studies did not show significant differences in hemolysis of erythrocytes in non-pregnant and pregnant rats (groups I and II), but the time of hemolysis in pregnant rats decreased by $0.4 \mathrm{~min}$, as compared with non-pregnant, and was $8.4 \mathrm{~min}$ (Fig. 1; Table 5). The erythrograms obtained as a result of the experiment are single-vertex, which indicates the normal erythropoiesis and the absence of pathologies in the formation of red blood cells. Erythrograms of the animals of experimental groups III, IV and V are slightly shifted to the right (Fig. 1), as compared with groups I and II, which indicates the regenerative effect of vanadium citrate on 
erythropoiesis and the appearance of young erythrocytes in pregnant animals consuming sample solutions. The identified differences in the resistance of erythrocytes to the action of acid hemolytic can be explained on the basis of the properties of the structure of the erythrocyte membrane, erythrocyte life expectancy, changes in metabolic processes in these cells and the effect of vanadium citrate (Dudok et al., 2016). Vanadium in complex compounds has a direct effect on the membrane organization of lipids. This is one of the possible mechanisms of enhancing the action of insulin. Also, it is known that vanadium is insulin-mimetic. Such changes in the organization of lipids contribute to the distribution of insulin receptors and other receptors on the membrane microdomains, which contributes to their (receptors) optimal functioning. Therefore, the use of vanadium citrate affects the resistance of erythrocyte membranes to hemolytic action (Roess et al., 2008).

The lifespan of erythrocytes in pregnant rats is shorter than in nonpregnant rats (Table 6). This causes an increase in the content of young erythrocytes in pregnant females. The reduced lifespan of erythrocytes can be explained by the fact that erythrocytes, formed under the conditions of enhanced erythropoiesis or increased metabolic rate, accelerate the aging process. This indicates a reduction in the lifespan of erythrocytes in late pregnancy, may contribute to a better understanding of increased erythropoiesis, on the one hand, and decreased hemoglobin, on the other hand, which often occurs in late pregnancy. Also, the increase in reticulocyte content in pregnant rats is due to organogenesis in the fetus (Mizoguchi et al., 2010). In our studies, a decrease in erythrocytes was observed in the animals of group II, which is also a consequence of the increase in the content of reticulocytes during the physiological pregnancy of the animals. These results indicate the ability of vanadium citrate to increase reticulocyte content at all investigated concentrations (Hogan, 2000). Studies by other authors showed a two-phase increase in reticulocytes under the effect of the compound vanadium - sodium orthovanadate (Aguirre et al., 2005).

During physiological pregnancy, the formation of erythrocytes and erythropoietin increases, while the mass of erythrocytes per unit of bodyweight remains unchanged throughout pregnancy. Hemoglobin and hematocrit constantly decrease until the third trimester of pregnancy. Erythrocyte life expectancy decreases during normal pregnancy due to "emergency hematopoiesis" in response to elevated erythropoietin levels (Lurie, 2000). However, the function of hematopoietic organs lags behind the rate of the increase in the volume of circulating blood. Therefore, autohemodilution takes place during pregnancy, which is accompanied by a decrease in hemoglobin and a decrease in the number of erythrocytes per unit volume of blood. This is a significant factor that contributes to the occurrence of anemia (Lymans'ka et al., 2020). We found a decrease in erythrocyte content and concentration of hemoglobin in the pregnant rats (Table 7). The decreased hemoglobin during pregnancy is a common phenomenon, which is consistent with the results of other researchers (Feleke \& Feleke, 2020). Changes in hemoglobin, occurring from early pregnancy to midpregnancy or late pregnancy, were inversely related to fetal weight at birth and placental weight (Jwa et al., 2015). The mean hemoglobin concentration in the erythrocytes of pregnant animals increased slightly. An increase in the mean percentage of reticulocytes was observed in mid-pregnancy, after which it remained at a high level until the delivery. The red blood cell distribution width (RDW) also increases in mid-pregnancy and then decreases before the delivery. The continuous change in the age distribution of erythrocytes in relation to the young cell population occurs from early pregnancy and lasts until the delivery (Lurie, 1993). In the maternal circulation, according to the results of Belo et al. (2002), the number of both damaged erythrocytes and young erythrocytes increases. This also causes a decrease in the number of erythrocytes, hemoglobin and hematocrit during pregnancy and the postpartum period (Belo et al., 2002). Under the effect of vanadium citrate at concentrations of $0.03-0.125 \mu \mathrm{g} \mathrm{V} / \mathrm{mL}$ the content of erythrocytes increased. The concentration of hemoglobin at concentrations of $0.125 \mu \mathrm{g} \mathrm{V} / \mathrm{mL}$ decreased, at concentrations of $0.50 \mu \mathrm{g} \mathrm{V} / \mathrm{mL}$ increased. Also, under the effect of vanadium citrate there was a decrease in the mean hemoglobin concentration in the erythrocytes at concentrations of $0.03-0.125 \mu \mathrm{g} \mathrm{V} / \mathrm{mL}$. Such changes in the number of erythrocytes and their functional properties in the peripheral blood of pregnant rats under the effect of vanadium citrate may be due to the ability of vanadium to some extent to delay the maturation of erythrocytes, as compared to non-pregnant animals fed with only water. This can be expressed by a decrease in the number of erythrocytes, hemoglobin levels and an increase in the number of reticulocytes and also polychromatophilic cells in the peripheral blood (Zaporowska \& Wasilewski, 1989).

Platelets (thrombocytes) are the smallest elements of the blood, being the key players in hemostasis and thrombosis. The defects affecting platelets during pregnancy can lead to heterogeneous complications such as thrombosis, miscarriage in the first trimester (early pregnancy) and postpartum haemorrhage. The incidence of complications increases if there are inherited platelet function disorders (Valera et al., 2010). In pregnant animals there was an increase in platelet count (Table 8). Increasing platelet count is one way to protect the body from the development of gestational diabetes in pregnant animals (Yang et al., 2015). It is known that physiological pregnancy is characterized by an increase in platelet activation and a decrease in the total number of circulating platelets (Szklanna et al., 2019). The value of thrombocrit in the pregnant rats increased, which is due to an increase in platelet count in the pregnant rats of group II. The relative platelet distribution width by volume in the pregnant animals decreased, which may be due to low blood agglutination in pregnant animals. In the pregnant animals, fed with vanadium citrate solutions, the platelet content decreased, at all investigated concentrations $(0.03-0.50 \mu \mathrm{g} \mathrm{V} / \mathrm{mL})$. The decrease in the increased content of platelets and thrombocrit in the blood of pregnant animals under the effect of vanadium citrate can prevent thrombosis during pregnancy, which is a consequence of blood thinning. The results of González-Villalva et al. (2011), who investigated the effect of vanadium pentoxide on the platelets of mice and humans, showed the inhibition of platelet aggregation in platelet-rich plasma under a four-week influence. The platelet condition returned to normal after eight weeks (González-Villalva et al., 2011).

Normal pregnancy is a complex process that involves many immunoregulatory mechanisms that protect the fetus from activating the maternal immune system. This involves qualitative and quantitative changes in lymphocyte function. The content of total leukocytes and lymphocytes in the pregnant animals of group II decreased, while the content of granulocytes increased (Table 9). The decrease in the content of leukocytes and lymphocytes, including in the pregnant animals of group II may indicate the suppression of cellular immunity during gestation (Pramanik et al., 2007). Also, the lymphocyte content decreases due to the susceptibility of $\mathrm{CD} 3(+) \mathrm{CD} 8(+) \mathrm{T}$ cells to apoptosis as a protective mechanism in early pregnancy (Darmochwal-Kolarz et al., 2014). A significant decrease in the phagocytic function of monocytes and neutrophilic granulocytes in healthy pregnancy may be a part of the mother's immune suppression, which is important for fetal protection (Lampé et al., 2015). Activation of granulocytes, NK-cells and extrathymic T-cells is essential for pregnancy preservation, but their excessive activation can cause pregnancy disorders. Pregnancy is associated with temporary changes in granulocyte surface markers, such as lower CD16 expression and higher CD64, partially imitating the protective response (Elghetany \& Lacombe, 2004). Under the effect of vanadium citrate, the content of leukocytes and lymphocytes increased in all investigated groups. The increase in the content of blood lymphocytes may be due to the increase in DNA synthesis of these cells under the effect of vanadium citrate (Sharma et al., 1981). The effect of vanadium citrate on the increase of T-lymphocytes has a desensitizing effect, increases the nonspecific resistance of the organism and has a normalizing effect on the indicators of humoral immunity (Tsiclauri, 2010). The content of granulocytes in the pregnant animals consuming vanadium citrate solutions decreased at all concentrations $(0.03-0.50 \mu \mathrm{g} \mathrm{V} / \mathrm{mL})$. In the study by Di Gioacchino et al. (2002), it is suggested that vanadium may have an important effect on the body's immune system. This is proved by the fact that under the action of $10^{-4} \mathrm{M} \mathrm{NaVO}_{3}$, the formation of granulocytes decreased by about $70 \%$, while under the influence of $10^{-7} \mathrm{M}$ vanadate, their formation also decreased, but to a lesser extent (Di Gioacchino et al., 2002).

\section{Conclusion}

The results of the study show that in pregnant animals, urea levels and alkaline phosphatase activity increase, while aspartate aminotransferase activity decreases. The total content of protein and albumin decreases, 
however, the content of $\beta$-globulins increases. Also, in pregnant animals there was a decrease in hemolysis time, the total content of erythrocytes and hemoglobin, the content of old and mature erythrocytes, while the content of young erythrocytes increased. Platelet content and thrombocrit increased in pregnant rats. The total content of leukocytes and lymphocytes in pregnant females decreased, while the content of granulocytes increased, in contrast to non-pregnant animals.

Under the effect of vanadium citrate at the concentration of $0.03 \mu \mathrm{g}$ $\mathrm{V} / \mathrm{mL}$, the level of albumin, creatinine and aspartate aminotransferase activity increased in blood plasma in comparison with group II. And under the effect of vanadium citrate at the concentration of $0.125 \mu \mathrm{g} \mathrm{V} / \mathrm{mL}$, the relative content of $\gamma$-globulins and aspartate aminotransferase activity increased, whereas alkaline phosphatase activity and urea level decreased, in comparison with group II. As well under the effect of vanadium citrate at the concentration of $0.50 \mu \mathrm{g} \mathrm{V} / \mathrm{mL}$, the relative $\alpha$ - and $\gamma$-globulins' content and aspartate aminotransferase activity increased, while the relative $\beta$-globulin content and urea level decreased, in comparison with group II. Also, under the effect of vanadium citrate at concentrations of $0.03-0.50 \mu \mathrm{g}$ $\mathrm{V} / \mathrm{mL}$, there was a significant increase in the maximum number of prohemolized erythrocytes, the time of maximum hemolysis was delayed by 0.4-0.6 min, as compared with the pregnant rats of group II. However under the effect of vanadium citrate, the increase in the content of young erythrocytes was observed, as compared with group II. The hemoglobin content decreased at a concentration of $0.125 \mu \mathrm{g} \mathrm{V} / \mathrm{mL}$, but increased at a concentration of $0.50 \mu \mathrm{g} \mathrm{V} / \mathrm{mL}$. Also, under the effect of vanadium citrate there was a decrease in the mean hemoglobin concentration in the erythrocytes. In the pregnant animals fed with vanadium citrate solutions, platelet content and thrombocrit, the relative platelet distribution width by volume decreased, as compared with the pregnant rats of group II. Further under the effect of vanadium citrate, the content of leukocytes, lymphocytes and granulocytes increased, as compared to the pregnant animals in group II.

To sum up, vanadium has normalizing properties for certain indicators of protein metabolism during pregnancy. It is able to normalize the hematological profile during pregnancy, increase the resistance of erythrocyte membranes to hemolytic action. This ensures a healthy pregnancy. Therefore, vanadium citrate can potentially be used as a dietary agent to stop the development of pregnancy complications.

The authors would like to thank s.r.f. A. Z. Pylypets for performing the methodology of electrophoresis in polyacrylamide gel.

\section{References}

Aguirre, M. V., Juaristi, J. A., Alvarez, M. A., \& Brandan, N. C. (2005). Characteristics of in vivo murine erythropoietic response to sodium orthovanadate. Chemico-Biological Interactions, 156(1), 55-68.

Alberghina, D., Casella, S., Vazzana, I., Ferrantelli, V., Giannetto, C., \& Piccione, G. (2010). Analysis of serum proteins in clinically healthy goats (Capra hircus) using agarose gel electrophoresis. Veterinary Clinical Pathology, 39, 312-317.

Aureliano, M., \& Ohlin, C. A. (2014). Decavanadate in vitro and in vivo effects: Facts and opinions. The Journal of Inorganic Biochemistry, 137, 123-130.

Baba, Y., Furuta, I., Zhai, T., Ohkuchi, A., Yamada, T., Takahashi, K., Matsubara, S., \& Minakami, H. (2017). Effect of urine creatinine level during pregnancy on dipstick test. Journal of Obstetrics and Gynaecology Research, 43(6), 967-973.

Belo, L., Rebelo, I., Castro, E. M. B., Catarino, C., Pereira-Leite, L., Quintanilha, A., \& Santos-Silva, A. (2002). Band 3 as a marker of erythrocyte changes in pregnancy. European Journal of Haematology, 69(3), 145-151.

Cantley, L. C., \& Aisen, J. P. (1979). The fate of cytoplasmic vanadium. Implications on (NA,K)-ATPase inhibition. Joumal of Biological Chemistry, 254(6), 1781-1784.

Crans, D. C., Yang, L., Haase, A., \& Yang, X. (2018). Health benefits of vanadium and its potential as an anticancer agent. Metal Ions in Life Sciences, 18, 251-280.

Dai, D. M., Cao, J., Yang, H. M., Sun, H. M., Su, Y., Chen, Y. Y., Fang, X., \& Xu, W. B. (2017). Hematocrit and plasma albumin levels difference may be a potential biomarker to discriminate preeclampsia and eclampsia in patients with hypertensive disorders of pregnancy. Clinica Chimica Acta, 464, 218-222.

Darmochwal-Kolarz, D., Sobczak, E., Pozarowski, P., Kolarz, B., Rolinski, J., \& Oleszczuk, J. (2014). T CD3+CD8+ lymphocytes are more susceptible for apoptosis in the first trimester of normal human pregnancy. Journal of Immunology Research, 2014, 670524.
Di Gioacchino, M., Sabbioni, E., Di Giampaolo, L., Schiavone, C., Di Sciascio, M. B., Reale, M., Nicola, V., Qiao, N., Paganelli, R., Conti, P., \& Boscolo, P. (2002). In vitro effects of vanadate on human immune functions. Annals of Clinical and Laboratory Science, 32(2), 148-154.

Dudok, K., Kaniuka, O., Fedorovych, A., Burda, V., \& Sybirna, N. (2016). NO-zalezhna zmina spivvidnoshennya lihandnykh form hemohlobinu u peryferychniy krovi lyudey [NO-dependent changing of the ligand form of hemoglobin in peripheral blood of people]. Visnyk of the Lviv University, Series Biology, 73, 130-136 (in Ukrainian).

Elghetany, M. T., \& Lacombe, F. (2004). Physiologic variations in granulocytic surface antigen expression: Impact of age, gender, pregnancy, race, and stress. Journal of Leukocyte Biology, 75(2), 157-162.

Faught, W., Gamer, P., Jones, G., \& Ivey, B. (1995). Changes in protein C and protein S levels in normal pregnancy. American Journal of Obstetrics and Gynecology, 172, 147-150.

Feleke, B. E., \& Feleke, T. E. (2020). The effect of pregnancy in the hemoglobin concentration of pregnant women: A longitudinal study. Journal of Pregnancy, 2020, 2789536.

Gitel'zon, I. I., \& Terskov, I. A. (1959). Eritrogrammy kak metod klinicheskogo issledovaniya krovi [The erythrogram as a method of clinical investigation of the blood]. Academy of Science of USSR, Siberian Department, Krasnoyarsk (in Russian).

Gloria, A., Veronesi, M. C., Carluccio, R., Parrillo, S., Amicis, De, I., \& Contri, A. (2018). Biochemical blood analysis along pregnancy in Martina Franca jennies. Theriogenology, 115, $84-89$.

González-Villalva, A., Piñón-Zárate, G., De la Peña Díaz, A., Flores-García, M., Bizarro-Nevares, P., Rendón-Huerta, E., Colín-Barenque, L., \& Fortoul, I. T. (2011). The effect of vanadium on platelet function. European Journal of Pharmacology: Environmental Toxicology and Pharmacology, 32(3), 447-456.

Gunasinghe, M. A., \& Kim, S. M. (2018). Antioxidant and antidiabetic activities of vanadium binding proteins purified from the sea squirt Halocynthia roretzi. Journal of Food Science and Technology, 55(5), 1840-1849.

Haenlein, G. F. W., \& Anke, M. (2011). Mineral and trace element research in goats: A review. Small Ruminant Research, 95(1), 2-19.

Hogan, G. R. (2000). Comparative erythropoietic effects of three vanadium compounds. Science of the Total Environment, 256, 185-189.

Jwa, S. C., Fujiwara, T., Yamanobe, Y., Kozuka, K., \& Sago, H. (2015). Changes in maternal hemoglobin during pregnancy and birth outcomes. BMC Pregnancy Childbirth, 15, 80 .

Kolla, V., Jeno, P., Moes, S., Lapaire, O., Hoesli, I., \& Hahn, S. (2012). Quantitative proteomic (iTRAQ) analysis of 1st trimestermaternal plasma samples in pregnancies at risk for preeclampsia. Journal of Biomedicine and Biotechnology, 305, 96-94.

Lampé R., Kövér, Á., Szücs, S., Pál, L., Ámyas, E., \& Póka, R. (2017). The effect of healthy pregnant plasma and preeclamptic plasma on the phagocytosis index of neutrophil granulocytes and monocytes of nonpregnant women. Pregnancy Hypertension, 36(1), 59-63.

Lampé, R., Kövér, Á., Szücs, S., Pál, L., Ámyas, E., Ádány, R., \& Póka, R. (2015). Phagocytic index of neutrophil granulocytes and monocytes in healthy and preeclamptic pregnancy. Journal of Reproductive Immunology, 107, 26-30.

Lesesve, J.-F., Franczak, C., \& Perrin, J. (2019). Erythrocytes morphology in pregnancy. Annales de Biologie Clinique, 77(1), 113-115.

Levina, A., McLeod, A. I., Pulte, A., Aitken, J. B., \& Lay, P. A. (2015). Biotransformations of antidiabetic vanadium prodrugs in mammalian cells and cell culture media: A XANES spectroscopic study. Inorganic Chemistry, 54, 6707-6718.

Luppi, P. (2003). How immune mechanisms are affected by pregnancy. Vaccine, 21(24), 3352-3357.

Lurie, S. (1993). Changes in age distribution of erythrocytes during pregnancy: A longitudinal study. Gynecologic and Obstetric Investigation, 36(3), 141-144.

Lurie, S., \& Mamet, Y. (2000). Red blood cell survival and kinetics during pregnancy. European Journal of Obstetrics and Gynecology and Reproductive Biology, 93(2), 185-192

Lymans'ka, A. Y., Tarnavs'ka, A. A., \& Neroznak, Y. P. (2020). Hematolohichni zminy pid chas vahitnosti ta $\mathrm{v}$ pislyapolohovomu periodi. Vrodzheni rozlady hemostazu [Hematological changes during pregnancy and postpartum period. Congenital disorders of hemostasis]. Akusherstvo, Hinekolohiya, Reproduktolohiya, 38(2), 16-17 (in Ukrainian).

Mizoguchi, Y., Matsuoka, T., Mizuguchi, H., Endoh, T., Kamata, R., Fukuda, K., Ishikawa, T., \& Asano, Y. (2010). Changes in blood parameters in New Zealand white rabbits during pregnancy. Laboratory Animals, 44(1), 33-39.

Mohammadi, M., \& Yazdanparast, R. (2010). Radical scavenging abilities and hepatoprotective effect of [N,N'-Bis(salicylidene)ethane-1,2-diaminato]oxovanadium (IV) complex in $\mathrm{CCl}_{4}$-treated rats. Experimental and Toxicologic Pathology, 62(5), 533-538.

Naccasha, N., Gervasi, M. T., Chaiworapongsa, T., Berman, S., Yoon, B. H., Maymon, E., \& Romero, R. (2001). Phenotypic and metabolic characteristics of monocytes and granulocytes in normal pregnancy and maternal infection. American Journal of Obstetrics and Gynecology, 185(5), 1118-1123. 
Pramanik, S. S., Pramanik, T., Mondal, S. C., \& Chanda R. (2007). Number, maturity and phagocytic activity of neutrophils in the three trimesters of pregnancy. Eastern Mediterranean Health Journal, 13(4), 862-867.

Roess, D. A., Smith, S. M. L., Winter, P., Zhou, J., Dou, P., Baruah, B., Trujillo, A. M., Levinger, N. E., Yang, X., Barisas, B. G., \& Crans, D. C. (2008). Effects of vanadium-containing compounds on membrane lipids and on microdomains used in receptor-mediated signaling. Chemistry and Biodiversity, 5(8), 1558-1570.

Salisu, A. I. (2009). Variant formula for predicting peak expiratory flow rate in pregnant women in kura local government area, Kano state, Nigeria. Bayero Journal of Pure and Applied Sciences, 2(2), 113-115.

Sánchez, C., Torres, M., Bermúdez-Pena, C. M., Aranda, P., Montes-Bayón, M., SanzMedel, A., \& Llopis, J. (2011). Bioavailability, tissue distribution and hypoglycaemic effect of vanadium in magnesium-deficient rats. Magnesium Research, 24(4), 196-208.

Sanci, M., Töz, E., Ince, O., Özcan, A., Polater, K., Hamdi, A. I., Beyan, E., \& Akkaya, E. (2017). Reference values for maternal total and differential leukocyte counts in different trimesters of pregnancy and the initial postpartum period in western Turkey. Journal of Obstetrics and Gynaecology, 37(5), 571-575.

Sharma, R. P., Bourcier, D. R., Brinkerhoff, C. R., \& Christensen, S. A. (1981). Effects of vanadium on immunologic functions. American Joumal of Industrial Medicine, 2(2), 91-99.

Suwalsky, M., Fierro, P., Villena, F., Gallardo, M. J., Jemiola-Rzeminska, M., Strzalka, K., Gul-Hinc, S., Ronowska, A., Zysk, M., \& Szutowicz, A. (2013). Effects of sodium metavanadate on in vitro neuroblastoma and red blood cells. Archives of Biochemistry and Biophysics, 535(2), 248-256.

Szklanna, P. B., Parsons, M. E., Wynne, K., O’Connor, H., Egan K., Allen, S., Áinle, F. N., \& Maguire, P. B. (2019). The platelet releasate is altered in human pregnancy. Proteomics Clinical Applications, 13(3), e1800162.

Toji, N., Shigeno, S., Kizaki, K., Koshi, K., Matsuda, H., Hashiyada, Y., Imai, K, Takahashi, T., Ishiguro-Oonuma, T., \& Hashizume, K. (2017). Evaluation of interferon-stimulated genes in peripheral blood granulocytes as sensitive responders to bovine early conceptus signals. The Veterinary Journal, 229, 37-44.

Tsiclauri, S. (2010). Impact off treatment with intranasal electrophoresis of vanadium on the allergic reactivity and immunological indices of patients with allergic rhinitis. Georgian Medical News, 179, 19-26.

Valera, M.-C., Parant, O., Vayssiere, C., Amal, J.-F., \& Payrastre, B. (2010). Physiologic and pathologic changes of platelets in pregnancy. Platelets, 21(8), 587-595.

Vlizlo, V. V. (Ed.). (2012). Laboratomi metody doslidzhen u biolohii, tvarynnytstvi ta veterynarnii medytsyni [Laboratory methods of investigation in biology, stock-breeding and veterinary]. Spolom, Lviv (in Ukrainian)

Yang, H., Zhu, C., Ma, Q., Long, Y., \& Cheng, Z. (2015). Variations of blood cells in prediction of gestational diabetes mellitus. Journal of Perinatal Medicine, 43(1), $89-93$.

Zaporowska, H., \& Wasilewski, W. (1989). Some selected peripheral blood and haemopoietic system indices in Wistar rats with chronic vanadium intoxication. Comparative Biochemistry and Physiology - Part C: Toxicology and Pharmacology, 93(1), 175-180. 


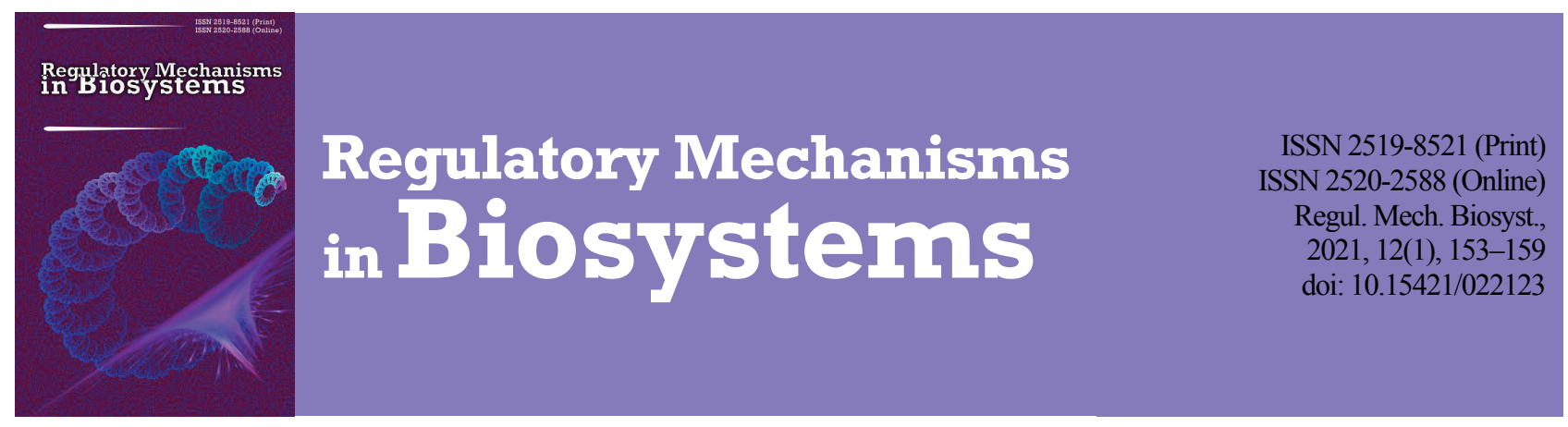

\title{
Features of modern winter wheat varieties in terms of winter hardiness components under conditions of Ukrainian Forest-Steppe
}

\author{
A. V. Pirych*, T. V. Yurchenko*, V. M. Hudzenko*, O. A. Demydov*, \\ H. M. Kovalyshyna**, O. V. Humeniuk*, V. V. Kyrylenko* \\ *The V. M. Remeslo Myronivka Institute of Wheat of the National Academy of Agrarian Sciences of Ukraine, Kyiv region, Ukraine \\ **National University of Life and Environmental Sciences of Ukraine, Kyiv, Ukraine
}

Article info

Received 10.02.2021

Received in revised form 15.03 .2021

Accepted 16.03.202

The V.M. Remeslo Myroniv$k a$ Institute of Wheat of

National Academy

of Agrarian Sciences

of Ukraine, Tsentralna st., 68

Tsentralne village,

Myronivka district, Kyi

region, 08853, Ukraine.

Tel.: +38-097-749-98-91.

E-mail:

alina22pirych@gmail.com

National University of Life and Environmental Sciences of Ukraine, Heroiv Oboron st, 15, Kyiv, 03041, Ukraine. $\mathrm{Tel} \cdot \mathbf{+}+38-096-410-45-16$ E-mail:

hkovalyshyna@gmail.com

Pirych, A. V., Yurchenko, T. V., Hudzenko, V. M., Demydov, O. A., Kovalyshyna, H. M., Humeniuk, O. V., Kyrylenko, V. V. (2021). Features of modern winter wheat varieties in terms of winter hardiness components under conditions of the Ukrainian Forest-Steppe. Regulatory Mechanisms in Biosystems, 12(1), 153-159. doi:10.15421/022123

In recent years, there has been a significant change in climatic conditions affecting the cultivation and yield of winter wheat. Therefore, the creation of wheat varieties with high adaptive potential is one of the main tasks of modern breeding. A significant component of the overall adaptive potential of winter wheat is winter hardiness, which is determined by a set of characters enabling plants to overwinter. To a large extent, winter hardiness is determined by gene systems that control vernalization requirement duration, photoperiod reaction, and frost resistance. The research is aimed at determining the features of modern winter wheat varieties developed at the V. M. Remeslo Myronivka Institute of Wheat of the National Academy of Agrarian Sciences of Ukraine in terms of winter hardiness components and adaptive potential in the environment of the Central part of the Ukrainian Forest-Steppe. Winter bread wheat varieties Estafeta myronivska, Hratsiia myronivska, MIP Assol, and Balada myronivska were studied. They also were crossed on incomplete diallele scheme with three near-isogenic lines derived from Erythrospermum 604 with different alleles of Vrd genes 1) Vrd1Vrd1vrd2vrd2, 2) vrdlvrd1Vrd2Vrd2, and 3) vrdlvrdlvrd2vrd2. It was established that vernalization requirement duration in the varieties Estafeta myronivska and Balada myronivska was short whereas in the varieties Hratsiia myronivska and MIP Assol it was medium. All the varieties studied have medium photoperiod sensitivity. The results of the hybridological analysis indicate the absence of the Vrd1 and Vrd2 genes in the varieties. Frost tolerance of these varieties is at the same level and higher than in the highly tolerant to the low temperatures variety Myronivska 808. Thus, the results indicate the possibility of recombining different levels of expression of these traits in genotypes by breeding efforts. This has great practical importance in farming, because in recent years the areas of crops harvested late (corn, sunflower, etc.) in the production conditions has significantly increased. It causes a shift in sowing dates of winter wheat to a later period. In this case, varieties Estafeta myronivska, Hratsiia myronivska, MIP Assol, and Balada myronivska are able to undergo sufficient hardening, to satisfy the vernalization requirement, and to form a high level of winter hardiness. Their relatively medium photoperiod sensitivity allows vegetation to be restored a little earlier in the spring and winter reserves of moisture to be used more effectively

Keywords: Triticum aestivum; frost tolerance; vernalization requirement; photoperiod sensitivity; hybridological analysis.

\section{Introduction}

In recent years, there has been a significant change in climatic conditions affecting the cultivation and yield of winter wheat (Kristensen et al., 2011; Blyzniuk et al., 2019). Therefore, the creation of varieties with increased adaptive potential is one of the priority tasks of winter wheat breeding today (Rybas et al., 2018). Winter hardiness is one of the main components of the general adaptive potential of winter wheat (Sandve et al., 2010). Genetic systems associated with winter hardiness include the genes determining plant response to vernalization $(\mathrm{Vrn})$, photoperiod sensitivity (Ppd) and frost resistance (Fr) (Sutka, 2001; McIntosh et al., 2013; Kiss, 2014).

Wheat photoperiod sensitivity is plant response to daylength expressed in the delay of heading date in photoperiod sensitive genotypes when daylength is shortening. The genes Ppd-A1, Ppd-B1, Ppd-D1 which control photoperiod sensitivity are located on the chromosomes 2A, 2B, 2D, respectively (Law et al., 1978; Worland et al., 1998). Variation in photoperiod sensitivity is a factor that leads to variability of adaptability and productivity of winter wheat varieties. Low responsiveness to the daylength reduction in the majority of varieties is due to the presence of the dominant allele Ppd-D1a in their genotype (Fayt et al., 2014). Varieties with dominant allele of the Ppd-D1 gene were less tolerant to low temperatures as compared to plants with an alternative recessive allele (Toptikov \& Chebotar, 2019).

Vernalization is prolonged exposure to low temperatures which induces the transition of winter crops from the vegetative to the generative stage of development (Deng et al., 2015). The combination of different dominant alleles of Vrn loci affects the heading date and, accordingly, duration of the whole growing season (Stelmakh, 1993). It has been shown that the mechanism for determining sensitivity to vernalization and heading date is based on mutations in the Vrn gene loci which correct the dependence of the transition to heading stage on the vernalization factor and transmit the gene from recessive into dominant (Distelfeld et al., 2009). More prolonged vernalization requirement leads to slower development in the initial stages of organogenesis, so the transition to formation of differentiated growth point and primordia of reproductive organs in such genotypes occurs much later (Prasil et al., 2004). The reduction of the vernalization duration may lead to an earlier transition of the plant from dormancy in spring and winter during thaws, which causes the reduction of winter hardiness and frost resistance. Sometimes it has significant negative influences on the grain yield (Fayt, 2003; Koemel et al., 2004). The winter type of development is manifested when the three major Vrn 
genes are represented by recessive alleles. However, the presence of only one dominant allele of $\mathrm{Vm}$-A1 gene provides complete insensitivity of plants to vernalization. Dominant alleles of the Vrn-B1 and Vrn-D1 loci only partially reduce the vernalization requirement (Pugsley, 1971; Pugsley, 1972). Genes determining plant growth habit are localized on different chromosomes: Vm-A1 (previous designation Vm1) on 5A, Vm-B1 (Vm2) on 5B, Vm-D1 (Vm3) and Vrn-D4 (Vrn4) on chromosome 5D. The Vm-B3 gene (earlier Vm5) is located in the short arm of chromosome 7B (Worland, 1996; Yan et al., 2006; Yoshiba et al., 2010). The efficacy of Vm and Ppd gene alleles marking for early diagnosis of plant response to vernalization and photoperiod has been reported (Cockram et al., 2009; Yang et al., 2009). The study of the duration of the stages of development of winter bread wheat in isogenic and substituted lines with different alleles of Vrn1 genes suggests that growing season duration depends mainly on the duration of period "tillering-the first node" (Pankova \& Kosner, 2004; Emtseva et al., 2013). Stelmakh et al. (2005) reported the identification of three vernalization requirement duration genes of winter wheat, designated by authors as Vrd1, Vrd2, and Vrd3. The Vrd1 gene is located on chromosome $4 \mathrm{~A}, \mathrm{Vrd} 2$ is on chromosome 5D. It was found that presence of dominant gene Vrdl reduces the vernalization requirement duration to 20-35 days, depending on the photoperiod sensitivity of the variety, and Vrd2 does to $40-45$ days (Balashova et al., 2006). Genotypes with recessive alleles of two Vrd genes (vrd1vrd1vrd2vrd2) require at least 50-60 days of vernalization for transition from the vegetative to the generative stage of development. A third gene (Vrd3) is also thought to be present, which determines the duration of vernalization up to 40 days and is located on one of the chromosomes 1A, 6A, or 4B (Fayt et al., 2007). Other scientists suggest that vernalization requirement duration is determined by changes in a locus of the Vrn-A1 gene (Yan et al., 2015) or Vrn-B1 (Guedira et al., 2013). It has also been suggested that the trait vernalization requirement duration in winter wheat may be controlled by the TaVRN-A1 gene at the protein level (Li et al., 2013). The study of the effects of genes controlling the vernalization duration (Vrd) on agronomic traits in isogenic lines of winter wheat shows that the dominant alleles of the genes Vrd1 and Vrd2 cause reduction in plant height as well as the shortening of the period to heading as compared to carriers of only recessive alleles of the gene vrd1vrd2 (Fayt, 2007).

Frost tolerance is the ability of plants to withstand negative temperatures during wintering (Sutton et al., 2009). Genes associated with freezing tolerance of winter wheat Fr1 and Fr2 are localized on chromosomes 5A and 5D, respectively (Sutka, 2001). It is assumed that the presence of the Vrn-D1 and Fr-D1 genes in the wheat genotype not only determines the level of freezing tolerance, but also plant resistance to snow mold (Francia et al., 2007; Erath et al., 2017).

Given the above, to characterize modern genotypes of winter wheat on genetic systems that determine the processes of vernalization, photoperiod sensitivity, frost resistance and their impact on growth, development and general adaptive potential is relevant (Bakuma, 2016; Fayt et al., 2017; Jones et al., 2017). It was found that under various agroclimatic conditions there are different combinations of vernalization requirement and photoperiod sensitivity in winter wheat genotypes, which leads to increased adaptive potential, in particular, frost resistance (Whittal et al., 2018; Kawakita et al., 2020; Royo et al., 2020).

The aim of the research was to identify the features of modern varieties of winter wheat developed at the V. M. Remeslo Myronivka Institute of Wheat of the National Academy of Agrarian Sciences of Ukraine (MIW) by vernalization requirement, photoperiod reaction and frost resistance as components of winter hardiness and adaptive potential in the Central part of Ukrainian Forest-Steppe.

\section{Materials and methods}

The research was conducted in 2016-2019 at the MIW. We used new Myronivka winter wheat varieties (Estafeta myronivska, Hratsiia myronivska, MIP Assol and Balada myronivska) which are included in the State Register of Plant Varieties Suitable for Dissemination in Ukraine since 2018. When analyzing the pedigrees of these varieties, it was established that the varieties Estafeta myronivska and Hratsiia myronivska were created on the basis of crossing local varieties and lines with each other while in creating the varieties Balada myronivska and MIP Assol, collection samples of different ecological origin from Hungary and Russia were used (Table 1).

Table 1

Genealogical characteristics of the studied winter wheat varieties

\begin{tabular}{|c|c|}
\hline $\begin{array}{c}\text { Variety, } \\
\text { biological variety }\end{array}$ & Genealogy \\
\hline $\begin{array}{c}\text { Estafeta } \\
\text { myronivska } \\
\text { (var. lutescens) }\end{array}$ & $\begin{array}{l}\text { Myronivska } 64 \text { [Myronivska yuvileina (Lutescens106/ Bezos- } \\
\text { taya 4) / KM 66-10-1-79] / Lutescens } 50713 \text { \{Myronivska } 27 \\
\text { [Lutescens } 6915 \text { (Prybii / Myronivska yuvileina) / Lutescens } \\
6538 \text { )] / Nike\} }\end{array}$ \\
\hline $\begin{array}{l}\text { Hratsiia } \\
\text { myronivska } \\
\text { (var. } \\
\text { erythrospermum) }\end{array}$ & $\begin{array}{l}\text { Erythrospermum } 52422 \text { [Erythrospermum } 9736 \text { (Narino } 59 \text { / } \\
\text { Veneda)] / Erythrospermum 52687 from Erythrospermum } \\
10071 \text { \{Erythrospermum } 5226 \text { [WRH* k-43822 / Lutescens } \\
2274 \text { (Lutescens } 106 \text { / Bezostaya } 4 \text { // Bezostaya 4)] / Lutescens } \\
6075\} \text { / Gama// Donskaya intensivnaya }\end{array}$ \\
\hline $\begin{array}{c}\text { MIP Assol } \\
\text { (var. lutescens) }\end{array}$ & $\begin{array}{l}\text { Sakwa / Myronivska } 65 \text { \{Myronivska 61 [Illichivka(Bezostaya } 4 \\
\text { / Myronivska 808) / Hadm. 6508-74)] / Myronivska } 27 \\
\text { [Lutescens 6915 (Prybii / Myronivska yuvileina) / Lutescens } \\
6538 \text { (Hadm. 6508-74)]\} // Lutescens } 52948 \text { \{Lutescens } 2060 \\
\text { from Myronivska } 27 \text { [Lutescens } 6915 \text { (Prybii / Myronivska } \\
\text { yuvileina) / Lutescens 6538]\} / Myronivska } 61 \text { [Illichivka (Be- } \\
\text { zostaya } 4 \text { / Myronivska 808) / Hadm. 6508-74] / Lutescens } \\
\text { 20051 \{Myronivska } 61 \text { [Illichivka (Bezostaya } 4 \text { / Myronivska } \\
\text { 808) / Hadm. 6508-74]\} / NS 954 / Kavkaz // Rezo / Lutescens } \\
\text { 8133 [Siete Cerros } 66 \text { / Myronivska yuvileina (Bezostaya } 4 \text { / } \\
\text { Myronivska 808)] }\end{array}$ \\
\hline $\begin{array}{l}\text { Balada } \\
\text { myronivska } \\
\text { (var. erythrosper- } \\
\text { mum) }\end{array}$ & $\begin{array}{l}\text { Donskaya polukarlikovaya / Estet (Illichivka / SK-2542, CZE // } \\
\text { CIMMYT-151) / Erythrospermum } 10071 \text { \{Erythrospermum } \\
5226 \text { [WRH k-43822 / Lutescens } 2274 \text { (Lutescens 106/ Bezos- } \\
\text { taya } 4 \text { // Bezostaya 4)] / Lutescens } 6075\} \text { // Erythrospermum } \\
53321 \text { [Lutescens } 9950 \text { (Illichivka / SK-2542 // CIMMYT-151)] } \\
\text { / Erythrospermum } 10071 \text { \{Erythrospermum 5226 [WRH k- } \\
\text { 43822 / Lutescens } 2274 \text { (Lutescens } 106 \text { / Bezostaya } 4 \text { // Bezos- } \\
\text { taya 4)]/ Lutescens 6075\} }\end{array}$ \\
\hline
\end{tabular}
Note: *WRH-wheat-rye hybrid.

To determine photoperiod sensitivity of the winter wheat varieties two variants of the experiment were laid: in the first the plants were grown under natural daylight; in the second they were under artificially shortened daylight (12 hours). Before sowing, the germinated seeds were artificially vernalized for 60 days (at $0 \ldots+1^{\circ} \mathrm{C}$ ). Using a special marker, germinated seeds of each variety were planted 20 pcs in each of two vegetative pots per variant of the experiment. Then the pots were placed in an open area. To shorten day length, the plants in the pots were covered with black boxes (Fig. 1a). The date of heading occurrence for individual plants was marked with labels (Fig. 1b). According to photoperiod sensitivity, wheat varieties were divided into three groups: high-, medium- and low sensitive. In our experiment, the first group included varieties that responded to the daylight reduction with significant heading delay of 10-13 days, the second group with delay of 6-9 days, and the third group with less than 6 days.

To determine vernalization requirement duration, 100 seeds of each variety were watered and placed for germination in a thermostat at the temperature of $+19 \ldots+20^{\circ} \mathrm{C}$ for one day. To go through vernalization, the seedlings were placed in the LVN-200G chamber at the temperature of $0 \ldots+1{ }^{\circ} \mathrm{C}$ for different periods $(50,40$, and 30 days). The vernalized seedlings were planted in spring at a time when the level of long-term air temperature avoids additional vernalization of experimental samples in the field (for the research period it was on April 14-18). Previously, the field was divided into strips of width $1 \mathrm{~m}$ and tracks between strips of $50 \mathrm{~cm}$. The seedlings were planted on two rows for each variant of the experiment, about 50 seeds per row. The plants were counted in early August using the envelope method. The duration of the vernalization period was considered to be sufficient if the most plants of the variety reached heading.

As testers that allow to one establish differences in wheat plant development at early stages of organogenesis we used near-isogenic by genes Vrd winter wheat lines Erythrospermum 604 Vrd1Vrd1vrd2vrd2, Erythrospermum 604 vrd1vrd1Vrd2Vrd2, Erythrospermum 604 vrd1vrd1vrd2vrd2 created at the Plant Breeding and Genetics Institute National Center of Seed and Cultivar Investigation of NAAS (Fayt, 2006). 

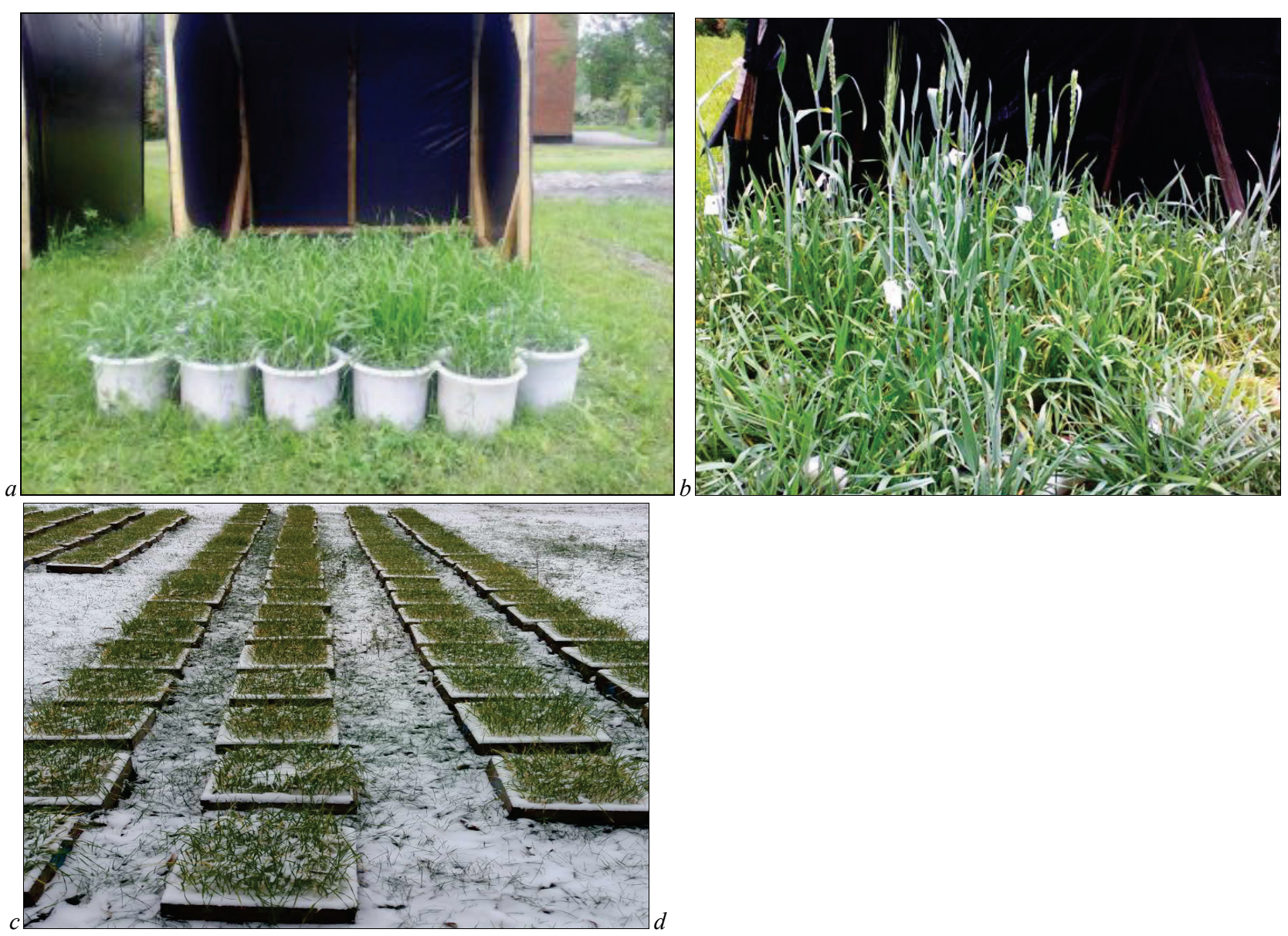
Table 2

Days to heading under the natural and shortened photoperiod in new varieties of winter wheat $(x \pm S E, n=30)$

\begin{tabular}{lllllll}
\hline \multirow{2}{*}{ Variety } & \multicolumn{2}{c}{2016} & \multicolumn{2}{c}{2017} & \multicolumn{2}{c}{2018} \\
\cline { 2 - 7 } & $\begin{array}{c}\text { natural } \\
\text { photoperiod }\end{array}$ & $\begin{array}{c}\text { shortened } \\
\text { photoperiod }\end{array}$ & $\begin{array}{c}\text { natural } \\
\text { photoperiod }\end{array}$ & $\begin{array}{c}\text { shortened } \\
\text { photoperiod }\end{array}$ & $\begin{array}{c}\text { natural } \\
\text { photoperiod }\end{array}$ & $\begin{array}{c}\text { shortened } \\
\text { photoperiod }\end{array}$ \\
\hline Estafeta myronivska & $51.0 \pm 0.5^{\mathrm{a}}$ & $58.4 \pm 1.0^{\mathrm{a}}$ & $55.0 \pm 0.2^{\mathrm{a}}$ & $61.5 \pm 0.3^{\mathrm{a}}$ & $59.5 \pm 1.3^{\mathrm{a}}$ & $68.7 \pm 1.7^{\mathrm{a}}$ \\
Hratsiia myronivska & $48.8 \pm 0.4^{\mathrm{b}}$ & $55.9 \pm 1.1^{\mathrm{b}}$ & $51.9 \pm 0.2^{\mathrm{b}}$ & $58.7 \pm 0.6^{\mathrm{b}}$ & $53.0 \pm 1.3^{\mathrm{b}}$ & $63.1 \pm 1.9^{\mathrm{b}}$ \\
MIP Assol & $51.8 \pm 0.4^{\mathrm{a}}$ & $57.5 \pm 0.4^{\mathrm{ab}}$ & $55.5 \pm 0.3^{\mathrm{a}}$ & $65.3 \pm 0.4^{\mathrm{c}}$ & $73.2 \pm 0.9^{\mathrm{c}}$ & $77.9 \pm 1.5^{\mathrm{c}}$ \\
Balada myronivska & $49.8 \pm 0.4^{\mathrm{ab}}$ & $55.7 \pm 0.6^{\mathrm{b}}$ & $54.3 \pm 0.3^{\mathrm{a}}$ & $59.0 \pm 0.7^{\mathrm{b}}$ & $56.2 \pm 1.2^{\mathrm{bb}}$ & $69.8 \pm 2.8^{\mathrm{a}}$ \\
\hline
\end{tabular}

Note: different letters indicate values which reliably differed one from another within one column of the table according to the results of comparison using the ANOVA with Bonferroni correction.

Table 3

Vernalization requirement duration and days to heading in new winter wheat varieties $(x \pm S E, n=90)$

\begin{tabular}{|c|c|c|c|c|c|c|c|}
\hline \multirow[b]{2}{*}{$\begin{array}{c}\text { Genotype of } \\
\text { near-isogenic line }\end{array}$} & \multicolumn{2}{|c|}{2016} & \multicolumn{2}{|c|}{2017} & \multicolumn{2}{|c|}{2018} & \multirow[b]{2}{*}{$\begin{array}{l}\text { Vernalization } \\
\text { requirement }\end{array}$} \\
\hline & $\begin{array}{l}\text { vernalization } \\
\text { requirement }\end{array}$ & $\begin{array}{l}\text { days to } \\
\text { heading }\end{array}$ & $\begin{array}{l}\text { vernalization } \\
\text { requirement }\end{array}$ & $\begin{array}{l}\text { days to } \\
\text { heading }\end{array}$ & $\begin{array}{c}\text { vernalization } \\
\text { requirement }\end{array}$ & $\begin{array}{l}\text { days to } \\
\text { heading }\end{array}$ & \\
\hline Vrd1Vrd1vrd2vrd2 & 30 & $65.3 \pm 1.8^{\mathrm{a}}$ & 30 & $57.4 \pm 2.6^{\mathrm{a}}$ & 40 & $55.9 \pm 0.9^{\mathrm{a}}$ & short duration \\
\hline vrd1 vrd1 Vrd2 Vrd2 & 40 & $72.4 \pm 4.1^{b}$ & 30 & $75.4 \pm 3.0^{b}$ & 40 & $74.8 \pm 2.0^{b}$ & (31-40 days) \\
\hline $\operatorname{vrd} 1 \mathrm{vrd} 1 \mathrm{vrd} 2 \mathrm{vrd} 2$ & 50 & $70.5 \pm 2.5^{\mathrm{ab}}$ & 50 & $72.3 \pm 2.6^{b}$ & 50 & $68.7 \pm 5.2^{\mathrm{b}}$ & $\begin{array}{l}\text { medium duration } \\
\text { (41-50 days) }\end{array}$ \\
\hline
\end{tabular}

Note: see Table 2 .

Table 4

Vernalization requirement duration and days to heading in winter wheat near-isogenic lines $(x \pm S E, n=90)$

\begin{tabular}{|c|c|c|c|c|c|c|c|}
\hline \multirow[b]{2}{*}{$\begin{array}{c}\text { Genotype of } \\
\text { near-isogenic line }\end{array}$} & \multicolumn{2}{|c|}{2016} & \multicolumn{2}{|c|}{2017} & \multicolumn{2}{|c|}{2018} & \multirow[b]{2}{*}{$\begin{array}{l}\text { Vernalization } \\
\text { requirement }\end{array}$} \\
\hline & $\begin{array}{l}\text { vernalization } \\
\text { requirement }\end{array}$ & $\begin{array}{c}\text { days to } \\
\text { heading }\end{array}$ & $\begin{array}{l}\text { vernalization } \\
\text { requirement }\end{array}$ & $\begin{array}{l}\text { days to } \\
\text { heading }\end{array}$ & $\begin{array}{l}\text { vernalization } \\
\text { requirement }\end{array}$ & $\begin{array}{l}\text { days to } \\
\text { heading }\end{array}$ & \\
\hline Vrd1Vrdlvrd2vrd2 & 30 & $65.3 \pm 1.8^{\mathrm{a}}$ & 30 & $57.4 \pm 2.6^{\mathrm{a}}$ & 40 & $59.4 \pm 0.9^{\mathrm{a}}$ & short duration \\
\hline vrd1 vrd1 Vrd2 Vrd2 & 40 & $72.4 \pm 4.1^{\mathrm{b}}$ & 30 & $75.4 \pm 3.0^{\mathrm{b}}$ & 40 & $74.8 \pm 2.0^{b}$ & (31-40 days) \\
\hline vrd1 vrd1 vrd2vrd2 & 50 & $70.5 \pm 2.5^{\mathrm{ab}}$ & 50 & $72.3 \pm 2.6^{\mathrm{b}}$ & 50 & $68.7 \pm 5.2^{\mathrm{b}}$ & $\begin{array}{l}\text { medium duration } \\
\text { (41-50 days) }\end{array}$ \\
\hline
\end{tabular}

Note: see Table 2 .

Table 5

The segregation ratio in $\mathrm{F}_{2}$ population for "heading occurrence: no heading occurrence" after vernalization duration 40 and 30 days

\begin{tabular}{|c|c|c|c|c|c|c|c|c|c|c|}
\hline \multirow{2}{*}{$\begin{array}{c}\text { Days of } \\
\text { vernalization }\end{array}$} & \multirow{2}{*}{ Variety } & \multicolumn{3}{|c|}{ vrd1vrd1vrd2vrd2 } & \multicolumn{3}{|c|}{ Vrd1Vrd1vrd2vrd2 } & \multicolumn{3}{|c|}{ vrd1vrd1Vrd2Vrd2 } \\
\hline & & fact & theoretical & $\chi^{2}$ & fact & theoretical & $\chi^{2}$ & fact & theoretical & $\chi^{2}$ \\
\hline \multirow{4}{*}{30} & Estafeta myronivska & $136: 132$ & $3: 1^{*}$ & 147.14 & $124: 14$ & $15: 1$ & 3.57 & $111: 25$ & $3: 1$ & 3.18 \\
\hline & Hratsiia myronivska & $13: 122$ & $1: 15$ & 2.63 & $118: 28$ & $13: 3$ & 0.02 & $13: 122$ & $1: 15$ & 2.63 \\
\hline & MIP Assol & $0: 143$ & - & - & $161: 27$ & $13: 3$ & 2.38 & $22: 107$ & $3: 13$ & 0.24 \\
\hline & Balada myronivska & $3: 113$ & $1: 15$ & 2.66 & 109:18 & $13: 3$ & 1.74 & 4:136 & $1: 15$ & 2.75 \\
\hline \multirow{4}{*}{40} & Estafeta myronivska & $113: 32$ & $3: 1$ & 0.66 & $146: 16$ & $15: 1$ & 3.63 & $85: 8$ & $15: 1$ & 0.88 \\
\hline & Hratsiia myronivska & $140: 36$ & $3: 1$ & 1.94 & $198: 35$ & $13: 3$ & 2.13 & $130: 11$ & $15: 1$ & 0.58 \\
\hline & MIP Assol & $97: 24$ & $3: 1$ & 1.72 & $213: 48$ & $13: 3$ & 0.02 & $119: 9$ & $15: 1$ & 0.13 \\
\hline & Balada myronivska & $105: 25$ & $3: 1$ & 2.31 & 108:6 & $15: 1$ & 0.19 & $137: 23$ & $13: 3$ & 2.01 \\
\hline
\end{tabular}

Note: $*$-does not correspond to the theoretical segregation ratio; $\chi^{2}<3.84$ at the $\mathrm{P}=0.05$.

Vernalization requirement. In 2016, duration 50 days was considered sufficient vernalization period for the winter wheat varieties Hratsiia myronivska and MIP Assol, as the highest percentage of heading plants was observed in this variant of the experiment (Table 3).

For the varieties Estafeta myronivska and Balada myronivska a high percentage of heading plants was found in the variant with 40 days vernalization. In 2017, plants of the variety Estafeta myronivska had the highest percentage of heading in the variant with vernalization during 50 days $(100 \%)$. However, after 40 days of vernalization duration, heading plants were observed at the level of $70.8 \%$, which makes it possible to consider this particular period to be necessary for transition of plants to generative state. The same period is necessary for plants of wheat varieties Hratsiia myronivska and MIP Assol. In the variety Balada myronivska, the higher percentage of heading plants was observed in both variants, therefore, for this variety, the vernalization requirement was 30 days. Vernalization requirement for the variety Hratsiia myronivska in 2018 was 50 days, because for this vernalization duration heading plants were observed at the level of $70 \%$. Whenever seedlings of this variety were vernalized during 40 and 30 days, the heading occurred only in $47.4 \%$ and $41.2 \%$ of plants, respectively. In the variety MIP Assol $91.7 \%$ of plants were heading at 50 days of vernalization and $65.0 \%$ at 40 days. After 30 days of vernalization duration there was a low percentage of heading plants, so we consider
40 days of vernalization to be sufficient for transition of plants of this variety to the generative state.

The varieties Balada myronivska and Estafeta myronivska required 40 days of vernalization too. They differ from the previous ones in that in the variant with 30 days vernalization most of the plants of these varieties remained at the tillering phase.

The heading dynamic of the varieties under study indicated that the average time to heading varied over the years from 55.9 to 77.9 days. The highest range of variation of this trait among the varieties was observed in 2018, and the lowest was in 2016. The shortest time to heading at the established duration of vernalization of 40 days in 2016 was noted in the varieties Estafeta myronivska and Balada myronivska ( $66.3 \pm 0.26$ and $65.1 \pm 0.50$ days). In 2017 and 2018 the shortest time to heading (59.8 and 59.0 days, respectively) was observed in the variety Hratsiia myronivska.

In varieties with short vernalization requirement duration, this period was, on average, 31-40 days, with medium vernalization requirement duration 41-50 days, and with a long-term - 51-60 days. The results of the research show that the varieties MIP Assol and Hratsiia myronivska require medium vernalization duration (41-50 days), whereas the varieties Estafeta myronivska and Balada myronivska require short vernalization duration (31-40 days). No varieties with long-term vernalization duration were revealed in our research. 
Vernalization duration requirement under environmental conditions of the Ukrainian Forest-Steppe was determined also in winter wheat nearisogenic lines Erythrospermum 604 Vrd1Vrd1vrd2vrd2, Erythrospermum 604 vrd1vrd1Vrd2Vrd2, and Erythrospermum 604 vrd1vrd1vrd2vrd2. In 2016 (Table 4), the lines Erythrospermum 604 with dominant allele of Vrd1 or Vrd2 genes required 30 and 40 days of vernalization duration, because in 70.0 and $63.0 \%$ of plants heading occurred. The line vrdl vrdl vrd2 vrd2 required 50 days of vernalization duration, because in variants 40 and 30 days of vernalization most plants remained at the tillering stage. In 2017, the line Vrd1Vrd1vrd2vrd2, with dominant allele of the Vrd1 gene, at the vernalization of seeds during 50,40, and 30 days demonstrated heading in $100 \%$ of plants. The same level was noted in the line vrdlvrd1Vrd2 Vrd2, which means vernalization duration 30 days was sufficient for it. Heading occurrence for the line vrd1vrd1vrd2vrd2 after 40 days of vernalization duration was noted only in $47 \%$ plants, after 30 days no heading was noted. After 50 days of vernalization duration, heading occurrence was observed in all plants. In 2018, the lines Erythrospermum 604 with dominant alleles of $\operatorname{Vrd} 1$ or $\operatorname{Vrd} 2$ genes required 40 days of vernalization duration, and then heading occurred in 70.6 and $64.0 \%$ of plants, respectively.

For the near-isogenic line Erythrospermum 604 vrd1vrd1vrd2vrd2 being a carrier of recessive allele of these genes, vernalization requirement duration was 50 days, because for shorter vernalization duration (30 and 40 days) no heading was noted. As indicated by heading dynamic for three years, heading time averaged 59.5 days in the line VrdlVrdlvrd2vrd2, 74.2 days in the line vrdlvrd1Vrd2Vrd2 and 70.5 days in the line vrdlvrdlvrd2vrd2. The variation in heading dynamic of the tester lines among the years is explained by differing weather conditions over the years of the research. Since, weather in April and May in 2017 was cooler as compared to these months in 2018, so more plants did not reach heading.

Hybridological analysis. The actual segregation ratio for "heading occurrence: no heading occurrence" in all cross combinations with recessive tester of gene Vrd corresponded to the theoretical 3:1 (Table 5).

The segregation ratio in populations Vrd1Vrd1vrd2vrd2/Estafeta myronivska and vrd1vrd1Vrd2 Vrd2/Estafeta myronivska corresponded to 15:1. The segregation ratio in combinations Vrd1Vrd1vrd2vrd2/Hratsiia myronivska, Vrd1Vrd1vrd2vrd2/MIP Assol and Vrd1Vrd1vrd2vrd2/Balada myronivska was 13:3, and in the population created with these varieties and tester line vrd1vrd1Vrd2Vrd2 it was 15:1. The segregation ratio in combinations Vrd1Vrd1vrd2vrd2/Balada myronivska and vrd1vrd1Vrd2 $\operatorname{Vrd} 2 /$ Balada myronivska was $15: 1$ and 13:3, respectively.

After 30 days vernalization in the population vrd1vrd1vrd2vrd2/Estafeta myronivska the fact segregation ratio for "heading occurrence: no heading occurrence" was 136:132, which did not correspond to the theoretical ratio 3:1. In combinations Vrd1Vrd1vrd2vrd2/Estafeta myronivska and vrd1vrd1Vrd2Vrd2/Estafeta myronivska this ratio was 15:1 and 3:1 respectively. In the combinations of the varieties Hratsiia myronivska and Balada myronivska with the tester of recessive genes (vrd1 vrd1 vrd2vrd2) the fact segregation corresponded to the theoretical ratio $1: 15$ as well as with tester of dominant gene $\mathrm{Vrd} 2$ to the ratio 13:3. In the combination vrd1vrd1vrd2vrd2/MIP Assol even for 90 days segregation was not observed. The segregation ratio with the tester Vrd1Vrd1 vrd2vrd2 was 13:3, and with the tester vrd1 vrd1 Vrd2Vrd2 it was 3:13.

Frost resistance. On average for 2017-2019, the percentage of viable plants of the variety Myronivska 808 after freezing at temperature minus $18{ }^{\circ} \mathrm{C}$ and minus $20^{\circ} \mathrm{C}$ was $87 \%$ and $58 \%$, respectively. Freezing tolerance at the level of the standard variety (according to Fisher's test) at both freezing temperatures was observed in the varieties Hratsiia Myronivska $(79 \pm 4.5,50 \pm 5.5)$ and Balada Myronivska ( $82 \pm 4.4,53 \pm 5.6$, Table 6). The variety Estafeta myronivska significantly exceeded the standard for the percentage of live plants after freezing at minus $18^{\circ} \mathrm{C}(99 \pm 1.2)$, and for the temperature minus $20^{\circ} \mathrm{C}$ - percentage of live plants was at its level $(59 \pm 5.6)$. In the variety MIP Assol percentage of live plants at the freezing temperature minus $18^{\circ} \mathrm{C}$ was of the level of the standard (91\%), and at the minus $20^{\circ} \mathrm{C}$ significantly exceeds the standard.

\section{Discussion}

It has been established that in the conditions of the south of Ukraine the Ppd-Dla allele significantly shortens the duration of time to heading, reduces plant height, reduces the spike and stem length, number of spikes and fertile spikelets per spike, spike density; increases grain number per spike and grain weight per main spike, grain weight of secondary stems, 1000 kernel weight (Bakuma et al., 2018). The genotype Ppd-A1b PpdBlb Ppd-Dla is prevalent in the varieties bred at Bila Tserkva Experimental and Breeding Station, the Ppd-Dla allele determines insensitivity to the photoperiod and promotes an earlier heading date. Only the variety Lehenda bilotserkivska is a carrier of the recessive allele Ppd-Dlb and has a later heading date (Filimonov et al., 2018). In the Ppd-1 gene system of the varieties bred at the Institute of Irrigated Agriculture of NAAS the dominant Ppd-Dla allele there were identified and recessive $b$ alleles were identified in the Ppd-A1 and Ppd-B1 loci (Bakuma et al., 2019). According to the results of our research, we assume that the new varieties of winter bread wheat of breeding at the MIW do not have the dominant allele of the Ppd-D1 gene, because varieties insensitive to the photoperiod were not detected among them.

\section{Table 6}

The percentage of surviving plants of winter wheat varieties after freezing $(\%, \mathrm{x} \pm \mathrm{SE}, \mathrm{n}=80), 2017-2019$

\begin{tabular}{lcc}
\hline \multirow{2}{*}{\multicolumn{1}{c}{ Variety }} & \multicolumn{2}{c}{ Temperature of freezing } \\
\cline { 2 - 3 } & $-18^{\circ} \mathrm{C}$ & $-20^{\circ} \mathrm{C}$ \\
\hline Myronivska 808, standard & $87.0 \pm 3.8^{\mathrm{a}}$ & $58.0 \pm 5.5^{\mathrm{a}}$ \\
Estafeta myronivska & $99.0 \pm 1.2^{\mathrm{b}}$ & $59.0 \pm 5.6^{\mathrm{a}}$ \\
Hratsiia myronivska & $79.0 \pm 4.5^{\mathrm{a}}$ & $50.0 \pm 5.5^{\mathrm{a}}$ \\
MIP Assol & $91.0 \pm 3.2^{\mathrm{a}}$ & $70.0 \pm 5.2^{\mathrm{b}}$ \\
Balada myronivska & $82.0 \pm 4.4^{\mathrm{a}}$ & $53.0 \pm 5.6^{\mathrm{a}}$ \\
\hline
\end{tabular}

Note: different letters indicate values which reliably differed one from another within one column of the table according to the results of comparison using the Fisher's criterion.

Vernalization requirement in wheat can be considered as an adaptive mechanism that provides delay in transition to the reproductive stage of development during winter (Muterko et al., 2015). Analysis of the assortment of winter wheat of Ukrainian breeding showed that among the genotypes created at the Plant Breeding and Genetics Institute - National Centre of Seed and Cultivar Investigation of NAAS the majority of wheat genotypes possessed dominant allele of the Vrd1 gene (54.5\%) (Fayt, 2012). Among the varieties of the Plant Production Institute nd. a. V. Y. Yuriev of NAAS, the majority of genotypes had the dominant allele Vrd3 (36.4\%) or the three recessive vrd genes (36.4\%). At the same time, the possibility of modifying the vernalization duration requirement by Ppd genes is not excluded (Stelmakh et al., 2019; Zubrich \& Avksentieva, 2019). It was noted that introduction into the modern enhanced in productivity wheat gene pool of genetic material relating to the rates of initial development typical for varieties of past generations would improve the adaptive properties of future breeding material (Stelmakh \& Fayt, 2015).

The segregation in F2 population for heading occurrence resulting from hybridological analysis (Fayt, 2006b, 2012) was not observed if the genotype of the variety and the tester coincided. When crossing a variety that is assumed to have dominant gene $\operatorname{Vrd} 1, \operatorname{Vrd} 2$ or $\operatorname{Vrd} 3$ with a recessive tester after 40 days of vernalization, the segregation ratio is $3: 1$. If in the genotype of the variety there are two dominant genes of vernalization requirement at the same time, the segregation ratio is 15:1. The segregation ratios of 3:1 and 15:1 indicate a difference in genes in the variety and tester studied. It was determined that the vernalization requirement duration of Vrd gene testers in the Right-bank Forest-Steppe of Ukraine was $30-50$ days. So, to reveal differences among genotypes in this agroclimatic zone 30 and 40 days are sufficient terms of vernalization.

In our case, after 30 days vernalization in the population vrdlvrd1 $\operatorname{vrd} 2 \mathrm{vrd} /$ Estafeta myronivska the fact segregation ratio for "heading occurrence : no heading occurrence" was 136:132, which did not correspond to the theoretical ratio $3: 1$, which could have been caused by weather conditions, at the same time it indicates the difference between the variety studied and the tester. In the combination vrdlvrd1vrd2vrd2/MIP Assol on the date of the last accounting 20 plants remained at tubing stage, and a significant number (123 plants) remained at the tillering stage The obtained results of plant accounting in this combination indicate the significant influence of weather conditions on plant development, because at 40 days of vernalization many of the plants reached heading, and the average time 
to heading was 80 days. Taking this into account, we can assume that the plants of this hybrid combination could reach heading after 93-94 days with corresponding theoretical segregation ratio of 1:3.

Theoretical segregation at 40 days of vernalization in the combinations with testers Vrd1Vrd1vrd2vrd2 and vrd1vrd1Vrd2Vrd2 in the ratio "heading occurrence: no heading occurrence" 13:3 in the varieties Hratsiia myronivska, MIP Assol and Balada myronivska is probably caused by different photoperiod sensitivity. The influence of weather conditions on the segregation pattern in hybrid populations has also been noted in earlier publications (Fayt, 2006b). Comparing the results of hybridological analysis obtained (Table 5) with the theoretically expected segregation ratio, we assume that in the varieties Estafeta myronivska, Hratsiia myronivska, MIP Assol and Balada myronivska the vernalization requirement duration is controlled by a gene (genes) other than Vrd1 and Vrd2.

Despite climate change, development of winter wheat varieties with increased frost tolerance is still one of the main tasks of scientific institutions not only in Ukraine but also abroad (Riabchun, 2012; Lytvynenko, 2016; Bulavka et al., 2018; Cherenkov et al., 2018; Grabovets, 2019). It is established that the level of frost tolerance in winter wheat varieties bred by institutions in the Forest-Steppe of Ukraine varies from $74.5 \%$ to 90.8\% (Golyk et al., 2017). In our research we have found that newly developed winter wheat varieties at MIW with increased productive and adaptive potential in the Forest-Steppe of Ukraine are characterized by medium photoperiod sensitivity as well as medium and short vernalization requirement duration. Moreover, frost tolerance of these varieties is at the level and above the variety Myronivska 808 , which is highly tolerant to low temperatures.

\section{Conclusion}

It was determined that winter wheat varieties Estafeta myronivska, Hratsiia myronivska, MIP Assol and Balada myronivska developed at MIW in recent years with increased productive and adaptive potential in the conditions of the Central part of the Ukrainian Forest-Steppe are characterized with medium photoperiod sensitivity, and medium or short vernalization requirement duration. We didn't establish the presence of Vrd1 and Vrd2 genes in these varieties. At the same time, the genetically determined frost tolerance of the varieties studied is at the level and above the variety Myronivska 808 , which is highly tolerant to low temperatures. Our results indicate the possibility to recombine in the genotype different levels of manifestation of these traits by selection and to develop varieties with their optimal combination for certain ecological conditions. This is of great practical importance in farming, as the increase in the share of sown areas of crops harvested late (corn, sunflower, etc.) in the Central part of the Forest-Steppe of Ukraine in recent years has caused a shift in winter wheat sowing dates to later. Under such conditions, the varieties mentioned above can undergo sufficient hardening, meet their vernalization requirement and form a high level of winter hardiness. The relatively medium level of photoperiod sensitivity allows the vegetation to be restored a little earlier in spring and winter reserves of moisture to be used more effectively.

\section{References}

Bakuma, A. O., Bulavka, N. V., \& Chebotar, S. V. (2016). Genotypy novykh Myronivskykh sortiv ozymoji pshenytsi za genamy Ppd-A1, Ppd-D1 ta jikh fotoperiodychna chutlyvist [The genotypes of modern Myronivsky varieties of winter wheat for Ppd-A1, Ppd-D1 genes and their sensitivity to photoperiod]. Odessa National University Herald, Biology, 21(1), 75-88 (in Ukrainian).

Bakuma, A. O., Chebotar, G. O., Lavrynenko, Y. O., \& Chebotar, S. V. (2019). Alelnyi stan geniv system Ppd-1 ta Vm-1 u sortiv ozymoi viakoi pshenytci Instytutu zroshuvanogo zemlerobstva NAAN Ukrainy [Allelic status of the gene Ppd-1 and $\mathrm{Vm}-1$ genetic systems in winter wheat varieties of the Institute of Irrigated Agriculture of NAAS Ukraine]. Odessa National University Herald, Biology, 24(1), 49-64 (in Ukrainian).

Bakuma, A. O., Popovych, Y. A., Motsnyy, I. I., Chebotar, G. O., \& Chebotar, S. V. (2018). Vplyv alelya Ppd-Dla na tempy rozvytku ta agronomichni oznaky pshenytci, vuznachenyy iz zastosuvannyam liniy-analogiv [Effects of the Ppd-D1a allele on growth rates and agronomical traits in wheat detected by the application of analogous lines]. Cytology and Genetics, 52(5), $28-40$ (in Ukrainian).
Balashova, I. A., Fayt, V. I., Zavesha, E. K., \& Sivolap, Y. M. (2006). Markirovanie gena Vrd1 u pshenitsi miagkoy ozimoy [Marking of the Vrd1 gene in the bread winter wheat]. Cytology and Genetics, 40(6), 11-14 (in Russian).

Blyzniuk, B. V., Los, R. M., Demydov, O. A., Kyrylenko, V. V., Humeniuk, O. V., \& Daniuk, T. A. (2019). Vplyv pohodnikh umov na tryvalist okremykh periodiv vegetatsii ta vrozhainist pshenytsi miakoi ozymoi u Lisostepu i Polissi [The influence of weather conditions on duration of particular vegetation periods and yield of bread winter wheat in Forest-Steppe and Polissia]. Myronivka Bulletin, 8, 73-90 (in Ukrainian).

Bulavka, N. V., Yurchenko, T. V., Kucherenko, O. M., \& Pirych, A. V. (2018). Sorty pshenytsi miakoyi ozymoyi, stiyki do vplyvu negatyvnykh chunnykiv dovkillia [Soft winter wheat varieties with resistance to negative environmental factors]. Plant Varieties Studying and Protection, 14(3), 255-261 (in Ukrainian).

Cherenkov, A. V., Gruzinov, S. K., \& Kobos, I. O. (2018). Vplyv peredposivnoi obrobky nasinnia na morozo- ta zymostiikist pshenycja ozymoi pislia riznykh poperednykiv [Influence of pre-seed treatment of seeds on frost and winter resistance of winter wheat after various predecessors]. Grain Crops, 2(1), 53-60 (in Ukrainian).

Cockram, J., Norris, C., \& O’Sullivan, D. M. (2009). PCR-based markers diagnostic for spring and winter seasonal growth habit in barley. Crop Science, 49(2), 403-410.

Deng, W., Casao, M. C., Wang, P., Sato, K., Hayes, P. M., Finnegan, E. J., \& Trevaskis, B. (2015). Direct links between the vernalization response and other key traits of cereal crops. Nature Communication, 6, 5882.

Distelfeld, A., Li, C., \& Dubcovsky, J. (2009). Regulation of flowering in temperate cereals. Current Opinion in Plant Biology, 12, 1-7.

Emtseva, M. V., Efremova, T. T., \& Arbuzova, V. S. (2013). Vliianie allelei VmBla i Vm-B1c na prodolzhitelnost faz razvitiia zamechonnykh i izohennykh linii miahkoy pshenitsy [The influence of Vrn-B1a and Vm-B1c alleles on the length of developmental phases of substitution and near-isogenic lines of common wheat]. Russian Journal of Genetics, 49(5), 545-552 (in Russian).

Erath, W., Bauer, E., Fowler, D. B., Gordillo, A., Korzun, V., Ponomareva, M., Schmidt, M., Schmiedchen, B., Wilde, P., \& Schen, C. (2017). Exploring new alleles for frost tolerance in winter rye. Theoretical and Applied Genetics, 130, 2151-2164.

Fayt, V. I. (2003). Geneticheskaia sistema kontrolia razlichii po prodolzhitelnosti iarovizatsii u ozimoy miahkoyi pshenitsi [Genetic control system of the differences in duration of vemalization in winter common wheat]. Cytology and Genetics, 37(5), 57-64 (in Russian).

Fayt, V. I. (2006a). Izogennye linii ozimoy miahkoy pshenicy po genam kontrolia prodolzhitelnosti jarovizatsii [Near-isogenic lines on the genes controlling differences in duration of vemalization in winter common wheat]. The Herald of Vavilov Society for Geneticists and Breeding Scientists, 10(3), 580-586 (in Russian).

Fayt, V. I. (2006b). Geneticheskii control prodolzhitelnosti yiarovizatsii sortov ozimoy pshenitsy [Genetic control of vernalization requirement duration of winter wheat cultivars]. Ecological Genetics, 4(2), 29-36 (in Russian).

Fayt, V. I. (2007). Efecty kontrolia prodolzhitelnosti iarovizatsii (Vrd) po agronomicheskim priznakam u ozimoy miagkoy pshenitsy [Effects of vernalization duration control genes (Vrd) on agronomical traits in winter bread wheat]. Cytology and Genetics, 41(5), 18-26 (in Russian).

Fayt, V. I. (2012). Identyficatsiia genofondu ozymoy miakoy pshenitsy (Triticum aestivum $\mathrm{L}$.) za genamy tryvalosti potreby v iarovyzatsii (Vrd) [Identification of winter bread wheat (Triticum aestivum $\mathrm{L}$.) gene pool for the genes of vernalization requirement duration (Vrd)]. Plant Genetic Resources, 10/11, 212-219 (in Russian).

Fayt, V. I., Balashova, I. A., Fedorova, V. R., \& Balvinska, M. S. (2014). Identificatciya genotipov Ppdl sortov psenitsi metodami geneticheskoho i STS-PCR analiza [Identification of bread wheat Ppdl-genotypes by hybridological and STS-PCR analysis]. Plant Physiology and Genetics, 46(4), 325-336 (in Russian).

Fayt, V. I., Symonenko, L. K., Mokanu, N. V., \& Popova, N. V. (2007). Hromosomnaya lokalizatsiya genov prodolzhitelnosti perioda yarovizatsiyi (Vrd) u ozimoy miahkoy pshenitsy [Chromosomal location of genes for vernalization requirement duration (Vrd) in winter bread wheat]. Russian Journal of Genetics, 43(2), 143-148 (in Russian).

Fayt, V., Pogrebniuk, O., \& Stelmakh, A. (2017). Identifikatsija ta efekty aleliv gena Vrd2 za hospodarsko cinnymy oznakamy pshenicy v umovakh Pivdennogo stepu Ukrainy [Identification and effects of alleles of gene Vrd2 according to economically valuable attributes of wheat in conditions of South Steppe of Ukraine]. Bulletin of Agricultural Science, 95(6), 41-47 (in Ukrainian).

Filimonov, V. M., Bakuma, A. A., Chebotar, G. A., Burdenyuk-Tarasevich, L. A., \& Chebotar, S. V. (2018). PLR-analiz geniv fotoperiodychnoi chutlyvosti u sortiv mjakoyi ozymoyi pshenyci selektciyi Bilotserkivskoyi doslidno-selektciynoyi stanciyi [PCR-analysis of photoperiod sensitivity genes in bread wheat varieties from Bilatserkovska Experimental Breeding Station]. The Bulletin of Ukrainian Society of Geneticists and Breeders, 16(2), 217-226 (in Ukrainian).

Francia, E., Barabaschi, D., Tondelli, A., Laido, G., Rizza, F., Stanca, A. M., Busconi, M., Fogher, C., Stockinger, E. J., \& Pecchioni, N. (2007). Fine mapping of a 
HvCBF gene cluster at the frost resistance locus Fr-H2 in barley. Theoretical and Applied Genetics, 115, 1083-1091.

Golyk, L., Starychenko, V., Kobernyk, N., Guba, I., \& Klymenko, I. (2017). Features of winter resistance of collections samples of winter wheat in the conditions of the Northern Forest-Steppe. Plant and Soil Science, 269, 126-136.

Grabovets, A. I., \& Fomenko, M. A. (2019). Plus-transgression in winter wheat breeding on frost resistance and productivity. Russian Agricultural Sciences, 45, $407-411$.

Guedira, M., Malony, P., Xiong, M., Petersen, S., Murphy, J. P., Marshall, D., Johnson, J., Harrison, S., \& Brown-Guedira, G. (2014). Vernalization duration requirement in soft winter wheat is associated with variation at the VRN-B1 locus. Crop Science, 54(5), 1960-1971.

Jones, H. E., Lukac, M., Brak, B., Martinez-Eixarch, M., Alhomedhi, A., Cooding, M. J., Wingen, L. U., \& Griffiths, S. (2017). Photoperiod sensitivity affects flowering duration in wheat. The Journal of Agricultural Science, 155, 32-43.

Kawakita, S., Ishikawa, N., Takahashi, H., Okuno, R., \& Takahashi, T. (2020). Winter wheat phenological development model with a vernalization function using sigmoidal and exponential functions. Journal of Agricultural Meteorology, 76(2), 81-88.

Kiss, T., Balla, K., Veisz, O., Lang, L., Bedo, Z., Griffiths, S., Isaac, P., \& Karsai, I. (2014). Allele frequencies in the VRN-A1, VRN-B1 and VRN-D1 vernalization response and PPD-B1 and PPD-D1 photoperiod sensitivity genes, and their affects on heading a diverse set of wheat cultivars (Triticum aestivum L.). Molecular Breeding, 34, 297-310.

Koemel, J., Guenzi, A., Anderson, J., \& Smith, E. (2004). Cold hardiness of wheat near-isogenic lines differing in vernalization alleles. Theoretical and Applied Genetics, 109(4), 839-846.

Kristensen, K., Schelde, K., \& Olesen, J. E. (2011). Winter wheat yield response to climate variability in Denmark. The Journal of Agricultural Science, 149, $33-47$.

Law, C. N., Sutka, J., \& Worland, A. J. A genetic study of day - length response in wheat (1978). Heredity, 41(2), 185-191.

Li G., Yu, M., Fang T., Cao, S., Carver, B. F. \& Yan, L. (2013). Vernalization requirement duration in winter wheat is controlled by $\mathrm{TaVm}-\mathrm{A} 1$ at the protein level. The Plant Journal, 76(3), 742-753.

Lytvynenko, M. A. (2016). 100 rokiv rozvytku selektsiynykh prohram psenytsi ozymoi [100-years history of the development of bread winter wheat breeding programs]. Plant Varieties Studying and Protection, 2(31), 75-82 (in Ukrainian).

McIntosh, R. A., Yamazaki, Y., Dubcovsky, J., Rogers, J., Morris, C., Appels, R., \& Xia, XC. (2013). Catalogue of gene symbols for wheat. 12th International Wheat Genetics Symposium. Paestum(Italy), 31

Muterko, A. F., Balashova, I. A., Fayt, V. I., \& Sivolap, Yu. M. (2015). Molekulyarno-genetychni mekhanismy regulyatsii typu rozvytku pshenytsi [Moleculargenetc mechanisms regulation of growth habit in wheat]. Cytology and Genetics, 49(1). 71-86 (in Ukrainian).

Pankova, K., \& Kosner, J., (2004). Chromosome substitutions with dominant loci Vm-1 and their effect on developmental stages of wheat. Czech Journal of Genetics and Plant Breeding, 40(2), 37-44.

Prasil, I. T., Prasilova, P., \& Pankova, K. (2004). Relationships among vernalization, shoot apex development and frost tolerance in wheat. Annals of Botany, 94(3), 413-418.

Pugsley, A. T. (1971). A genetic analysis of the spring-winter habit of growth in wheat. Australian Journal of Agricultural Research, 22(1), 21-23.

Pugsley, A. T. (1972). Additional genes inhibiting winter habit in wheat. Euphytica, 21, 547-552.

Royo, C., Dreisigacker, S., Soriano, J. M., Lopes, M., Ammar, K., \& Villegas, D. (2020). Allelic variation at the vernalization response (Vm-1) and photoperiod sensitivity (Ppd-1) genes and their association with the development of durum wheat landraces and modern cultivars. Frontiers in Plant Science, 11, 838.

Ryabchun, N. I. (2012). Formuvannja oznakovykh kolektsiy ta kolektsiy sortiv-etaloniv za oznakoyu zymostiykosti u ozymykh zlakiv [Forming trait collections and collections of varieties-standards on the basis of winter hardiness in winter cereals]. Plant Breeding and Seed Production, 101, 247-253.

Rybas, I. A., Marchenko, D. M., Nekrasov, E. I., Ivanisov, M. M., Grichanikova, T. A., \& Romanyukina, I. V. (2018). Otsenka parametrov adaptivnosti sortov ozimoy miagkhoy pshenitsy [Assesment of parameters of winter soft wheat adaptability]. Grain Economy of Russia, 4, 51-54 (in Russian).

Sandve, S., Kosmola, A., Rudi, H., Fjellheim, S., Rapacz, M., Yamada, T., \& Rognli, O. (2011). Molecular mechanisms underlying frost tolerance in perennial grasses adapted to cold climates. Plant Science, 180(1), 69-77.

Stelmakh, A. F. (1992). Genetic effects of Vrn genes on heading date and agronomic traits in bread wheat. Euphytica, 65, 53-60.

Stelmakh, A. F., \& Fait, V. I. (2015). Systemy kontroliu pochatkovoho rozvytku suchasnykh selektsiinykh zrazkiv ozymykh zemovykh kultur u SGI-NCNS [Systems of initial development control in modern cereal breeding speciment PBGI-NCSCI]. Factors in Experimental Evolution of Organisms, 16, 156-160 (in Ukrainian).

Stelmakh, A. F., \& Fait, V. I. (2019). Osoblyvosti tempiv pochatkovoho rozvytku novukh evropeiskykh sortiv ozymoyi pshenytsi miakoyi u zviazku z systemamy geniv Ppd-1 ta Vrd [Related to Ppd-1 and Vrd gene systems peculiarities of initial development rate in new European winter bread wheat cultivars]. Factors in Experimental Evolution of Organisms, 24, 166-171 (in Ukrainian).

Stelmakh, A. F., \& Herasymenko, V. P. (2008). Dialelnyi analiz daty kolosinnja ozymoyi mjakoyi pshenyci pry varijuvanni jarovyzaciyi ta fotoperiodu [Diallel analisys of date heading of bread winter wheat at the variations vernalization and photoperiod]. Plant Breeding and Seed Production. 96, 244-251 (in Ukrainian).

Stelmakh, A., Zolotova, N., \& Fayt, V. (2005). Genetic analysis of differences in duration vernalization requirement of winter bread wheat. Cereal Research Communications, 33(4), 713-718.

Sutka, J. (2001). Genes for frost resistance in wheat. Euphytica, 119, 169-177.

Sutton, F., Chen, D.-G., Ge, X., \& Kenefick, D. (2009). Cbf genes of the Fr-A2 allele are differentially regulated beetwen long-term cold acclimated crown tissue of freeze-resistant and -susceptible, winter wheat mutant lines. BMC Plant Biology, $9,34$.

Syvolap, Y. M., Balashova, I. A., \& Fayt, V. I. (2007). Identyficatsiia genotypiv ozumoyi miakoyi psenytsi z korotkym terminom yarovuzatsiynoyi potreby [Identification genotypes of bread winter wheat with shot period of vernalization requirement duration]. Odesa (in Ukrainian).

Toptikov, V. A., \& Chebotar, S. V. (2019). Genetyko-biokhimichni aspekty zvjazku alelnoho skladu lokusu Ppd-D1 i stiykosti ozymoi pshenyci do nyzkoi temperatury [Genetic and biochemical aspects of the association of the Ppd-D1 locus with the resistance of winter soft wheat to low temperature]. Odesa National University Herald, Biology, 24(2), 11-37 (in Ukrainian).

Whittal, A., Kaviani, M., Graf, R., Humphrey, G., \& Navabi, A. (2018). Allelic variation of vernalization and photoperiod response genes in a diverse set of North American high latitude winter wheat genotypes. PLoS One, 13(8), e0203068.

Worland, A. J. (1996). The influence of flowering time genes on environmental adaptability in European wheats. Euphytica, 89, 49-57.

Worland, A. J., Borner, A., Korzun, V., Li, W. M., Petrovic, S., \& Sayers, E. J. (1998). The influence of photoperiod genes on the adaptability of European winter wheats. Euphytica, 100, 385-394.

Yan, L., Fu, D., Li, C., Blechl, A., Tranquilli, G., Bonafedl, M., Sanchez, A., Valarik, M., Yasuda, S., \& Dubcovsky, J. (2006). The wheat and barley vernalization gene Vrn-3 is an orthologue of FT. Proceedings of the National Academy of Sciences of the United States of America, 103(51), 19581-19586.

Yang, F. P., Zhang, X. K., Xia, X. C., Laurie, D. A., Yang, W. X., \& He, Z. H. (2009). Distribution of the photoperiod insensitive Ppd-D1a allele in Chinese wheat cultivars. Euphytica, 165(3), 445-452.

Yoshida, T., Nishida, H., Akashi, Y., Kato, K., Zhu, J., Nitcher, R., Distelfeld, A., \& Dubcovsky, J. (2010). Vm-D4 is a vernalization gene located on the centromeric region of chromosome 5D in hexaploid wheat. Theoretical and Applied Genetics, $120(3), 543-552$.

Zubrich, O. I., \& Avksentieva, O. O. (2019). Vplyv fotoperiodu na morphogenetychni procesy u izogennykh za genamy PPD liniyi pshenytsi mjakoyi [Influence of photoperiod on morphogenetic processes in near-isogenic lines in Ppd genes of soft wheat]. Factors in Experimental Evolution of Organisms, 24, 302-307 (in Ukrainian). 


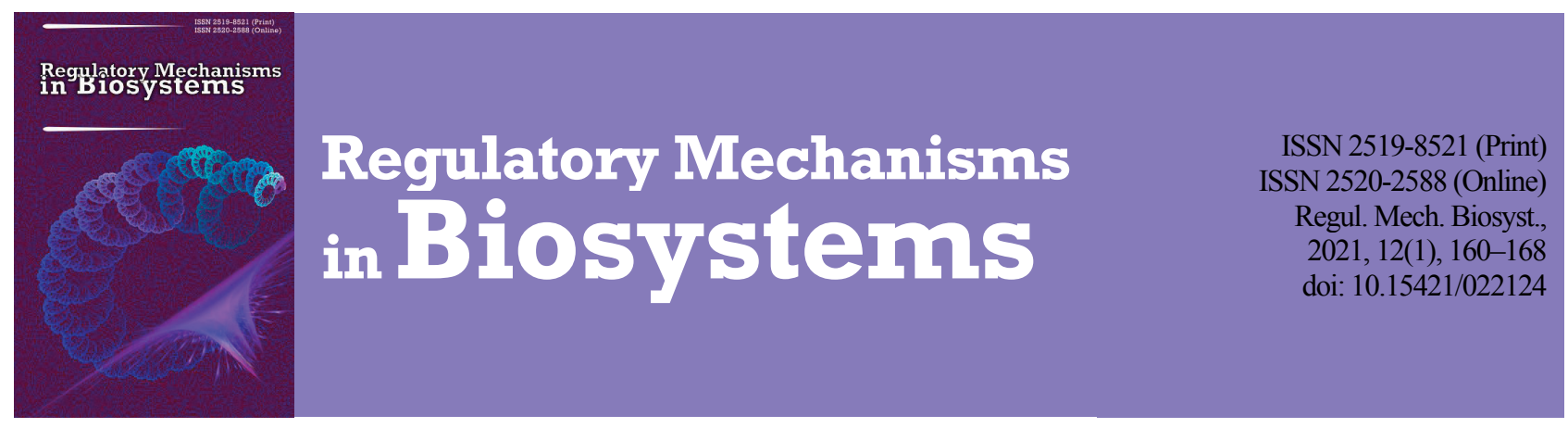

\title{
Staphylococcus aureus and $S$. epidermidis in biological systems of hospital environment: Antibiotic resistance patterns in regions of Ukraine
}

\author{
A. V. Berezhna*, V. O. Tertyshnyi**, V. I. Makarova*, T. O. Chumachenko* \\ *Kharkiv National Medical University, Kharkiv, Ukraine \\ **SI Poltava Oblast Laboratory Center of the MoH of Ukraine, Poltava, Ukraine
}

Article info

Received 19.02.2021

Received in revised form 10.03.2021

Accepted 11.03.2021

Kharkiv National

Medical University

Nauky av., 4,

Kharkiv, 61022, Ukraine

$\mathrm{Tel} \cdot+38-067-358-12-08$

E-mail:

a.v.berezhna@gmail.com

SI Poltava Oblast Laborato ry Center of the $\mathrm{MoH}$ of Ukraine, Vatutina st.

35-a, Poltava,

36039, Ukraine.

Tel.: +38-066-882-31-79

E-mail:

vladissimo11@gmail.com

Berezhna, A. V., Tertyshnyi, V. O., Makarova, V. I., \& Chumachenko, T. O. (2021). Staphylococcus aureus and S. epidermidis in biological systems of hospital environment: Antibiotic resistance patterns in regions of Ukraine. Regulatory Mechanisms in Biosystems, 12(1), 160-168. doi:10.15421/022124

Staphylococcus bacteria are ubiquitous and often circulate in the biological systems of the hospital environment. Staphylococci have developed antibiotic resistance mechanisms resulting in a significant medical and economic burden to the healthcare system. The goal of our research was to conduct a comparative analysis of resistance to antibiotics in $S$. aureus and $S$. epidermidis isolates found in surgical hospitals in Kharkiv and Poltava regions. In 2013 through 2019, 151,015 and 98,754 tests were made by discdiffusion method to identify the sensitivity in the S. aureus strains to antibiotics in Kharkiv and Poltava regions respectively. In 20132015, 15,589 tests were made in Kharkiv region to identify antibiotics sensitivity in S. epidermidis strains. Comparison of antibiotic resistance of the $S$. aureus strains in Kharkiv and Poltava regions was performed using the Pearson Chi-square test $\left(\chi^{2}\right)$ and Fisher's exact test. The proportion of S. aureus strains resistant to penicillins, cephalosporins, carbapenems, aminoglycosides, and macrolides was higher in Kharkiv region in terms of statistical validity than in Poltava region. Overall, the proportion of S. aureus strains resistant to lincozamids, tetracycline antibiotics, and fluoroquinolones in Poltava region was higher in terms of statistical validity than in Kharkiv region. An analysis of resistance of $S$. aureus strains to linezolid demonstrated that in Poltava region the proportion of resistant microorganisms was higher in terms of statistical validity in 2013-2014 and in 2016-2018. In Kharkiv region, in 2013 and in 2014, $96.3 \%$ and $89.1 \%$ of isolated strains of $S$. aureus respectively, were resistant to vancomycin. In 2019 , more than a quarter of the located isolates (26.6\%) in Poltava region were resistant to this antibiotic. The analysis of the dynamic of resistance in S. epidermidis isolates demonstrated that in 2015 nearly half of the isolates located in Kharkiv region were insensitive to penicillin antibiotics. Between 2013 and 2015, the spread of resistance to cephalosporins, aminoglycosides, macrolides, and fluoroquinolones among the S. epidermidis isolates noticeably increased. When S. epidermidis resistance to vancomycin was analyzed, a decrease in the proportion of resistant strains from $88.0 \%$ in 2013 to $8.7 \%$ in 2015 was noted. A promising direction for further research is the creation of passports of microorganism resistance in the regions and various health-care settings, as well as the creation of a unified national database network on microorganism resistance using modern methodologies for determining the phenotypes and genotypes of microorganisms.

Keywords: healthcare-associated infections; catheter-related bloodstream infections; biofilms; infection control; bacteremia; genomic variability.

\section{Introduction}

Bacteria of the Staphylococcus genus, especially S. aureus are among most frequently encountered infectious agents associated with rendering medical aid (Canadian Nosocomial Infection Surveillance Program, 2020; Voidazan et al., 2020). This is partially due to the fact that staphylococci colonize the mucous membranes and skin of humans. The nose is considered the most frequent localization of $S$. aureus (Wertheim et al., 2005; Brown et al., 2014). Extranasal localizations of S. aureus include the skin, crotch area, armpits, and the gastrointestinal tract. It should be noted that a nasal $S$. aureus carrier is prone to be a source of extranasal transmission. For instance, $90 \%$ of $S$. aureus nasal carriers usually have the skin on their hands contaminated as well (Wertheim et al., 2005). Another potentially dangerous hospital infection pathogen is $S$. epidermidis. Microorganisms of this genus are referred to resident microflora of the human external surface and are usually normal representatives of the microbiocenosis of every healthy person's skin, which is also a significant link in the pathogenesis of infections associated with rendering of medical aid (Hellmark et al., 2013). Previously published researches point to the existing problem of incidence of methicillin-resistant genotypes of S. aureus and S. epidermidis in healthcare workers at hospitals (Du et al., 2013; Widerström et al., 2016; Sharma et al., 2019). In cases of violation of aseptic and antiseptic rules and improper observance of hand hygiene, microorganisms that are on medical personnel's skin are transmitted to patients, medical devices, equipment, and other objects of the medical environment. When invasive manipulations like catheterization of vessels are conducted, microorganisms may pass from medical personnel's hands to the surface of a vessel catheter and be the cause of development of catheter-related bloodstream infections (Cherifi et al., 2014)

It is general knowledge that patients in hospitals have at least one peripheral intravenous catheter installed in $30 \%$ to $80 \%$ of cases (Zhang et al., 2016; Aghdassi et al., 2019). The patients, who need a transfusion of massive amounts of liquid, total parenteral feeding, hemodialysis, or for other reasons, have central venous catheters installed (Smith \& Nolan, 2013). Considering the broad application of vessel appliances (including peripheral intravenous catheters) in medical practice, infectious complications associated with vessels' catheterization account for a large share of infections associated with health care provision. The incidence of blood- 
stream infections connected with application of peripheral intravenous catheters varies from $0.0 \%$ to $2.2 \%$, amounting on average to $0.18 \%$, with the incidence of nosocomial catheter-related bloodstream infections due to peripheral venous catheters reaching $6.2 \%$ to $60.0 \%$ (Mermel, 2017). In the etiological structure of infection complications associated with peripheral and central veins catheterization, the $S$. aureus strains and coagulazonegative staphylococci, including S. epidermidis, prevail (Zhang et al., 2016; Guembe et al., 2017; Nguyen et al., 2017; Mandolfo et al., 2019; Tatsuno et al., 2019).

Due to the ability of staphylococci to produce biofilms, the infections caused by them are more difficult to treat and may develop into chronic forms. The biofilm forms of bacteria possess a considerably higher resistance to antibiotics than the plankton forms (Wu et al., 2003; Costerton et al., 2005; Kaplan, 2011). S. aureus strains producing biofilms possess a higher resistance level to most medications, which is prognostically an unfavourable factor in such patients' treatment (Manandhar et al., 2018).

Under conditions of growth in microorganism resistance to medications, of grave concern are bacteremia cases caused by antibiotic-resistant strains of $S$. aureus and S. epidermidis. It is established that bacteremia caused by methicillin-resistant strains of $S$. aureus is more often associated with health care provision, in particular with application of central venous catheters. In such cases, apart from considerable economic losses, the life prognosis for patients is unfavourable. The mortality in a 28-day-period from methicillin-resistant $S$. aureus bacteria is 1.6 times higher than from bacteremia caused by $S$. aureus strains producing penicillinase (Jokinen et al., 2017).

Identifying microorganism resistance and determining the mechanisms influencing their resistance to antibiotics and their ability to produce biofilm forms, as well as an increase in their virulence and pathogenicity should be one of priority directions in the healthcare system of any state. Due to staphylococci's (especially $S$. aureus) possessing a high degree of adaptability and genomic variability (Deurenberg et al., 2007; Deurenberg \& Stobberingh, 2008; Lindsay, 2010; Conlan et al., 2012), it is necessary to maintain a permanent monitoring of their resistance.

In 2018, the results of a wide-scale multicentered epidemiology research project on determining antibiotic-resistance (Survey of Antibiotic Resistance, SOAR) concerning Ukraine and Slovakia were published. On the example of non-hospital respiratory infections agents Streptococcus pneumoniae and Haemophilus influenzae, territorial differences in the resistance level of the located isolates in the two neighbouring countries were found (Torumkuney et al., 2018). Overall, other studies on microorganism resistance to antibiotics, currently conducted in Ukraine, are narrowly specialized and do not encompass the problem in general.

It should be noted that there are differences in antibacterial resistance in organisms circulating in different departments of the same healthcare setting. For instance, the strains found in intensive care patients are often more resistant and may possess multiple resistance to antibiotics (Kollef \& Fraser, 2001; Brusselaers et al., 2011). It was also noted that in the countries with lower income levels, the burden of antibiotic resistance in intensive care units is much heavier than in the countries with high incomes (Saharman et al., 2021). Everything mentioned above points to the expediency of estimating territorial differences in staphylococci antibacterial resistance in the regions of Ukraine. Therefore, the goal of this study is to perform a comparative analysis of antibiotic resistance in $S$. aureus and S. epidermidis isolates identified in surgical hospitals of two neighbouring areas: the Kharkiv and the Poltava regions.

\section{Materials and methods}

The study included clinical specimens collected from surgical patients by bacteriological laboratories in health-care settings of Kharkiv and Poltava regions in 2013-2019. S. aureus and S. epidermidis strains were isolated and identified according to standard methods. Antibacterial resistance in staphylococci was determined using the disc-diffusion method on Mueller-Hinton agar according to Clinical and Laboratory Standards Institute Guidelines (Bauer et al., 1966; Clinical Laboratory Standards Institute, 2014). In total, 151,015 and 98,754 tests to determine antibacterial resistance of $S$. aureus in Kharkiv and Poltava regions respectively were carried out in 2013-2019 and 15,589 tests to determine antibiotic resis- tance in S. epidermidis strains in Kharkiv region were carried out in 20132015 (Table 1).

\section{Table 1}

Number of tests carried out for detecting resistance to various antibiotics in staphylococci isolates in health-care settings at bacteriological laboratories in Kharkiv and Poltava regions in 2013-2019

\begin{tabular}{|c|c|c|c|}
\hline \multirow{2}{*}{$\begin{array}{l}\text { Antibiotics group } \\
\text { or antibiotic }\end{array}$} & \multicolumn{2}{|c|}{$\begin{array}{c}\text { S. aureus } \\
(2013-2019)\end{array}$} & \multirow{2}{*}{$\begin{array}{c}\begin{array}{c}\text { S. epidermidis } \\
(2013-2015)\end{array} \\
\begin{array}{c}\text { Kharkiv } \\
\text { region }\end{array}\end{array}$} \\
\hline & $\begin{array}{c}\text { Kharkiv } \\
\text { region }\end{array}$ & $\begin{array}{c}\text { Poltava } \\
\text { region }\end{array}$ & \\
\hline Penicilins & 28,904 & 15,676 & 3,579 \\
\hline Cephalosporins & 17,359 & 5,340 & 2,818 \\
\hline Carbapenems & 3,202 & 3,038 & 396 \\
\hline Aztreonam & 0 & 0 & 11 \\
\hline Aminoglycosides & 21,144 & 10,762 & 1,782 \\
\hline Macrolides & 7,642 & 10,092 & 590 \\
\hline Lincozamides & 10,156 & 8,792 & 772 \\
\hline Tetracyclines & 3,534 & 9,934 & 596 \\
\hline Vancomycin & 7,870 & 7,120 & 939 \\
\hline Rifampicin & 5,606 & 908 & 237 \\
\hline Fluoroquinolones & 33,619 & 15,771 & 3,297 \\
\hline Linezolid & 11,210 & 8,097 & 544 \\
\hline Co-trimaxazol & 14 & 1,025 & 0 \\
\hline Chloramphenicol & 755 & 1,355 & 28 \\
\hline Phosphomicin & 0 & 293 & 0 \\
\hline Fusidic acid & 0 & 220 & 0 \\
\hline Nitrofuran derivatives & 0 & 331 & 0 \\
\hline Total & 151,015 & 98,754 & 15,589 \\
\hline
\end{tabular}

For assessment of the resistance of $S$. aureus strains, the tested antibiotics included penicillins (penicillin, benzylpenicillin, ampicillin, amoxicillin, oxacillin, carbenicillin, ampicillin/sulbactam, amoxicillin/clavulanat), cephalosporins (cefazolin, cefalotin, cephalexin, cefuroxime, cefoperazon, cefotaxime, ceftriaxone, ceftazidime, cefixime, cefepim, cefpirom, cefoperazon/sulbactam), carbapenems (imipenem, meropenem, imipenem/cilastatin), aminoglycosides (kanamycin, gentamycin, tobramycin, netilmycin, amikacin), macrolides (erythromycin, clarithromycin, azithromycin, spiramycin), lincozamides (clindamycin, lincomycin), tetracyclines (tetracycline, doxycycline, tigecycline), glycopeptides (vancomycin), an antituberculosis medicine rifampicin, fluoroquinolones (ciprofloxacin, ofloxacin, cefloxacin, norfloxacin, lomefloxacin, levofloxacin, moxifloxacin, gatifloxacin), oxazolidions (linezolid), sulphanilamides (co-trimoxazol), amphenicols (chloramphenicol) and others (phosphosycin, fusidic acid, nitrofuran derivatives).

Depending on the year and the region, the study to estimate resistance in the S. aureus strains had its peculiarities. In particular, in 2013, 2014 , 2018, 2019, no tests were made in Poltava region to estimate resistance to cephalosporin group antibiotics and carbapenems in $S$. aureus isolates. In 2013, 2014, 2018, 2019, resistance in S. aureus isolates was studied in relation to only one antibiotic of the aminoglycoside group, gentamicin, and to only one antibiotic of the macrolide group, erythromycin in Poltava region. In 2013 and 2014, the resistance in S. aureus isolates was studied in relation to only one antibiotic of the tetracycline group, tetracycline in Kharkiv region. Resistance in $S$. aureus isolates to co-trimoxazol in Kharkiv region was assessed only in 2015 and 2018. Resistance of S. aureus isolates to chloramphenicol in Kharkiv region was not assessed in 2013 and 2014. Resistance of $S$. aureus isolates to phosphomycin, fusidic acid, and nitrofuran derivatives was estimated only in Poltava region (in 2014, 2015, and 2017 - to phosphomycin; in 2016-2018 - to fusidic acid; in 2015, 2016, and 2018 - to nitrofuran derivatives).

To increase data validity, we calculated the average proportion of S. aureus isolates resistant to antibiotics groups (penicillins, cephalosporins, etc.) rather than to individual medications (with the exception of vancomycin, rifampicin, co-trimoxazol, chloramphenicol, phosphomycin, fusidic acid as the sole representatives of their antibiotic groups).

For estimation of resistance of $S$. epidermidis strains, the tested antibiotics included penicillins (penicillin, ampicillin, amoxicillin, oxacillin, carbenicillin, ampicillin/sulbactam, amoxicillin/clavulanat), cephalosporins (cefazolin, cefalotin, cephalexin, cephaklor, cefuroxime, cefoperazon, cefotaxime, ceftriaxone, ceftazidime, cefixime, ceftibuten, cefepim), carbapenems (imipenem, meropenem), monobacts (aztreonam), aminogly- 
cosides (gentamycin, tobramycin, amikacin), macrolides (erythromycin, clarithromycin, azithromycin), lincozamides (clindamycin, lincomycin), tetracyclines (tetracycline, doxycycline), glycopeptides (vancomycin), an antituberculosis medicine rifampicin, fluoroquinolones (ciprofloxacin, ofloxacin, pefloxacin, norfloxacin, lomefloxacin, levofloxacin), oxazolidions (linezolid), sulphanilamides (co-trimoxazol), amphenicols (chloramphenicol). In some years, the resistance of $S$. epidermidis isolates was tested only for one antibiotic within a certain class: in 2013 - for imipenem, aztreonam, tetracycline; in 2014 - for erythromycin, tetracycline; in 2015 - for amikacin, clindamycin and doxycycline.

By analogy with $S$. aureus, to increase data validity, we calculated the mean proportion of $S$. epidermidis isolates resistant to antibiotics of the following groups: penicillins, cephalosporins, carbapenems, aminoglycosides, macrolides, lyncozamides, and fluoroquinolones.

We performed statistical analysis using the Epi Info ${ }^{\mathrm{TM}}$ for Windows (Version 7.2). For estimation of the standard deviation of proportions we calculated the standard error (SE). Comparison of S. aureus strains' antibiotic resistance in Kharkiv and Poltava regions was performed using the Pearson Chi-square test $\left(\chi^{2}\right)$ and Fisher's exact test. The level of significance was set at $5 \%(\mathrm{P}<0.05)$.

\section{Results}

In Kharkiv region, the largest proportion of $S$. aureus strains resistant to the penicillin group drugs was identified in 2013 (62.7\%), and the smallest proportion - in 2016 (10.4\%). In Poltava region, as well as in Kharkiv region, the largest proportion of $S$. aureus isolates resistant to penicillin antibiotics was identified in 2013 (30.1\%). The smallest proportion of S. aureus strains resistant to the penicillin group drugs in Poltava region was identified in $2015(16.7 \%)$. During the whole period of the study (except 2016), the proportion of $S$. aureus strains resistant to penicillins was statistically significantly higher in Kharkiv region than in Poltava region (Fig. 1a). On the whole, in 2013-2019 the proportion of S. aureus strains resistant to the penicillin drugs group in Kharkiv region was 2.3 times statistically significantly higher than in Poltava region $(50.8 \%$ / $\mathrm{n}=14,687$ of 28,904 versus $21.8 \% / \mathrm{n}=3,412$ of 15,$676 ; \chi^{2}=3,555.9$; $\mathrm{P}<0.001)$.

The comparative analysis of $S$. aureus resistance to medications of the cephalosporin group has demonstrated in dynamics that the largest proportion of resistant S. aureus strains in both regions was identified in 2015 (39.9\% in Kharkiv region; 9.5\% in Poltava region), while the smallest proportion was identified in 2016 (4.0\% in Kharkiv region; 6.4\% in Poltava region). It should be noted that in 2015 and in 2017 the proportion of S. aureus strains resistant to cephalosporins was statistically significantly higher in Kharkiv region than in Poltava region. Nevertheless, in 2016 the proportion of $S$. aureus isolates resistant to cephalosporin antibiotics was statistically significantly higher in Poltava region (Fig. 1b). On the whole, in 2015-2017, the proportion of S. aureus strains resistant to the cephalosporin medication group was 1.7 times statistically significantly higher in Kharkiv region compared with Poltava region $(14.7 \% / \mathrm{n}=1,590$ of 10,815 versus $8.9 \% / \mathrm{n}=473$ of 5,$\left.340 ; \chi^{2}=109.6 ; \mathrm{P}<0.001\right)$.

The analysis of resistance in $S$. aureus isolates to carbapenems demonstrates that the largest proportion of resistant strains in Kharkiv region was identified in 2017 (42.0\%), while in Poltava region - in 2015 $(10.0 \%)$. The smallest proportion of S. aureus strains resistant to carbapenems was identified in Kharkiv region in $2013(9.0 \%)$, and in Poltava region - in $2016(1.7 \%)$. Statistically significant differences between the proportion of $S$. aureus strains resistant to carbapenems in Kharkiv and Poltava regions were not found in 2015 (Fig. 1c). Nevertheless, during the period from 2015 to 2017 in general, the proportion of S. aureus strains resistant to carbapenem drugs was statistically significantly higher by 3.7 times in Kharkiv region $(26.6 \% / \mathrm{n}=337$ of 1,268 versus $7.1 \% / \mathrm{n}=$ 215 of 3,$\left.038 ; \chi^{2}=304.4 ; \mathrm{P}<0.001\right)$.

When identifying the resistance in $S$. aureus isolates to aminoglycosides, the largest proportion of resistant strains in both regions was identified in 2013 (32.9\% in Kharkiv region; 22.3\% in Poltava region) The smallest proportion of resistant isolates in Kharkiv area was identified in 2016 (2.6\%), while in Poltava region - in 2014 (6.4\%). During the whole period of study (except 2016), the proportion of $S$. aureus isolates resistant to aminoglycosides was statistically significantly higher in Kharkiv region (Fig. 1d). Overall, in 2013-2019, the proportion of S. aureus strains resistant to medications of the aminoglycoside group was 1.2 times statistically significantly higher in Kharkiv region compared with Poltava region $(16.0 \% / \mathrm{n}=3,377$ of 21,144 versus $13.2 \% / \mathrm{n}=1,424$ of 10,762 ; $\left.\chi^{2}=41.9 ; \mathrm{P}<0.001\right)$.

The largest proportion of $S$. aureus isolates resistant to macrolides in Kharkiv region was identified in 2017 (55.4\%), and in Poltava region - in 2019 (42.0\%). The smallest proportion of $S$. aureus isolates resistant to macrolides in Kharkiv region was identified in 2013 (6.5\%), and in Poltava region - in $2015(12.5 \%)$. It was found that the proportion of S. aureus isolates resistant to macrolides in 2013, 2016, and 2019 was statistically significantly higher in Poltava region. In other years (except 2014) statistically significant differences were found to be in favour of a higher resistance of S. aureus isolates in Kharkiv region (Fig. 2a). Generally, during the period from 2013 to 2019, the proportion of S. aureus strains resistant to the macrolides group medications was slightly higher (1.1 times) in Kharkiv region $(19.9 \% / \mathrm{n}=1,522$ of 7,642 versus $18.1 \% / \mathrm{n}=1,827$ of 10,$\left.092 ; \chi^{2}=9.3 ; \mathrm{P}=0.002\right)$.

In Kharkiv region, the largest proportion of $S$. aureus strains resistant to lincozamids was identified in 2015, and the smallest - in $2013(41.6 \%$ and $3.1 \%$ respectively). In Poltava region more than half of the identified S. aureus strains in 2014 (54.0\%) were resistant to lincozamids group antibiotics. The lowest resistance to lincozamids in Poltava region was in S. aureus strains identified in 2015 (10.0\%). Statistically significant differences in proportion of $S$. aureus strains resistant to lincozamids in the compared regions were found in 2013-2015 and in 2017-2019 (Fig. 2b). On the whole, during the analyzed period 1.9 times more $S$. aureus isolates resistant to lincozamids were identified in Poltava region than in Kharkiv region $(16.3 \% / \mathrm{n}=1,436$ of 8,792 versus $8.5 \% / \mathrm{n}=864$ of 10,$\left.156 ; \chi^{2}=270.6 ; \mathrm{P}<0.001\right)$.

The proportion of $S$. aureus isolates resistant to the tetracycline medications group in Kharkiv region varied within $0.6 \%$ in 2013 to $15.3 \%$ in 2016. The proportion of tetracycline resistant $S$. aureus strains in Poltava region reached its maximum in 2019 , amounting to $30.5 \%$. The smallest proportion of the resistant isolates in Poltava region was identified in 2015 (9.1\%). The statistically significant differences between the proportion of tetracycline-resistant $S$. aureus isolates in the compared regions were identified in 2013, 2014, and 2016-2019 (Fig. 2c). On the whole, during the studied period, the proportion of $S$. aureus strains resistant to tetracycline antibiotics was 1.9 times higher in Poltava region $(15.7 \% / \mathrm{n}=1,560$ of 9,934 versus $8.3 \% / \mathrm{n}=294$ of 3,$\left.534 ; \chi^{2}=119.7 ; \mathrm{P}<0.001\right)$.

In Kharkiv region in 2013 and 2014, 96.3\% and $89.1 \%$ isolated S. aureus strains respectively were resistant to vancomycin. The smallest amount of $S$. aureus strains resistant to vancomycin in Kharkiv region was identified in $2016(0.6 \%)$. In Poltava region, of the 1063 S. aureus isolates studied in 2017, none was resistant to vancomycin. Nevertheless, more than the quarter of the identified isolates in $2019(26.6 \%)$ in Poltava region were resistant to this antibiotic. In 2013, 2014 and 2017, the proportion of $S$. aureus isolates resistant to vancomycin was statistically significantly higher $(\mathrm{P}<0.001)$ in Kharkiv region (Fig. 3a).

Using Fisher's exact test, we found statistically significant differences in proportion of rifampicin resistant isolates of $S$. aureus in the compared regions in 2013, 2014 and $2016(\mathrm{P}<0.05)$. The proportion of rifampicinresistant isolates of $S$. aureus in the Poltava region was higher. It should be noted that during the whole studied period, the proportion of rifampicinresistant $S$. aureus isolates in Kharkiv region did not exceed 7.8\% $(\mathrm{n}=19$ of 244 in 2017), and in Poltava region it did not exceed $11.6 \%$ ( $n=11$ of 95 in 2016).

Comparative analysis by the regions of resistance of $S$. aureus isolates to fluoroquinolones medications showed that in Poltava region the proportion of resistant strains prevailed over that of Kharkiv region during the whole period of observation except 2017 (Fig. 3b). In Poltava region, the proportion of the resistant strains varied between $15.6 \%$ in 2014 and $24.5 \%$ in 2019 . In Kharkiv region, the proportion of the resistant isolates was between $3.0 \%$ in 2013 and $26.9 \%$ in 2017 . Overall, during the studied period, the proportion of fluoroquinolone resistant $S$. aureus strains was 3.3 times higher in Poltava region $(19.7 \% / \mathrm{n}=3,110$ of 15,771 versus $5.9 \% / \mathrm{n}=1995$ of 3,$\left.3619 ; \chi^{2}=2201.3 ; \mathrm{P}<0.001\right)$. 
The analysis of $S$. aureus strains resistant to linezolid has demonstrated that in Poltava region the proportion of resistant microorganisms was statistically significantly higher in 2013-2014 and 2016-2018 (Fig. 3c). Notably, in Kharkiv region linezolid-resistant strains accounted for $19.3 \%$ of antibiotic resistant strains identified in 2015, which exceeded by $8.5 \%$ the maximum proportion of linezolid-resistant strains of S. aureus identi- fied in Poltava region. Due to the small number of co-trimoxazol sensitivity tests $(\mathrm{n}=14)$ of $S$. aureus made in Kharkiv region, it is impossible to interpret correctly the negative results obtained. Nevertheless, more tests were made in Poltava region, and the proportion of resistant isolates varied there between $3.4 \%(n=9$ of 268$)$ in 2019 and $43.7 \%(n=52$ of 119$)$ in 2016.
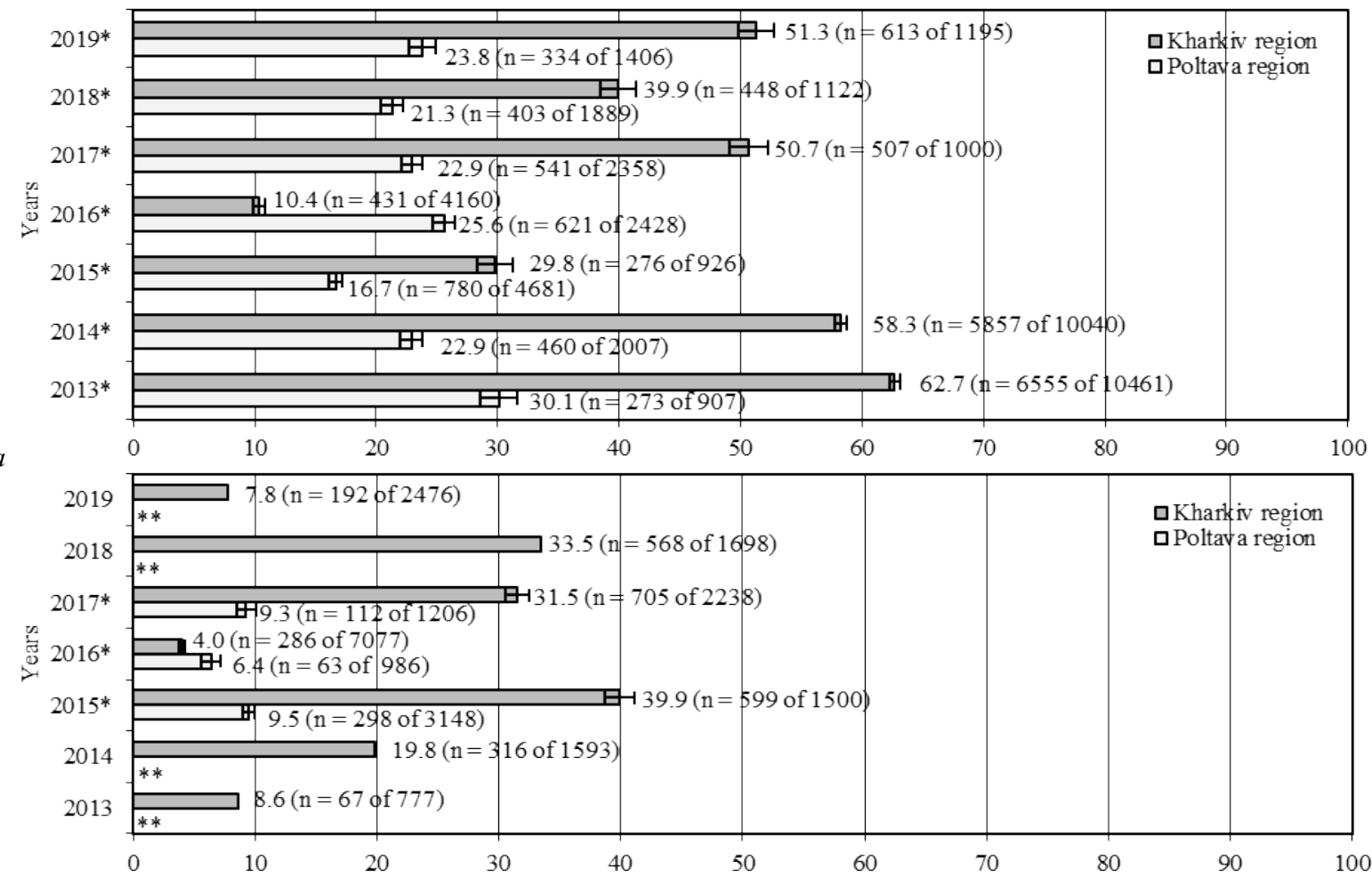

$b$
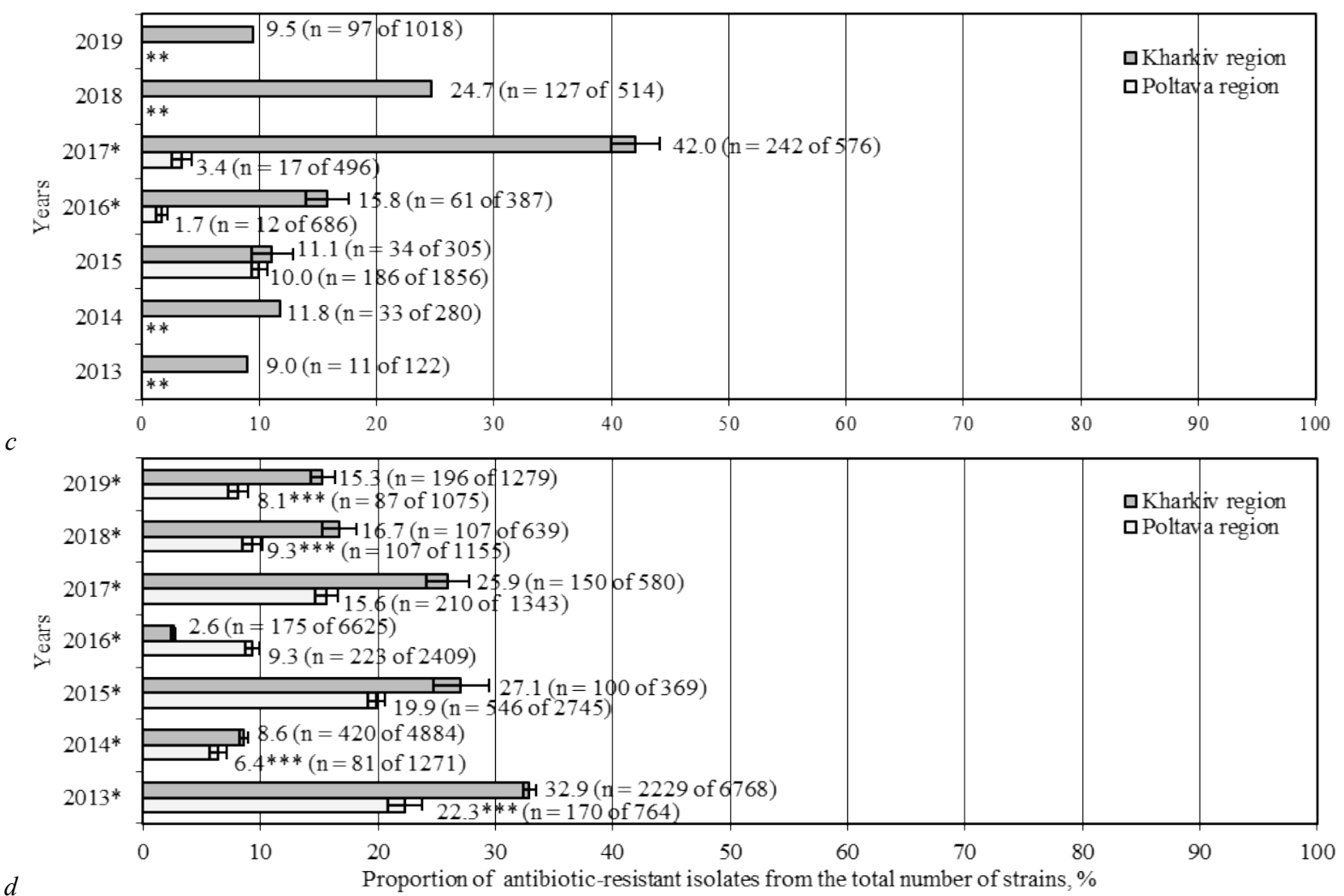

Fig. 1. Proportion ( $\mathrm{x} \pm \mathrm{SE}, \%)$ of penicillin antibiotics-resistant (a), cephalosporin antibiotics-resistant $(b)$, carbapenem antibiotics-resistant $(c)$, aminoglycoside antibiotics-resistant $(d)$ strains of $S$. aureus in Kharkiv and Poltava regions during 2013-2019: * - the differences are statistically significant at $\mathrm{P}<0.01,{ }^{* *}$ - antibiotic resistance was not studied in Poltava region that year, *** - there are available data on resistance to only one amiglycoside antibiotic (gentamycin) 


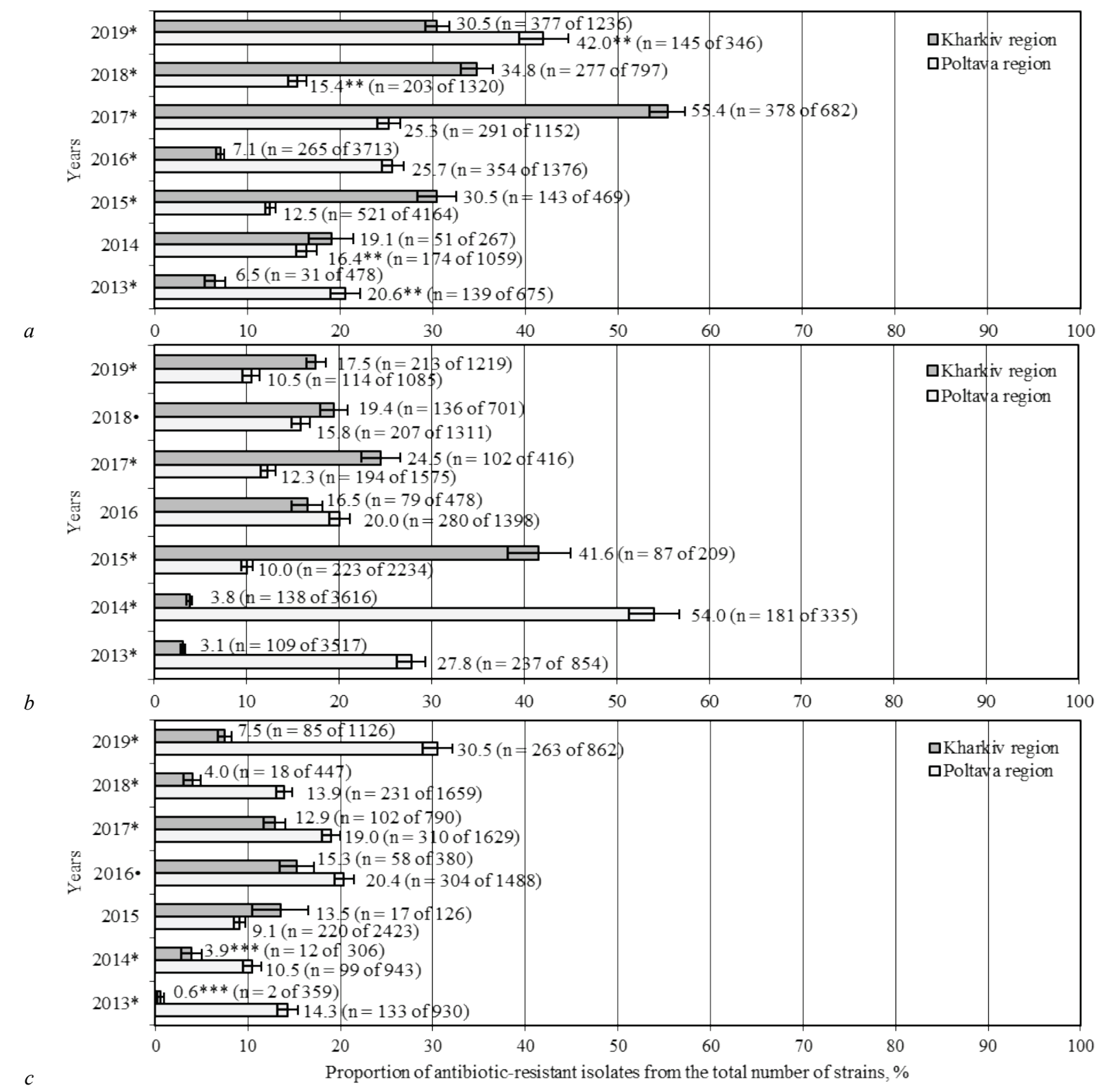

Fig. 2. Proportion ( $\mathrm{x} \pm \mathrm{SE}, \%)$ of macrolide antibiotics-resistant $(a)$, lincozamid antibiotics-resistant $(b)$, tetracycline antibiotics-resistant $(c)$, strains of S. aureus in Kharkiv and Poltava regions during 2013-2019: * - the differences are statistically significant at $\mathrm{P}<0.01$,

- -the differences are statistically significant at $\mathrm{P}<0.05,{ }^{* *}$ - there are available data on resistance to only one macrolide antibiotic (erythromycin), $* * *$ - there are available data on resistance to only one tetracycline antibiotic (tetracycline)

The largest proportion of $S$. aureus isolates resistant to chloramphenicol was identified in Kharkiv region in 2018 (60.4\%), and in Poltava region - in 2014 (63.6\%). In 2016-2019, the differences in both regions were statistically significant (Fig. 3d). During the period of 2014-2015 and in 2017, in Poltava region 9.2\% $(\mathrm{n}=27$ of 293$)$ of $S$. aureus isolates were found to be resistant to phosphomycin. $8.2 \%(\mathrm{n}=18$ of 220$)$ of $S$. aureus strains were found to be resistant to fusidic acid in Poltava region in 20162018. Also, in 2015-2016 and in 2018 in Poltava region, 41.4\% $(n=137$ of 331) of S. aureus isolates were identified as resistant to nitrofuran derivatives. The analysis of S. epidermidis isolates' resistance has demonstrated that in Kharkiv region in 2015 , nearly half $(47.6 \%)$ of the isolates were found to be resistant to the penicillin antibiotics (Fig. 4).

Notably, from 2012 to 2015 among the S. epidermidis isolates there was a growth in the prevalence of resistance to cephalosporins, aminoglycosides, macrolides, and fluoroquinolones. When determining the carbapenems resistance in $2013,3.1 \%(\mathrm{n}=1$ of 32$)$ of $S$. epidermidis were found to be resistant to imipenem. In 2014 and 2015, the proportion of the carbapenems-resistant strains was considerably larger, $15.5 \%(\mathrm{n}=25$ of $161)$ and $16.3 \%(n=33$ of 203) respectively. In 2013, sensitivity in 11 strains of $S$. epidermidis to aztreonam was determined. In three cases, the isolates were resistant. In 2013 and 2014, relatively few lincozamid-resistant isolates were identified: $1.7 \%(\mathrm{n}=8$ of 470$)$ and $5.5 \%(\mathrm{n}=16$ of 289$)$ respectively. In 2015, sensitivity to clindamycin was identified in 13 S. epidermidis strains. In four cases, the isolates were resistant. The proportion of tetracycline-resistant isolates in 2013 comprised $4.2 \%(n=9$ of 213 ), in $2014-4.9 \%(\mathrm{n}=11$ of 223$)$. When analyzing $S$. epidermidis resistance to vancomycin, a decrease in the proportion of resistant strains from $88.0 \%$ in 2013 to $8.7 \%$ in 2015 was noted. The resistance of S. epidermidis isolates to rifampicin was studied only in 2013 and 2014. The proportion of the resistant strains was $3.7 \%(n=8$ of 214$)$ and $8.7 \%(n=2$ of 23$)$ respectively. In 2015, the proportion of linezolid-resistant strains grew sharply. In 2015 , sensitivity to chloramphenicol was identified in 28 S. epidermidis strains. In 24 cases (85.7\%), the isolates were resistant.

\section{Discussion}

The study has confirmed the existence of differences in the prevalence of S. aureus isolates resistant to various groups of antibacterial medications in Kharkiv and Poltava regions. In Kharkiv region, strains resistant to medications of penicillin group, cephalosporins, carbapenems, amino- 
glycosides, and macrolides were identified more often than in Poltava region. In Poltava region, strains resistant to lincozamids, tetracycline antibiotics, and fluoroquinolones were identified more often than in Kharkiv region. This can be ascribed to the regional peculiarities in antibiotics consumption by the population and in medical practices. A high occurrence of $S$. aureus isolates resistant to natural and some synthetic and semisynthetic penicillin antibiotics (penicillin, ampicillin) is confirmed by other authors' studies (Deyno et al., 2017; Y1lmaz \& Aslantaş, 2017). Inhibitor-protected penicillins still remain quite efficient, although the high adaptability of $S$. aureus can make antibiotics of this group totally inefficient rather soon.

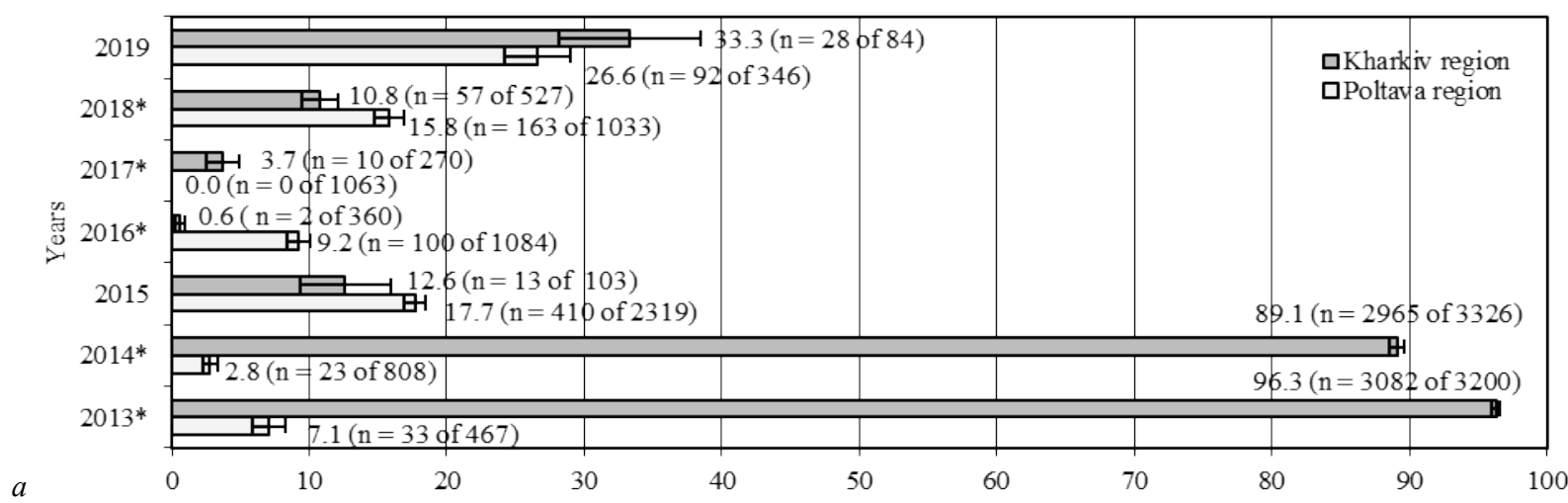

$a$

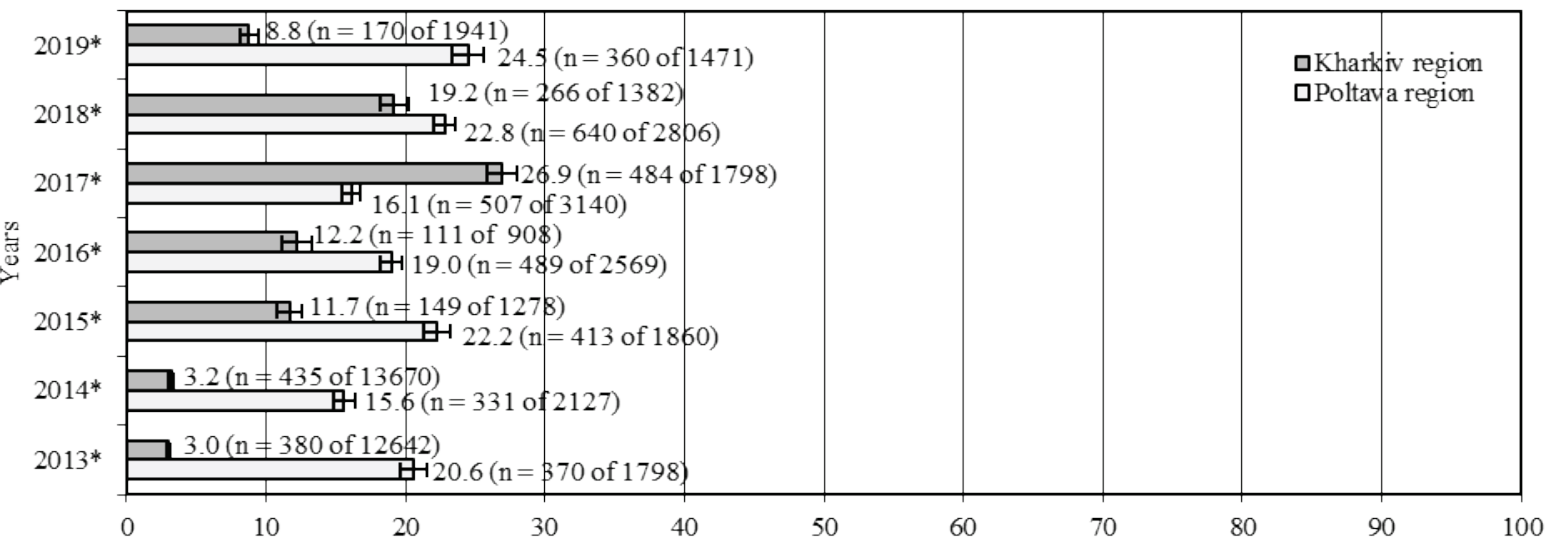

$b$
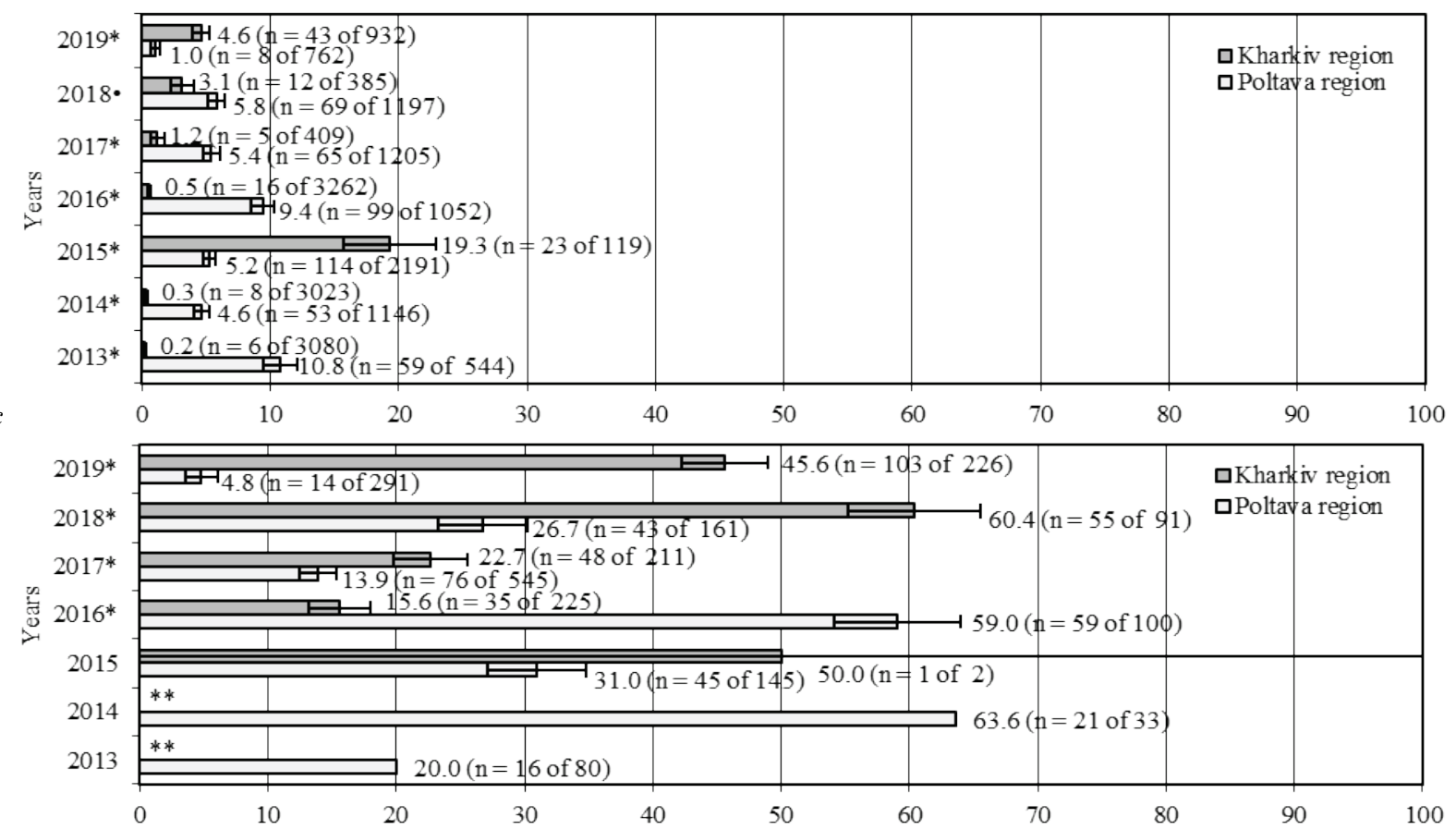

$d$

Proportion of antibiotic-resistant isolates from the total number of strains, \%

Fig. 3. Proportion ( $\mathrm{x} \pm \mathrm{SE}, \%$ ) of vancomycin-resistant $(a)$, fluoroquinolones-resistant $(b)$, linezolid-resistant $(c)$, chloramphenicol-resistant $(d)$ strains of $S$. aureus in Kharkiv and Poltava regions during 2013-2019: * - the differences are statistically significant at $\mathrm{P}<0.01$, - - the differences are statistically significant at $\mathrm{P}<0.05,{ }^{* *}$ - antibiotic resistance was not studied in Kharkiv region in this year

We noted that in Poltava region, the proportion of $S$. aureus isolates resistant to cephalosporins and carbapenems is relatively low. The monitoring of resistance to these antibiotics groups in Poltava region is not conducted on a regular basis. In Kharkiv region, the largest proportion of strains resistant to cephalosporins and carbapenems medications amounted to $39.9 \%$ and $42.0 \%$ respectively. Therefore, Poltava region also needs to monitor on a regular basis the resistance of $S$. aureus to these groups of medications and to apply them in treatment protocols with care. 


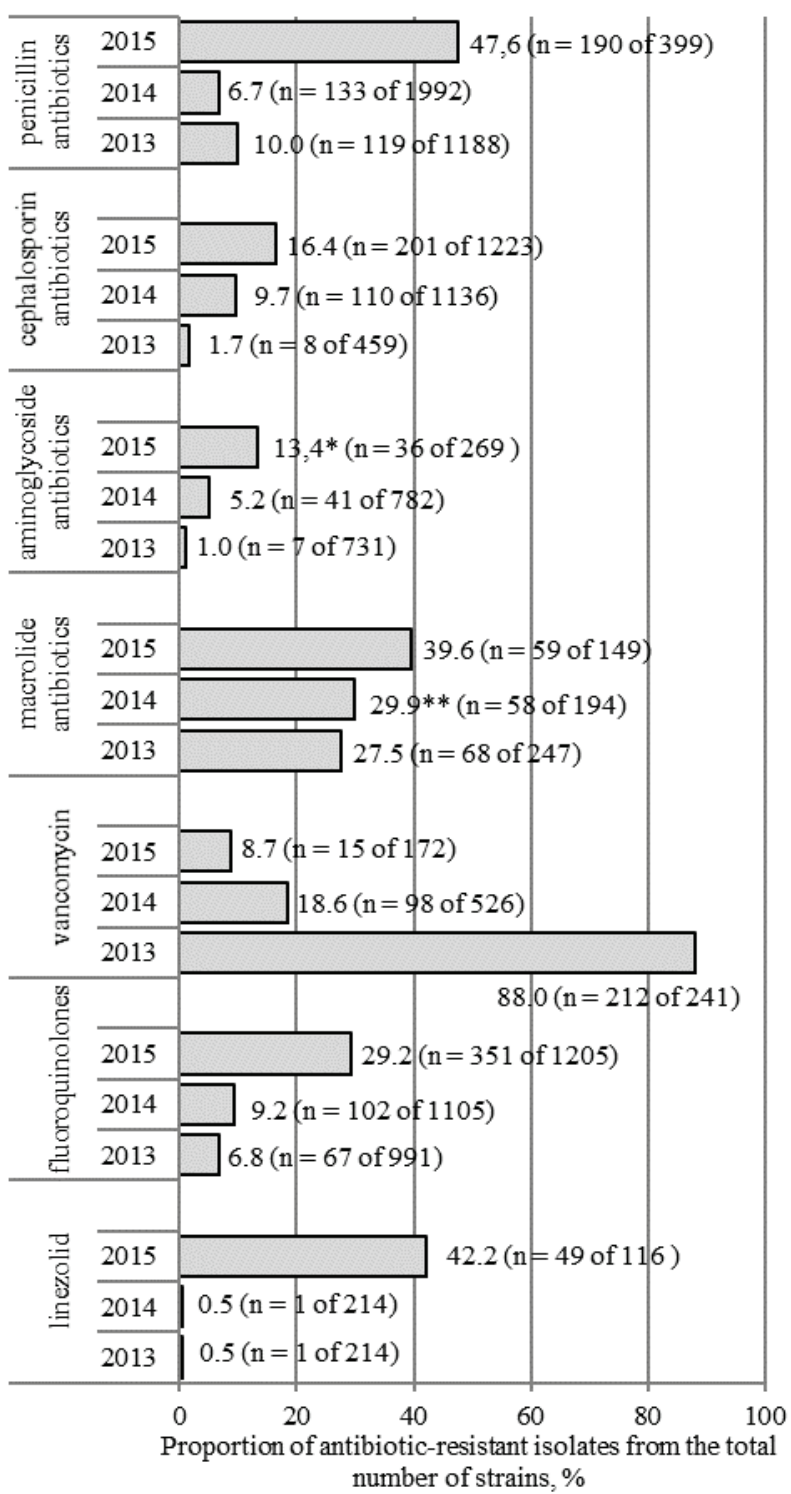

Fig. 4. Proportion (\%) of antibiotic-resistant strains of S. epidermidis in Kharkiv region during 2013-2015: * - there are available data on resistance to only one amiglycoside antibiotic (amikacin),

** - there are available data on resistance to only one macrolide antibiotic (erythromycin)

Hauschild et al. (2008) reported that $38.1 \%$ of $S$. aureus isolates in their study were resistant to at least one antibiotic of the aminoglycoside group. In the present study, the aminoglycoside resistance in both regions was generally much lower. In comparison with the work by Liu et al. (2017), the authors identified a high resistance in S. aureus isolates to the macrolides group. Also, the authors have identified a generally lower resistance in $S$. aureus isolates to the tetracycline group medications than Ullah et al. (2013).

It is considered that resistance in S. aureus to fluoroquinolones is formed as a result of treating illnesses caused by other agents when the skin of the hands and mucous coverings of a person receiving medications of this group are colonized by S. aureus. In that case, S. aureus is influenced by sub-therapeutic concentrations of drugs, which may cause mutations (Lowy, 2003). In the our study, fluoroquinolone-resistant S. aureus strains were identified in some years in a quarter of cases. Therefore, departing from the resistance formation mechanism, prescribing of any antibacterial medication should be duly substantiated.

In comparison with the study by Rağbetli et al. (2016), we have identified a high resistance to linezolid ( $0 \%$ of resistant strains according to their data versus $19.3 \%$ of resistant strains identified in 2015 in Kharkiv region in our study). Linezolid is an antibiotic which is efficient against gram-positive flora including metycillin-resistant staphylococci (Gu et al.,
2012), therefore the results obtained by us in this study call for further study and identifying the causes of such a high resistance.

Similar data (compared with Poltava region) concerning S. aureus resistance to co-trimoxazol were demonstrated by Deyno et al. (2017). Due to the insufficient amount of tests in Kharkiv region, we think that it is necessary to continue studying the sensitivity to co-trimaxazol in Kharkiv region to find out whether there are any territorial differences in S. aureus resistance to this antibiotic.

When analyzing the dynamics of prevalence of resistant $S$. aureus strains in the regions, we found a broad difference in the proportion of isolates resistant to some antibiotics. For instance, in Kharkiv region, 96.3\% of S. aureus isolates were found to be vancomycin-resistant in 2013, while in 2016 - less than 1\%. Also in Kharkiv region, 3.1\% of strains were found to be resistant to the lincozamid group in 2013, while in 2015 $41.6 \%$. These results can be probably ascribed to the disproportional amount of cultures sampled in healthcare settings for our study. This indicate that every healthcare setting has unique microbiological profile.

The research by Mohaghegh et al. (2015) has demonstrated efficiency in using chloramphenicol against $S$. aureus isolates sampled from the patients with suspected bacteremia. In our study, the proportion of chloramphenicol-resistant isolates was high in both regions in certain years. In view of this, we think that the study of $S$. aureus sensitivity to this medication should be continued by increasing the number of the studied isolates.

As to $S$. epidermidis, it should be noted that despite its long since proven pathogenicity (Morgunov \& Kukharchik, 1986), this microorganism is still underestimated in medical practice as being a cause of a number of infections. At the same time, S. epidermidis possesses properties and mechanisms owing to which it manages to fix itself on the human body and avoid being destroyed by the immune system. Normally, owing to its adhesive properties, S. epidermidis fixes itself to the host's proteins in the skin, and in cases of damage, wounds, introduction of foreign bodies (prosthetics, vessels catheterization), the infectious agent fixes itself to deeper-laying tissues or to the surface of the implanted appliances (Sabaté Brescó et al., 2017).

The analyses on determining $S$. epidermidis strains resistance to antibiotics made in Kharkiv region show in the dynamics a rise in the proportion of isolates resistant to most of the antibiotics groups: to penicillins, cephalosporins, aminoglycosides, macrolides, and fluoroquinolones. As early as in 1980, Archer \& Tenenbaum in their study on patients surviving heart operations reported a high proportion of $S$. epidermidis isolates resistant to naphycillin, penicillin (100\% each), to cephalotin ( $93 \%)$, to cephamandol $(80 \%)$, to streptomycin $(67 \%)$. Other researchers report the high prevalence of resistance in hospital $S$. epidermidis strains to many medications: to penicillin, cefazolin, tetracycline, erythromycin. Moreover, in the isolated strains simultaneous resistance to more than three groups of antibiotics was observed, and in $17.4 \%$ - to seven different groups of antibiotics (Chabi \& Momtaz, 2019). Of great concern is the high proportion of vancomycin-resistant $S$. epidermidis strains isolated in Kharkiv region in 2013. Nunes et al. (2016) state that the resistance in S. epidermidis strains to glycopeptide antibiotics is influenced by the thickness of the cell's membrane. Also, the authors report the heterogenic resistance of S. epidermidis to glycopeptides. At the same time, in another study, vancomycin is viewed as the most efficient medicine against $S$. epidermidis for treating patients with suspected bacteremia (Mohaghegh et al., 2015). Chabi \& Momtaz (2019) also reported the high prevalence of S. epidermidis resistance to co-trimaxazol. Because in the present study we did not identify resistance to this medication, it should be accounted for in further studies. Therefore, considering the aforementioned, the study of resistance of S. epidermidis isolates should be obligatory all over the country without limitation to individual regions. Our study demonstrates that in Ukraine there is a need for the introduction of a complex approach to the issue of antibiotics resistance. Epidemiological monitoring of hospital infectious agents should be strengthened at the national level, and in the regions, the scope of conducted bacteriological researches should be broadened with further identification of antibiotic sensitivity in the isolated strains. It is also necessary to identify in the isolated microorganisms the ability to form biofilms and the traits of their biofilm forms. Additional introduction of moleculargenetic methods, identifying hetero-resistance in microorganisms and the study of their subpopulations can help the patients whose treatment does 
not fit into standard procedures and ensure an individual approach to every patient within personalized healthcare.

The territorial differences in antibiotic resistance of $S$. aureus isolates disclosed in the present study attest to the expediency in maintaining microbiological monitoring both on the regional level and the institutional level. Considering the growing resistance in S. epidermidis isolates to penicillins, cephalosporins, aminoglycosides, macrolides, and fluoroquinolones identified in Kharkiv region, obligatory assessment of sensitivity of this genus of microorganisms to antibacterial medication should be conducted on a regular basis at healthcare settings of both Kharkiv region and other districts and regions. Forming the unified national data network on microorganism resistance in regions will become the foundation for developing strategies on infection control and prevention of cases of infection associated with rendering of health-care aid, including prevention of catheter-related bloodstream infections. Considering the available data on resistance in hospital strains of microorganisms, it is necessary to develop new and improve the acting local protocols of patients' antibiotic treatment. Rational and scientifically substantiated application of antibiotic medications in medical practices will enable efficient prevention of formation of microorganism-resistant strains, which will raise the quality of health-care aid rendered to the population, decrease the number of complications, and diminish economic losses caused by infections associated with resistant microorganisms.

\section{Conclusion}

We identified peculiarities in antibiotic resistance patterns in regions of Ukraine. In total, the proportion of $S$. aureus strains resistant to penicillins, cephalosporins, carbapenems, aminoglycosides, and macrolides was higher in Kharkiv region in terms of statistical validity than in Poltava region. Overall, the proportion of $S$. aureus strains resistant to lincozamids, tetracycline antibiotics, and fluoroquinolones in Poltava region was higher in terms of statistical validity than in Kharkiv region. Assessment of antibiotic resistance in S. epidermidis isolates in Kharkiv region showed increase in resistance to the most antibiotics (penicillins, cephalosporins, aminoglycosides, macrolides, and fluoroquinolones).

Further studies are needed to create of passports of microorganism resistance in the regions and medical institutions, as well as to create a unified national database network on microorganism resistance using modern methodologies of determining the phenotypes and genotypes of microorganisms.

The authors would like to express their express their sincere gratitude to the SI Kharkiv Oblast Laboratory Center of the MoH of Ukraine and to SI Poltava Oblast Laboratory Center of the $\mathrm{MoH}$ of Ukraine for their assistance in conducting this study.

The study has been performed within the framework of the science-and-research work Epidemiology Department of Kharkiv National Medical University titled "To develop a scientifically substantiated strategy of prevention of antibiotic resistance of bacteria causing healthcare-associated infections in healthcare facilities" (State Registration No 0118U000944).

\section{References}

Aghdassi, S., Schröder, C., Gruhl, D., Gastmeier, P., \& Salm, F. (2019). Point prevalence survey of peripheral venous catheter usage in a large tertiary care university hospital in Germany. Antimicrobial Resistance and Infection Control, 8(1), 15.

Archer, G., \& Tenenbaum, M. (1980). Antibiotic-resistant Staphylococcus epidermidis in patients undergoing cardiac surgery. Antimicrobial Agents and Chemotherapy, 17(2), 269-272.

Bauer, A., Kirby, W., Sherris, J., \& Turck, M. (1966). Antibiotic susceptibility testing by a standardized single disk method. American Journal of Clinical Pathology, 45(4), 493-496.

Brown, A., Leech, J., Rogers, T., \& McLoughlin, R. (2014). Staphylococcus aureus colonization: Modulation of host immune response and impact on human vaccine design. Frontiers in Immunology, 4, 507.

Brusselaers, N., Vogelaers, D., \& Blot, S. (2011). The rising problem of antimicrobial resistance in the intensive care unit. Annals of Intensive Care, 1(1), 47.

Canadian Nosocomial Infection Surveillance Program (2020). Healthcare-associated infections and antimicrobial resistance in Canadian acute care hospitals, 2014 2018. Canada Communicable Disease Report, 46(5), 99-112.
Chabi, R., \& Momtaz, H. (2019). Virulence factors and antibiotic resistance properties of the Staphylococcus epidermidis strains isolated from hospital infections in Ahvaz, Iran. Tropical Medicine and Health, 47(1), 56.

Cherifi, S., Byl, B., Deplano, A., Nagant, C., Nonhoff, C., Denis, O., \& Hallin, M. (2014). Genetic characteristics and antimicrobial resistance of Staphylococcus epidermidis isolates from patients with catheter-related bloodstream infections and from colonized healthcare workers in a Belgian hospital. Annals of Clinical Microbiology and Antimicrobials, 13(1), 20

Clinical and Laboratory Standards Institute (2014). Performance standards for antimicrobial susceptibility testing; twenty-fourth informational supplement. CLSI document M100-S24. Wayne, Pennsylvania.

Conlan, S., Mijares, L., NISC Comparative Sequencing Program, Becker, J., Blakesley, R., Bouffard, G., Brooks, S., Coleman, H., Gupta, J., Gurson, N., Park, M., Schmidt, B., Thomas, P., Otto, M., Kong, H., Murray, P., \& Segre, J. (2012). Staphylococcus epidermidis pan-genome sequence analysis reveals diversity of skin commensal and hospital infection-associated isolates. Genome Biology, 13(7), R64.

Costerton, J., Montanaro, L., \& Arciola, C. (2005). Biofilm in implant infections: Its production and regulation. The International Journal of Artificial Organs, 28(11), 1062-1068.

Deurenberg, R., \& Stobberingh, E. (2008). The evolution of Staphylococcus aureus. Infection, Genetics and Evolution, 8(6), 747-763.

Deurenberg, R., Vink, C., Kalenic, S., Friedrich, A., Bruggeman, C., \& Stobberingh, E. (2007). The molecular evolution of methicillin-resistant Staphylococcus aureus. Clinical Microbiology and Infection, 13(3), 222-235.

Du, X., Zhu, Y., Song, Y., Li, T., Luo, T., Sun, G., Yang, C., Cao, C., Lu, Y., \& Li, M. (2013). Molecular analysis of Staphylococcus epidermidis strains isolated from community and hospital environments in China. PloS One, 8(5), e62742.

Gu, B., Kelesidis, T., Tsiodras, S., Hindler, J., \& Humphries, R. (2012). The emerging problem of linezolid-resistant Staphylococcus. Journal of Antimicrobial Chemotherapy, 68(1), 4-11.

Guembe, M., Pérez-Granda, M. J., Capdevila, J. A., Barberán, J., Pinilla, B., MartínRabadán, P., Bouza, E., on behalf of the NUVE Study Group, Millán, J., Pérez de Oteyza, C., Muiño, A., Villalba, M., Cuenca, C., Castaño, J. G., Delgado, C. M., Zamorano, S., Gómez, B., Collado, J. M., Salinas, M. T, Amat, A. S., Lázaro, J. R., Sordo, V. V., Sánchez, M. V., Benach, Á. F., Vidal, E., Albiach, L., Aparicio, J. M. A., Arroniz, E. S. A., Casademont, I., Pou, J., Solchaga, V. P., Castellón, F. E., Obanos, T. R., Egurbide Arberas, M. V., Arana, J. N., López, E. G., Gaviria, A. Z., Clemente, I. N., Ruíz, P. C., Salomó, A. C., Iftimie, S. M., Castillo, A. M., Barberá Farré, J. R., Lavería, A. O., Ribera, M. C., Pallarés, N. B., Suárez, P. C., Piomo, F. J. C., Andrés, N. A., Tarazona, R. E. R., Zapata, M. M. R., \& Cerdá, M. A. C. (2017). Nationwide study on peripheral-venouscatheter-associated-bloodstream infections in internal medicine departments. Journal of Hospital Infection, 97(3), 260-266.

Hauschild, T., Sacha, P., Wieczorek, P., Zalewska, M., Kaczyńska, K., \& Tryniszewska, E. (2008). Aminoglycosides resistance in clinical isolates of Staphylococcus aureus from a University Hospital in Bialystok, Poland. Folia Histochemica et Cytobiologica, 46(2), 225-228.

Hellmark, B., Söderquist, B., Unemo, M., \& Nilsdotter-Augustinsson, Å. (2013). Comparison of Staphylococcus epidermidis isolated from prosthetic joint infections and commensal isolates in regard to antibiotic susceptibility, agr type, biofilm production, and epidemiology. International Journal of Medical Microbiology, 303(1), 32-39.

Jokinen, E., Laine, J., Huttunen, R., Rahikka, P., Huhtala, H., Vuento, R., Vuopio, J., \& Syrjänen, J. (2017). Comparison of outcome and clinical characteristics of bacteremia caused by methicillin-resistant, penicillin-resistant and penicillinsusceptible Staphylococcus aureus strains. Infectious Diseases, 49(7), 493-500.

Kaplan, J. (2011). Antibiotic-induced biofilm formation. International Journal of Artificial Organs, 34(9), 737-751.

Kollef, M., \& Fraser, V. (2001). Antibiotic resistance in the intensive care unit. Annals of Internal Medicine, 134(4), 298-314.

Lindsay, J. (2010). Genomic variation and evolution of Staphylococcus aureus. International Journal of Medical Microbiology, 300(2-3), 98-103.

Liu, X., Deng, S., Huang, J., Huang, Y., Zhang, Y., Yan, Q., Wang, Y., Li, Y., Sun, C., \& Jia, X. (2017). Dissemination of macrolides, fusidic acid and mupirocin resistance among Staphylococcus aureus clinical isolates. Oncotarget, 8(35), 58086-58097.

Lowy, F. (2003). Antimicrobial resistance: The example of Staphylococcus aureus. Journal of Clinical Investigation, 111(9), 1265-1273.

Manandhar, S., Singh, A., Varma, A., Pandey, S., \& Shrivastava, N. (2018). Biofilm producing clinical Staphylococcus aureus isolates augmented prevalence of antibiotic resistant cases in tertiary care hospitals of Nepal. Frontiers in Microbiology, 9, 2749 .

Mandolfo, S., Anesi, A., Maggio, M., Rognoni, V., Galli, F., \& Forneris, G. (2019). High success rate in salvage of catheter-related bloodstream infections due to Staphylococcus aureus, on behalf of project group of Italian society of nephrology. The Journal of Vascular Access, 21(3), 336-341. 
Mermel, L. (2017). Short-term peripheral venous catheter-related bloodstream infections: A systematic review. Clinical Infectious Diseases, 65(10), 1757-1762.

Mohaghegh, M., Ghazvini, K., Jafari, R., Alikhani, M., Safari, M., Azari Garamjan, G., Falahi, J., \& Bordbar, D. (2015). Retrospective study on the prevalence and antibiotic resistance pattern of Staphylococcus aureus and Staphylococcus epidermidis among patients suspicious of bacteremia during 2006-2011. International Journal of Enteric Pathogens, 3(2), e22930.

Morgunov, I. N., \& Kukharchik, T. A. (1986). Immunologicheskie kriterii patogennosti epidermal'nogo stafilokokka [Immunological criteria of the pathogenicity of epidermal Staphylococcus]. Mikrobiologicheskii Zhurnal, 48(5), 32-35 (in Russian).

Nguyen, D. B., Shugart, A., Lines, C., Shah, A. B., Edwards, J., Pollock, D., Sievert, D., \& Patel, P. R. (2017). National Healthcare Safety Network (NHSN) dialysis event surveillance report for 2014. Clinical Journal of the American Society of Nephrology, 12(7), 1139-1146.

Nunes, A., Teixeira, L., Iorio, N., Bastos, C., Fonseca, L., Soutopadron, T., \& Dossantos, K. (2006). Heterogeneous resistance to vancomycin in Staphylococcus epidermidis, Staphylococcus haemolyticus and Staphylococcus warneri clinical strains: Characterisation of glycopeptide susceptibility profiles and cell wall thickening. International Joumal of Antimicrobial Agents, 27(4), 307-315.

Rağbetli, C., Parlak, M., Bayram, Y., Guducuoglu, H., \& Ceylan, N. (2016). Evaluation of antimicrobial resistance in Staphylococcus aureus isolates by years. Interdisciplinary Perspectives on Infectious Diseases, 2016, 9171395.

Sabaté Brescó, M., Harris, L., Thompson, K., Stanic, B., Morgenstern, M., O’Mahony, L., Richards, R., \& Moriarty, T. (2017). Pathogenic mechanisms and host interactions in Staphylococcus epidermidis device-related infection. Frontiers in Microbiology, 8, 1401.

Saharman, Y., Karuniawati, A., Severin, J., \& Verbrugh, H. (2021). Infections and antimicrobial resistance in intensive care units in lower-middle income countries: A scoping review. Antimicrobial Resistance and Infection Control, 10(1), 22.

Sharma, A., Kalita, J., \& Nag, V. (2019). Screening for methicillin-resistant Staphylococcus aureus carriage on the hands of healthcare workers: an assessment for hand hygiene practices. Indian Journal of Critical Care Medicine, 23(12), 590-592.
Smith, R. N., \& Nolan, J. P. (2013). Central venous catheters. The British Medical Journal, 347(11), f6570.

Tatsuno, K., Ikeda, M., Wakabayashi, Y., Yanagimoto, S., Okugawa, S., \& Moriya, K. (2019). Clinical features of bloodstream infections associated with peripheral versus central venous catheters. Infectious Diseases and Therapy, 8(3), 343-352.

Torumkuney, D., Pertseva, T., Bratus, E., Dziublik, A., Yachnyk, V., Liskova, A., Sopko, O., Malynovska, K., \& Morrissey, I. (2018). Results from the survey of antibiotic resistance (SOAR) 2014-16 in Ukraine and the Slovak Republic. Journal of Antimicrobial Chemotherapy, 73(suppl. 5), v28-v35.

Ullah, F., Malik, S., Ahmed, J., Ullah, F., Shah, S., Ayaz, M., Hussain, S., \& Khatoon, L. (2013). Investigation of the genetic basis of tetracycline resistance in Staphylococcus aureus from Pakistan. Tropical Joumal of Pharmaceutical Research, 11(6), 925-931.

Voidazan, S., Albu, S., Toth, R., Grigorescu, B., Rachita, A., \& Moldovan, I. (2020). Healthcare associated infections - a new pathology in medical practice? International Joumal of Environmental Research and Public Health, 17(3), 760.

Wertheim, H., Melles, D., Vos, M., Van Leeuwen, W., Van Belkum, A., Verbrugh, H., \& Nouwen, J. (2005). The role of nasal carriage in Staphylococcus aureus infections. The Lancet Infectious Diseases, 5(12), 751-762.

Widerström, M., Wiström, J., Edebro, H., Marklund, E., Backman, M., Lindqvist, P., \& Monsen, T. (2016). Colonization of patients, healthcare workers, and the environment with healthcare-associated Staphylococcus epidermidis genotypes in an intensive care unit: A prospective observational cohort study. BMC Infectious Diseases, 16(1), 743.

Wu, J., Kusuma, C., Mond, J., \& Kokai-Kun, J. (2003). Lysostaphin disrupts Staphylococcus aureus and Staphylococcus epidermidis biofilms on artificial surfaces. Antimicrobial Agents and Chemotherapy, 47(11), 3407-3414.

Yılmaz, E., \& Aslantaş, Ö. (2017). Antimicrobial resistance and underlying mechanisms in Staphylococcus aureus isolates. Asian Pacific Joumal of Tropical Medicine, 10(11), 1059-1064.

Zhang, L., Cao, S., Marsh, N., Ray-Barruel, G., Flynn, J., Larsen, E., \& Rickard, C. (2016). Infection risks associated with peripheral vascular catheters. Journal of Infection Prevention, 17(5), 207-213. 


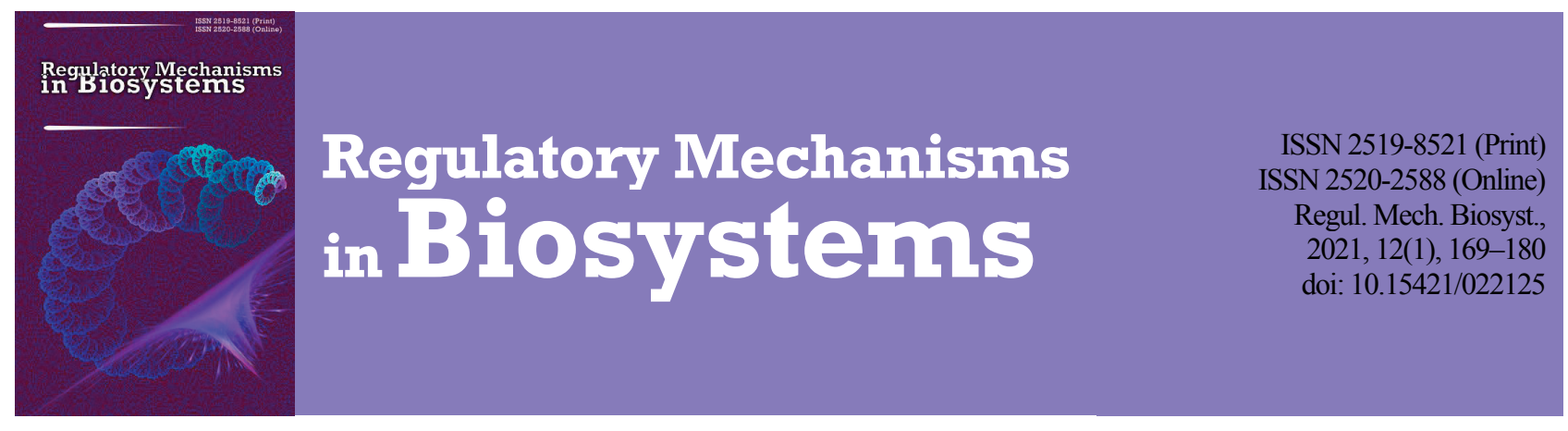

\title{
Influence of Lavandula angustifolia, Melissa officinalis and Vitex angus-castus on the organism of rats fed with excessive fat-containing diet
}

\author{
M. A. Lieshchova*, V. V. Brygadyrenko*, ** \\ *Dnipro State Agrarian and Economic University, Dnipro, Ukraine \\ **Oles Honchar Dnipro National University, Dnipro, Ukraine
}

Article info

Received 27.01.2021

Received in revised form 24.02.2021

Accepted 25.02.2021

Dnipro State Agrarian and Economic University Serhii Efremov st., 25 Dnipro, 49600, Ukraine. Tel.: +38-067-256-24-86 E-mail:

lieshchova.m.o@dsau.dp.ua

Oles Honchar Dnipro National University,

Gagarin av., 72,

Dnipro, 49010, Ukraine.

Tel.: +38-050-93-90-788

E-mail:brigad@ua.fm

Lieshchova, M. A., \& Brygadyrenko, V. V. (2021). Influence of Lavandula angustifolia, Melissa officinalis and Vitex anguscastus on the organism of rats fed with excessive fat-containing diet. Regulatory Mechanisms in Biosystems, 12(1), 169-180. doi:10.15421/022125

Plant food additives are becoming more and more popular and broadly applied products, though the information on risks they poses to the organism is limited and contradictive. Obesity and overeating are some of the commonest health issues around the world, and people are increasingly consuming workability-enhancing preparations as a simple and fast method of weight control. The plantbased preparations are considered less harmful than the synthetic chemical ones. Lavandula angustifolia Mill., Melissa officinalis L. and Vitex angus-castus L. are broadly used as food additives and medicinal plants, despite the fact that their complex physiological assessment on model animals in the conditions of obesity has not yet been performed. We carried out a 30-day experiment on white male rats. All the animals were given high-fat diet, and the experimental animals, in addition to this diet, received $5 \%$ crumbled dry herbs of $L$. angustifolia, $M$. officinalis or $V$. angus-castus. Taking into account the overall amount of consumed food, the mean daily gain in body weight; at the end of the experiment, we determined the index of the weight of the internal organs, biochemical and morphological blood parameters. At the beginning and the end of the experiment, the rats were examined for motor and orienting activities, and emotional status. Rats on high-fat diet gained up to $112 \%$ body weight by the end of the experiment, while rats that had received $V$. angus-castus gained up to $119 \%$, M. officinalis - 135\%, L. angustifolia - 139\%, compared with the initial body weight. Addition of medicinal plants to the diet led to increase in average daily weight increment, significantly and reliably after consuming lavender and lemon balm, less significantly and unreliably after eating Vitex. L. angustifolia and M. officinalis reduced the relative brain weight, and ingestion of $L$. angustifolia and M. officinalis caused notable decrease in the relative mass of the thymus (down to $58 \%$ and $47 \%$ of the relative weight of thymus in animals of the control group respectively). Also, these plants decreased the motor and orienting activities of the rats by the end of the experiment. As for the biochemical parameters of blood, the activity of alkaline phosphatase significantly increased to $406 \%$ following consumption of Melissa, to $350 \%$ after consuming lavender, and to $406 \%$ after Vitex, compared to the control group. Furthermore, all the groups were observed to have increased AST and ALT activities. Intake of lavender led to increases in cholesterol (to 125\%) and LDL cholesterol (to 228\%), whereas the groups that consumed lemon balm were observed to have decreases in urea nitrogen (to 79\%), totalbilirubin (to 63\%) and triglycerides (to 63\%). Addition of Vitex led to increase in the index of aterogenecity against the background of notable fall in HDL cholesterol (to $52 \%$ of the control group). The medicinal plants also contributed to the normalization of the glucose level. Morphological analysis of blood revealed no significant changes, except heightened content of monocytes in blood, which is characteristic of all groups, including the control. Effects of $L$. angustifolia, $M$. officinalis and $V$. angus-castus on the organism of rats on excessive-fat diet require additional histological, histochemical and immunological surveys.

Keywords: relative mass of the organs; increase in the body weight; high-fat diet; high-calorie diet; obesity; phytopreparations; motor activity; orienting activity; emotional status; biochemical blood parameters.

\section{Introduction}

Metabolic diseases such as diabetes mellitus and dyslipidemia occur due to a complex of genetic predisposition and environmental factors. Lifestyle and diet contribute to their development as well, causing significant compliations, malfunctioning and failure of brain, heart and other organs, and likely death. Despite the fact that the authorized medicines may be efficiently used to control blood glucose and cholyterol levels, they also may cause deleterious side effect. Thus, treating metabolic diseases requires seeking new agents for development of novel preparations (Heghes et al., 2020). Against the backround of obesity, metabolic diseases such as dyslipidemia, atherosclerosis and type 2 diabetes have become health problems at the global level (Shin \& Yoon, 2020). Course of obesity is attributed to angiogenesis and extracellular matrix (ECM) remodeling. Angiogenesis develops in adult adipose tissues (Arika et al., 2019;
Lieshchova et al., 2019, 2020). Adipose tissue is closely related with the blood vessels. In fact, adipocytes tissue contains have extensive systems of capillaries. Adipocytes generate endothelial growth factor A and fibroblast growth factor 2 , both proangiogenic factors driving the neovascularization of the tissue. Moreover, development of the adipose tissue and maturation of microvessels is greatly contributed by matrix metalloproteinases (MMPs), including MMP-2 and MMP-9, which modify the ECM. Therefore, modulating angiogenesis and MMP activity could likely be therapeutic means of controlling obesity and accompanying impairments (Shin \& Yoon, 2020).

Application of medicinal plants may help to decrease body weight during obesity and other metabolic disorders (Martin, 2019; Bukvicki et al., 2020). Most often, for those purposes, the treatment involves plants of Lamiaceae family (Michel et al., 2020). Zvezdina et al. (2020) have made a review of 71 species from 30 genera of Lamiaceae family, and 
drew the conclusion that the immense potential of plants of this family is still unexplored. These valuable medicinal plants could help in development of neurotropic preparations. Biologically active substances of Lamiaceae plants comprise phenolic compounds, chiefly phenolcarboxylic and cinnamic acids and their derivatives, flavonoids, including flavones, isoflavones, flavanols, flavanones, flavanones, flavans, flavans 3,4-diols, catechins, biflavonoids and proanthocyanidins (Milevskaya et al., 2019). Rich in biologically active compounds (BAC), species of Lamiaceae family are broadly used in pharmacology.

Melissa officinalis L. is a perennial herbaceous plant of Lamiaceae family. It can reach $150 \mathrm{~cm}$ in height. Its is considered to have been originated from the territory spanning from the Eastern Mediterranean to Iran, Central Asia, the Black Sea and Western Asia, and also North Africa. Currently, this plant is cultivated ubiquously for its essential oil. Content of essential oil ranges $0.02-0.20 \%$, only seldom reaching $0.80 \%$. Content of essential oil in the herbs is $0.06-0.13 \%$, and $0.39-0.44 \%$ in the leaves. Leaves and young shoots of lemon balm that had been cut before blooming are used as spices in the European and American quisines. Fresh and dried, they are added to salads, cheese, soups, meat, fish dishes, mushrooms, tea, vinegar, liquors, salting of cucumbers and tomatos (Shakeri et al., 2016). Furthermore, essential oil of Melissa, similarly to other species of plants considered in this article, has for a long time been used to eliminate or scare off storage pest insects (Martynov et al., 2019a, 2019b). The essential oil's most distinctive constituents are monoterpens citral (geranial + neral), geraniol, nerol, citronellol, citronellal. Essential oil of lemon balm also contains linalool, geranilacetate, myrcene, para-cimol, $\beta$ caryophyllene oxide, $\beta$-caryophyllene and other terpenoids. More than 200 constituents of the essential oil have been described, including neral and geranial, which are responsible for lemon odour. Their proportion is $3: 4$, and the presence of 6-methyl-5-hepten-2-one and $\beta$-caryophyllene are the criteria of identification of lemon balm oil. The second group of the substances of lemon balm are phenylpropanoids, including rosmarinic acid as the most distinctive ones (Noguchi-Shinohara et al., 2015). Phenylpropanoids are also represented by ethyl oil of rosmarinic acid, caffeic acid, chlogenic acid, para-coumaric acid, ferulic acid and sinapinic acid. Using the method of liquid chromatography, we determined that content of rosmarinic acid in the leaves of lemon balm accounts for $0.54-1.79 \%$. Among the phenol substances, antioxidant activity was exhibited by flavonoids apigenin, cosmosiin, luteolin, cynaroside, and also ramno-citrin (7-metoxy kaempferol) and iso- quercetin (3- quercetin glucoside), rhamnazin (3,7 dimetoxycampheroll). Moreover, the plant contains phenolcarbonic acids: gentisic, salicylic, p-hydroxybenzoic, vanillic, syringic, protocatechuic acids, and also tannins and coumarins. Out of sterols, the plant was observed to have daucosterol, out of saponins - ursolic acid. Broad spectrum of therapeutic effect of the plant-based preparations is related to the content of various substances: sedative effect was described for citronellal, and spasmolytic - for geraniol and citronellol. Phenylpropanoids (rosmarinic, caffeic, chlorogenic and other hydroxycinnamic acids) are responsible for anti-viral, immune-modulling, antihistamine, antioxidant and antimicrobial properties (Bounihi et al., 2013; Seol et al., 2013; Joukar et al., 2014; Joukar \& Asadipour, 2015; Hamza et al., 2016; Jeung et al., 2016; Safaeian et al., 2016; Shakeri et al., 2016; Sedighi et al., 2019). Furthermore, the plant has for a long time been broadly used as sedative preparation and so as to optimize the irritation of the nervous system (Bayat et al., 2012; de Cássiada Silveirae Sá et al., 2013; FeliúHemmelmann et al., 2013; Akbarzadeh et al., 2015; Ozarowski et al., 2016; Naderi Dastjerdi et al., 2019). There are reports about antihyperglicemia effect of Melissa essential oil in laboratory experiment (Hasanein \& Riahi, 2015), positive effect from regulation of visceral adipose-tissue function in the conditions of nonalcoholic fatty liver diseases caused by high-fat diet (Kim et al., 2017). Park et al. (2015) indicate that angiogenesis inhibitor ALS-L1023 of M. officinalis helps to decrease the adipose tissue mass. Melissa speeds up the rates of restoration of traumas of the spinal marrow (Hosseini, 2020). Traditional Persian Medicine recommends rosmarinic acid-containing lemon balm as a dietary component for improving memory, treating cognitive disorders and, due to its antiamyloidogenic and other properties, for consumption when having Alzheimer's disease (Iranshahy \& Javadi, 2019). Its flavour is generated by geraniol (3-40\%), neral (3-35\%), geranial (4-85\%), (E)-caryophyllene
(0-14\%), and citronellal (1-44\%) (Setzer, 2009). Lemon balm has been traditionally used as tonic, antispasmodic, carminative, diaphoretic, surgical dressing for wounds, sedative-hypnotic preparation that strengthens the memory, and relieves of stress-induced headaches, though modern pharmacology evalueates its efficacy against mild to moderate Alzheimer's diseases, migraines and rheumatism, antitumel and antioxidant activities (Moradkhani et al., 2010).

M. officinalis is widely used not only in the traditional medicine of the Old World, but in the folk medicine of the Americas as well. For instance, in the state of Rio Grande do Sul (South Brazil), this plant is used (Gross et al., 2019) against symptoms related to the central nervous system (M. officinalis was included in $77.7 \%$ of ethnobotanical that cited 94 species of plants). Records of practices involving $M$. officinalis in traditional medicine are reported mostly for European countries, Mediterranean region and Middle East countries (Shakeri et al., 2016).

Lemon balm is third plant according to the content of antioxidants out of 57 species of spicy and medicinal plants used in the experiment (Sammar et al., 2019). Citral it contains is able to efficiently inhibit cancer cells and induce cell apoptosis (Bailly, 2020). Its complex anticancer mechanism involves three actions: (I) the preparation leads to accumulation of reactive oxygen types in cancer cells, thus entailing an oxidative burst and damage to DNA, (II) a colchicine-like inhibition of tubulin polymerization and promotion of microtubule depolymerization, associated with inhibition of the microtubule affinity-regulating kinase MARK4, and (III) a potent inhibition of aldehyde dehydrogenase isoform ALDH1A3, related to cancer stem cell proliferation and chemoresistance (Bailly, 2020). Unfortuanately, the citral's potential is limited, mostly due to insufficient stability of the drug and its low bioavailability, and low selectivity for cancer cells against non-tumour cells. Nonetheless, citral is promising for development of effective analogues and drug combinations having a reinforced potential to treat tumours (Bailly, 2020).

Rosmarinic acid, present in many plants of Laminiaceae family, is broadly used as culinary herbs: Ocimum basilicum L. (basil), Ocimum tenuiflorum L. (holy basil), M. officinalis L. (lemon balm), Salvia rosmarinus Spenn. (rosemary), Origanum majorana L. (marjoram), Salvia officinalis L. (sage), Thymus vulgaris L. (thyme) and Mentha $\times$ piperita L. (peppermint) (Clifford, 1999; Sik et al., 2019). Rosmarinic acid is a secondary metabolite of plants, which they synthesize to protect themselves against fungi and bacteria, as well as herbivorous organisms. Plant contains rosmarinic acid in the vacuoles, separately from oxidase enzymes. In case of plant's trauma, oxidases influence the rosmarinic acid, and the phenol hydroxyl group of rosmarinic acid become oxidized to orto-chinons. They bind with proteins of bacteria, fungi or herbivorous animal, thus inactivating them (Häusler et al., 1993). Rosmarinic acid of Lamiaceae plants exerted inhibition of chlorine esterase, and was reported to be effective in dementia intervention. Shinjyo \& Green (2017) reviewed the reports on efficiency of these herbs, finding seven out of eight articles on lemon balm indicating its positive effects on mood and cognition, while one study observed no effect (Shinjyo \& Green, 2017). The summary by Shakeri et al. (2016) describes the botanical characterization, traditional uses, phytochemistry, pharmacological activities, pharmacokinetics and toxicity of M. officinalis, and discusses blanks in the data and perspectives of surveying this plant.

M. officinalis and its major constituent - rosmarinic acid - exhibit powerful antioxidant and anti-inflammatory activities. Likewise, studies demonstrated that $M$. officinalis and rosmarinic acid mitigates the effects of memory loss caused by Alzheimer's disease (Eivani \& Khosronezhad, 2020). Rosmarinic acid is considered to be metabolized by gut microbiota, thus providing phenolic elements that may be absorbed more easily. In the human organism, molecules of rosmarinic acid alter their structure, undergo conjugation reactions, and are removed with excrements (Hitl et al., 2021).

Lavandula angustifolia Mill. is a perennial shrub of Lamiaceae family. Height of cultivated plants reaches $100-200 \mathrm{~cm}$, and the plants in the nature grow up to $50-70 \mathrm{~cm}$. The leaves are opposite, elongated-linear, with bent margins, $2-6 \mathrm{~cm}$ in length, grey-green from the indumentum. All the parts of the plant contain essential oil: leaves - up to $0.4 \%$, the stems - to $0.2 \%$, inflorescences $-3.5-4.5 \%$. The main constituents of the essential oil (30-60\%) are complex ethers of L-linalool alcohol and acids (acetic, butyric, valeric, and caproic acids). Furthermore, it was found to 
contain cineol, geraniol, borneol (Karabagias et al., 2019). The gas chromatography revealed the shares of the main components to equal as follows: linalyl acetate $(25-46 \%)$, linalool $(20-45 \%)$, terpinen-4-ol $(1.2$ $6.0 \%)$, lavendulyl acetate $(>1.0 \%), 1,8$-cineole $(<2.5 \%), 3$-octanone $(<2.5 \%)$, camphor $(<1.2 \%)$, limonene $(<1.0 \%)$, and alpha-terpineol $(<2.0 \%)$ (Koriem, 2021). Flowers and oil of lavender are used as a culinary spice. It is particularly popular in Spanish, French and Italian cuisines. Sedative effect of lavender during neurasthenia and heightened pulse is achieved through baths. It is also used in dental practice for inhalation treatment of rhinites, laryngitis; it is applied to speed up the wound healing after surgeries (Wang et al., 2012; Yu \& Seol, 2017; Mekonnen et al., 2019). Lavender oil is used to improve the odor of medicines. In folk medicine, the alcohol solutions of oil of lavender and inflorescence are applied to treat migranes, neurasthenia, stress (Kennedy \& Wightman, 2011; Lundstrom et al., 2017; Uritu et al., 2018), rheumatism, heartvascular diseases, kidney-stone disease and pyelonephritis, for medical baths during joint inflammation, for would-healing, durig skin diseases and neuralgias, bruises and paralyses (Ziaee et al., 2015; Sadeghzadeh et al., 2017; Samarth et al., 2017; Xu et al., 2017; Cardia et al., 2018; Boukhatem et al., 2020). In households, the flowers of lavender are used to scare off mosquitoes, blackflies and no-see-ums, and protect fur goods against moths. Similarly to other species of Laminiaceae family, lavender is a good nectar-bearer whose honey is considered healing. Lavender hybrids are called lavandins. Hybrids between $L$. angustifolia and $L$. latifolia (spike lavender) are called Lavandula $\times$ intermedia. They bloom later than the common English lavenders. Based on lavender, complex medicinal nano particle-containing preparations are developed (Shokri et al., 2017; Belova et al., 2019).

For centuries, the most commonly used species of Lavandula genus have been $L$. angustifolia, $L$. latifolia, $L$. stoechas and $L . \times$ intermedia (Cavanagh \& Wilkinson, 2002; Woronuk et al., 2011). Despite the research data on this subject oftentimes being inconclusive and controversial, the benefits of lavender have nonetheless been confirmed by a number of studies (Cavanagh \& Wilkinson, 2002). The surveys mainly focused on its effect on pain, anxiety, learning, memory, attention, arousal, relaxation, sedation and sleep (Dobetsberger \& Buchbauer, 2011). Constituents of lavender essential oil have immune-moduling activity, increase phagocytic activity of macrophages toward the bacteria (Peterfalvi et al., 2019). Likewise, it is being considered for treatment of epilepsy, stress, dementia and Alzheimer's disease (Dobetsberger \& Buchbauer, 2011; Oskouie et al., 2018). Essential oils from L. angustifolia improved cognitive performance and took positive effects on animals and humans suffering neurodegenerative disorders such as Alzheimer disease and dementia (Ayaz et al., 2017). Also, this oil was reported to have neuroprotective effects (Ayaz et al., 2017). Lavender and lavandin essential oils prepared by stem distillation are usually composed of terpenes (e.g. linalool and linalyl acetate) and terpenoids (e.g. 1,8-cineole), responsible for their distinctive flavour and biological and therapeutic properties (Lesage-Meessen et al., 2015). Extract from $L$. angustifolia exhibited positive influence of motor dysfunction on the model of SCI bruise and contributed to the morphological improvement, having therapeutic potential for treatment of spinal cord damage (Kaka et al., 2019). Traditional medical practices all around the globe prescribe essential oils to treat a number of health issues (Raut \&Karuppayil, 2014). The study by Todorov et al. (2014) discussed phytochemical composition of the essential oil concerning the influence on particular stages of viral life. The composition of the essential oil of the plant varies depending on various climates, as well as light, nutrients, temperature, and cultural practice genotype and oter factors. Nonethless, the major components are always citral (geranial and neral), citronellal, geraniol (Moradkhani et al., 2010).

Herbal essential oils are being more and more often used in pharmacology, medicine and food processing (Greff et al., 2020). Lemon balm and lavender are among the top ten most broadly applied medicinal and aromatic plants (Greff et al., 2020). Well-substantiated is the woundhealing property of essential oil of lavender (Samuelson et al., 2020). It significantly enhanced would healing and heightened the expression level of collagen, as well as activity of proteins taking part in tissue remodeling in wounds (Samuelson et al., 2020). Through studies of essential oil, it is possible to identify new bioactive compounds and find formu- lae of new preparations to treat cardiovascular diseases such as arterial hypertension, angina pectoris, heart failure, and myocardial infarction (Saljoughian et al., 2018). Over the recent five years, in the USA, health care-expenses related to cardiovascular diseases have increased $50 \%$, accounting for 350 billion dollars (Bojic et al., 2019). In the recent decade, the number of research on antiaggregatory effect of polyphenol increased two-fold. Bojic et al. (2019) reviewed the antiaggregatory effects of most abundant polyphenols and flavonoids and plyphenols-rich plants (for example $L$. angustifolia and $M$. officinalis) on platelet aggregation, association of chemical composition and antioxidant properties with the observed biological effect, and possible clinical significance of the results they published. Cardiovascular diseases are among the most damaging health issues nowadays. Strokes and heart attacks often cause death, and another threat is posed by development of thrombus. Therefore, the therapy pays great attention to the level of primary hemostasis, first of all the clot formation, using acetylsalicyc acid and clopidogrel treatment. Use of plants rich in polyphenols to prevent thrombus development is relevant, as indicated by the two-fold increase in research on this issue over the last decade (Bojic et al., 2019).

Vitex agnus-castus L. is a tree-like shrub of the Lamiaceae family of up to $800 \mathrm{~cm}$ height. The plant is grey from pubulent dense adjascent hairs with distinctive aroma. The leaves are large, opposite, palmate, on long petioles. Has numerous blue flowers. Its range comprises North Africa, Southern Europe, West Asia, Transcaucasia, and Central Asia (Artz, 2007; Brown \& Murray, 2012). It has been cultivated in gardens as an ornamental plant since the Middle Ages. The medicinal raw material is leaves, flowers, fruits, branches, and more rarely bark (Ross, 2001). All the parts of the plant contain iridoidglycoside (agnuside, aucubin), flavonoids (casticin, vitexin, isovitaxin, orientin, isoorientin), p-hydroxybenzoicacid, alkaloids, tannins, essential oil (Stojković etal., 2011). The essential oil from leaves contains 1,8-cineole, trans-beta-farnesene, alphapinene, trans-beta-caryophyllene, andterpinen-4-ol. The oil from leaves of $V$. agnus-castus contains 46 compounds. The major constituents of the leaves are 1,8-cineole $(22.0 \%)$, trans-beta-farnesene (9.4\%), alpha-pinene (9.4\%), trans-beta-caryophyllene (8.2\%), terpinen-4-ol (7.8\%), limonene (4.8\%), alpha-terpineol (3.8\%), sclarene (3.3\%), alpha-terpinyl acetate (3.1\%), p-cymene (3.0\%) (Stojković et al., 2011). 1,8-cineole and alphapinene exerted notable antimicrobial potency as well (Stojković et al., 2011). The oil, particularly such from white flowering plants, is surveyed for its potential antibacterial effects (Stojković et al., 2011). Extract from V. agnus-castus exhibited the greatest cytotoxic activity out of 57 medicinal plants tested in the experiment (Sammar et al., 2019). The authors also indicate that powerful cytotoxicity is not related to low concentrations of antioxydants in it, but manifests through other signal pathways. The ripe fruit of $V$. angus-castus could be a promising anticancer agent (Kikuchi et al., 2014). Vitex was observed to induce dose- and timedependent decrease in cell viability following the induction of apoptosis and $\mathrm{G}(2) / \mathrm{M}$ cell cycle arrest. Clinical applications of Vitex revealed new data on interaction of Vitex with other conventional drugs able to affect intracellular redox status (Kikuchi et al., 2014). Alpha,beta-unsaturated gamma-lactam moiety, 9 alpha-hydroxy-13(14)-labden-16,15-amide (1), together with five known ones, were isolated from the fruits of $V$. anguscastus (Pal et al., 2013).

Fruits and herbs of $V$. agnus-castus are included in the European pharmacopoeia. The plant is used during insufficient lactation, menstrual period problems, and also as diuretic and irritating preparation. The leaves are added to meat meals, soups, jam and half-smoked sausage, canned fish. During food preservation, vitex is used as a substitute of allspice. In men's bodybuilding, it is used to control testosterone level. Vitex-based preparations are used in gynecology during premenstrual syndrome accompanied by edemas, poor bleedings or absence of them, anovulatory cycles, period disorders after using birth control preparations, infertility related to hyperprolactinaemia, breast pains (Arzi et al., 2019). For this purpose, the plant is processed to prepare cyclodynon, mastodynon, pregnatone, prefemin, biocycline, and others. Vitex is traditionally recommended medicine against premenstrual stress syndrome, premenstrual dysphoric disorder and other reproductive health issues in women. Nonetheless, despite the fact that it is often recommended in Germany, there are some indications that $V$. agnus-castus may lead to complications during 
pregnancy. In the studies by Maleki-Saghooni et al. (2018), V. agnus-castus and $M$. officinalis mitigated symptoms of premenstrual syndrome (PMS).

Safarabadi et al. (2018) consider $L$. officinalis and $V$. agnus-castus some of the most important analgesic plants. The research notes that the herbs have anti-nociceptive effects, inhibition of the release of arachidonic acid, synthesis of prostaglandins and action toward the opioid system, with peripheral anti-nociceptive mechanism and cholinergic pathways, stimulation of GABA A receptors, COX-1 and 5- $\mathrm{LO}$ and central and environmental mechanisms (Safarabadi et al., 2018).

Nonetheless, topically applied herbal medicinal preparations made of L. angustifolia may lead to such side-effects as contact dermatitis (Gangemi et al., 2015). Biological properties of linalool, namely sedative, anxiolytic, analgesic, anticonvulsant, anti-inflammatory, local anaesthetic, are discussed in the context of the molecule's chirality influence, the mechanisms of activity and type of study (in vitro, in vivo, clinical studies) (Aprotosoaie et al., 2014). The recently obtained data on properties of linalool to skin synthesis are considered in report by Aprotosoaie et al. (2014).

Despite the relatively thorough degree of study of the chemical composition and application of those plants during separate human and animal diseases (Wynn \& Fougère, 2007; Lee et al., 2014; Zarei et al., 2014; Kubo et al., 2015; Saberi et al., 2016; Dolatabadi et al., 2018; EFSA Panel et al., 2020; Torki et al., 2021), no complex impact of these three species of medicinal plants during high-fat diet and excessive consumption of food was found. Therefore, the objectives of this study were overall effects of M. officinalis, L. angusti folia, $V$. agnus-castus on weight gain, changes in index of body weight, biochemical and morphological blood parameters, orienting-motor activity and emotional status of white laboratory rats against the background of excessive fat diet.

\section{Materials and methods}

Selection of animals for the experiment, the study protocols, euthanasia of animals were approved by the local ethics committee of the Dnipro State Agrarian-Economical University. Content, feeding, care for the animals and withdrawal of the animals from the experiment were performed following the principles formulated in the European Convention for the Protection of Vertebrate Animals used for Experimental and Other Scientific Purposes (Strasburg, March 18, 1986, ETS No. 123) and the order No. 3447-IV as of 21.02.2006 "On protection of animals against abuse" (Ukraine).

In the experiment, we used 32 adult white outbred laboratory male rats of $200 \pm 10 \mathrm{~g}$ weight. The rats were divided into the control and experimental groups with 8 animals in each. The rats were kept in polycarbonate cells with steel grid covers, food pit, 4 individuals per a cell. The rats were maintained in the room with the temperature of $20-22^{\circ} \mathrm{C}$ and relative air moisture of $50-65 \%$. Light regime was $12 \mathrm{~h}$ of light and $12 \mathrm{~h}$ of dark. The ventilations were performed according to the regime. The animals received water ad libitum.

The diet of all animals had excessive fat content $(3,600 \mathrm{ccal} / \mathrm{kg})$ High-fat diet was composed based on the standard diet ( $75 \%$ of grain mixture (maize, sunflower seeds, wheat, barley), $8 \%$ of root vegetables (potatos, carrot), $2 \%$ of meat and bone meal, $2 \%$ of mineral-vitamin complex) with introduction of $15 \%$ of sunflower oil. The control group of animals received high-fat diet, while the experimental group was fed with high-fat diet supplemented with the medicinal plants. The first experimental group, in addition to high-fat diet, was given 5\% dry crumbled young shoots of $L$. angustifolia; the second experiment $-5 \%$ M. officinalis; the third experimental $-5 \% \mathrm{~V}$. agnus-castus. The main ingredients of the diet were crushed in the mill (grain, meat and bone meal, mineral-vitamin complex, dry shoots of medicinal plants) and mixed. Then we have added sunflower oil, and prepared granules assessing the amount equaling 4,200 $\mathrm{g}$ for each group for the whole period of the experiment (30 days). Fresh root vegetables in the corresponding amount were given additionally daily. The animals had free access to the food. During the experiment, we recorded the amount of food consumed by each group a day and its total amount thoughout the experiment.

Morphometric parameters (live mass, belly volume) were determined on the first and the 30th days of the experiment (Lieshchova et al., 2018, 2019, 2020). The calculated parameters were the overall increase in live mass and daily weight gains.

Orienting-motor activity and emotional status of the organisms of the experimental animals were studied in the "open field" test using an installation of $1 \mathrm{~m}^{2}$ square area divided into 16 squares and limited nontransparent $20 \mathrm{~cm}$-heigh wall. The experiment was performed in complete silence with intense light on the field itself. An experimental animals had been taken from the cage from previously shadowed compartment and placed in the center of the field. The exposure time was 2 min. The animals were tested for 4 days (1-4th days) at the beginning of the experiment and 4 days at the end (26-30th). We counted the number of squares the animals passed: peripheral and central ones - we assessed moving activity; peripheral (with reliance on the wall) and central (without reliance on the wall) stances - orienting activity; the amount of acts of grooming, defecation and urination - emotional status (Fig. 1).

The animals were euthanized on the 30th day of the experiment under narcosis $(80 \mathrm{mg} / \mathrm{kg}$ of cetamine and $12 \mathrm{mg} / \mathrm{kg}$ of xylazine, intraperitoneal injection) by cardiac exsanguination. After the autopsy, we visually assessed the condition of the internal organs on the presence of pathological changes. The extraction of the organs and the tissues (heart, liver, lungs, thymus, spleen, stomach, thin and large intestines, kidneys) was carried out using surgical tools. The weight of the internal organs was determined with the accuracy of $\pm 0.01 \mathrm{~g}$.
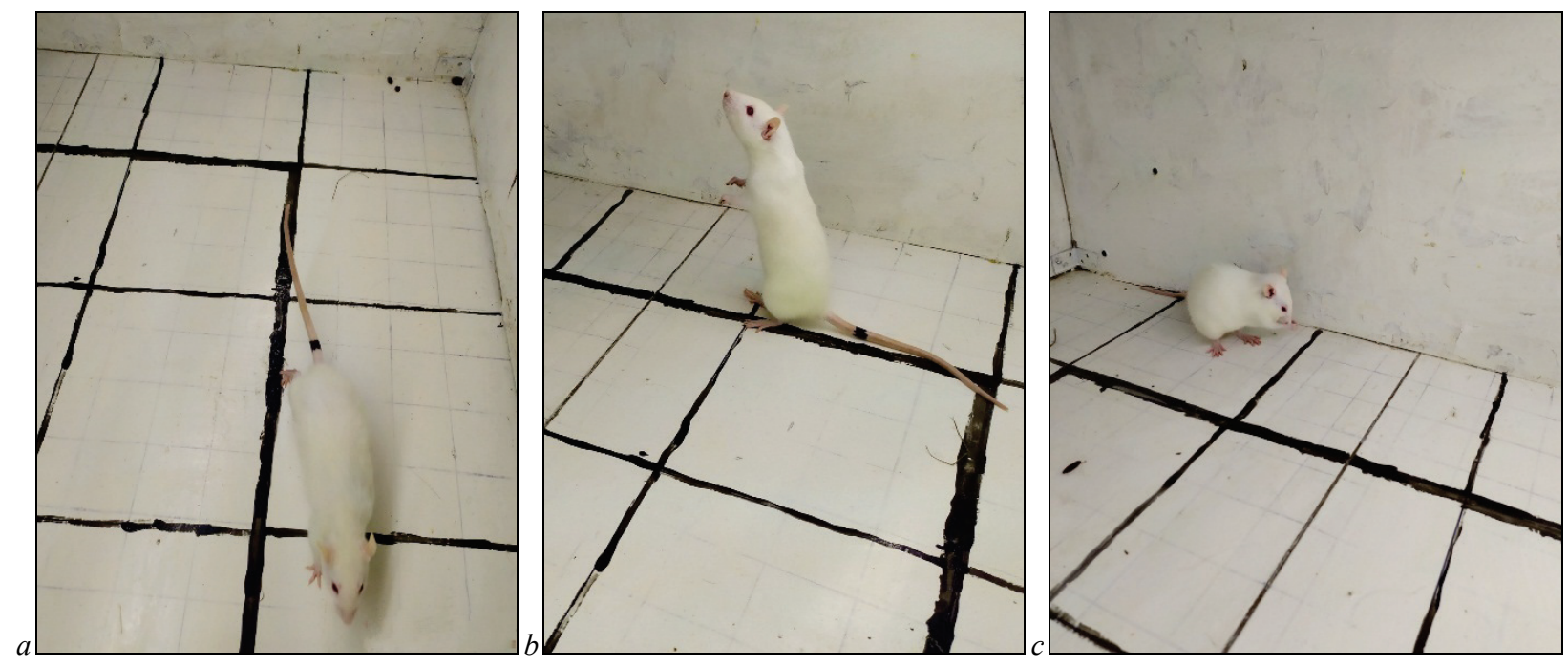

Fig. 1. Behaviour of rats in the "open field" test: $a$-crossing of peripheral squares, $b$-central stance, $c$-act of grooming 
Blood samples taken during te euthanasia were then used for biochemical and morphological assays. Biochemical parameters were determined using Miura automated analyzer (I.S.E. Srl, Italy) and a set of HighTechnology reagents (USA), PZCormay S.A. (Poland) и Spinreact S.A. (Spain). The erythrocytes and leukocytes in stabilized blood were counted using automated BC-2800Vet analyzer (Mindray, China).For the leukogam, we prepared blood smears according to Pappenheim with subsequent Romanovsky-Giemsa staining. The numbers of erythrocytes and leukocytes in stabilized blood of mice were determined using automatic haematological analyzer BC-2800Vet and Mindray (Lieshchova et al., 2018, 2019, 2020; Brygadyrenko et al., 2019).

The data were analyzed using Statistica 8.0 program (StatSoft Inc., USA). The tables demonstrate the results as $\mathrm{x} \pm \mathrm{SD}$ (standard deviation). Differences between the values of the control and experimental groups were determined using the Tukey test, where the differences were considered significant at $\mathrm{P}<0.05$.

\section{Results}

The median of the body weight on the 11th day increased to $110.2 \%$ compared with the initial weight in the control group of animals (Fig. 2a). By the end of the experiment (by the 30th days), the body weight did not exceed $112.0 \%$ of the initial weight. Stems of $L$. angustifolia caused almost even gain in body weight of the animals to $139.2 \%$ by the 30 th days as compared with the initial weight for this group. Male rats that consumed shoots of $M$. officinalis, to the 30th days of the experiment, had the weight of $134.5 \%$ of their individual initial weight (Fig. 2b). Shoots of $V$. angus-castus caused slower weight gain than lavender and lemon balmto $118.8 \%$ of the body weight at the beginning of the experiment (Fig. 2c).

Shoots of $L$. angustifolia and $M$. officinalis significantly decreased the food intake to $83.0 \%$ and $84.1 \%$ compared with the control respectively (Table 1). Water intake in the experimental groups was no different from the control.

At the same time, adding shoots of $L$. angustifolia and M. officinalis caused reliable (more than 2.5-fold) increase in the mean daily body weight gain (Table 1): instead of $700 \mathrm{mg} /$ day, the animals gained 1,943 and $2,024 \mathrm{mg} /$ day, respectively. Herbs of $V$. angus-castus led to less notable and statistically insignificant increase (up to $138.1 \%$ of the control Table 1

Change in the body weight and food consumption of young male rats under the impact of addition of crumbled shoots of Lavandula angustifolia Mill., Melissa officinalis L. and Vitex angus-castus L. to their $\operatorname{diet}(\mathrm{x} \pm \mathrm{SD}, \mathrm{n}=8$, duration of experiment -30 days)

\begin{tabular}{|c|c|c|c|c|c|c|c|}
\hline Parameter & Control & L. angustifolia & $\begin{array}{l}\text { L. angustifolia } \\
\text { compared to the } \\
\text { control, } \%\end{array}$ & M. officinalis & $\begin{array}{l}\text { M. officinalis } \\
\text { compared to the } \\
\text { control, } \%\end{array}$ & V. angus-castus & $\begin{array}{l}V \text {. angus-castus } \\
\text { compared to the } \\
\text { control, } \%\end{array}$ \\
\hline $\begin{array}{l}\text { Consumption of food } \\
\text { by animals, g/day }\end{array}$ & 20.09 & 16.67 & 83.0 & 16.90 & 84.1 & 18.81 & 93.6 \\
\hline $\begin{array}{l}\text { Consumption of liquid } \\
\text { by animals, g/day }\end{array}$ & 18.42 & 18.50 & 100.5 & 19.05 & 103.4 & 18.93 & 102.8 \\
\hline Change in body weight, $\mu \mathrm{g} /$ day & $700 \pm 271$ & $1943 \pm 496^{* * *}$ & 277.6 & $2024 \pm 393 * * *$ & 289.1 & $1171 \pm 417$ & 167.3 \\
\hline Change in body weight, $\% /$ day & $13.6 \pm 5.9$ & $35.7 \pm 8.0 * * *$ & 261.7 & $36.7 \pm 7.9^{* * *}$ & 269.3 & $18.8 \pm 6.5$ & 138.1 \\
\hline Объем живота, см & $14.0 \pm 0.5$ & $14.0 \pm 0.9$ & 99.9 & $13.8 \pm 0.4$ & 98.9 & $14.8 \pm 1.0$ & 106.0 \\
\hline
\end{tabular}

Note: ${ }_{-}^{*} \mathrm{P}<0.05,{ }^{* *}-\mathrm{P}<0.01,{ }^{* *}-\mathrm{P}<0.001$, significant differences within one line of the table according to the results of ANOVA with Bonferroni correction.

Table 2

Changes in relative mass of the organs (\%) of male rats under the influence of addition of crumbled shoots of Lavandula angustifolia Mill., Melissa officinalis $\mathrm{L}$. and Vitex angus-castus $\mathrm{L}$. to their $\operatorname{diet}(\mathrm{x} \pm \mathrm{SD}, \mathrm{n}=8$, duration of experiment -30 days)

\begin{tabular}{|c|c|c|c|c|c|c|c|}
\hline Organ & Control & L. angustifolia & $\begin{array}{l}\text { L. angustifolia } \text { com- } \\
\text { pared to the control, } \%\end{array}$ & M. officinalis & $\begin{array}{l}\text { M. officinalis compared } \\
\text { to the control, } \%\end{array}$ & $\begin{array}{l}\text { V. angus- } \\
\text { castus }\end{array}$ & $\begin{array}{l}V . \text { angus-castus com- } \\
\text { pared to the control, } \%\end{array}$ \\
\hline Heart & $0.352 \pm 0.023$ & $0.362 \pm 0.036$ & 103.0 & $0.330 \pm 0.025$ & 93.7 & $0.352 \pm 0.033$ & 100.2 \\
\hline Liver & $4.08 \pm 0.17$ & $4.32 \pm 0.36$ & 105.8 & $3.87 \pm 0.36$ & 94.8 & $3.71 \pm 0.26$ & 91.0 \\
\hline Lungs & $0.979 \pm 0.169$ & $0.880 \pm 0.190$ & 89.9 & $0.872 \pm 0.138$ & 89.2 & $0.967 \pm 0.365$ & 98.8 \\
\hline Brain & $0.867 \pm 0.052$ & $0.700 \pm 0.073^{* * *}$ & 80.8 & $0.738 \pm 0.075^{*}$ & 85.2 & $0.698 \pm 0.142$ & 80.5 \\
\hline Thymus & $0.285 \pm 0.046$ & $0.166 \pm 0.077^{* *}$ & 58.3 & $0.133 \pm 0.040^{* * *}$ & 46.7 & $0.221 \pm 0.043$ & 77.6 \\
\hline Spleen & $0.370 \pm 0.036$ & $0.473 \pm 0.159$ & 128.0 & $0.412 \pm 0.150$ & 111.5 & $0.470 \pm 0.070^{*}$ & 127.0 \\
\hline Stomach & $0.699 \pm 0.060$ & $0.769 \pm 0.211$ & 110.0 & $0.764 \pm 0.206$ & 109.4 & $0.847 \pm 0.266$ & 121.3 \\
\hline Small intestine & $2.58 \pm 0.52$ & $2.16 \pm 0.25$ & 83.8 & $2.20 \pm 0.25$ & 85.0 & $2.44 \pm 0.32$ & 94.7 \\
\hline Cecum & $0.509 \pm 0.176$ & $0.457 \pm 0.099$ & 89.9 & $0.422 \pm 0.077$ & 82.9 & $0.509 \pm 0.262$ & 100.1 \\
\hline Large intestine & $0.374 \pm 0.085$ & $0.397 \pm 0.121$ & 106.2 & $0.400 \pm 0.082$ & 107.0 & $0.431 \pm 0.089$ & 115.4 \\
\hline Rectum & $0.398 \pm 0.073$ & $0.307 \pm 0.077$ & 77.2 & $0.203 \pm 0.104^{* *}$ & 51.0 & $0.366 \pm 0.063$ & 92.0 \\
\hline Right kidney & $0.358 \pm 0.031$ & $0.321 \pm 0.027$ & 89.6 & $0.317 \pm 0.031$ & 88.4 & $0.310 \pm 0.026$ & 86.4 \\
\hline Left kidney & $0.372 \pm 0.040$ & $0.319 \pm 0.022$ & 85.7 & $0.321 \pm 0.039$ & 86.4 & $0.308 \pm 0.030$ & 82.8 \\
\hline
\end{tabular}

Note: see Table 1. group) in daily body weight increment of the animals compared with the sed by the three tested species of plants. Under the influence of addiof the shoots of $L$. angustifolia and M. officinalis to the diet, we seen (he rats. When consignificantly decreased (to $58.3 \%$ and $46.7 \%$ of the relative mass of the thymus in animals of the control group, respectively). Intake of the shoots of $V$. angus-castus led to statistically significant increase in the relative (Table 2). , which manifested in almost two-fold elevation of the level of was in the norm. Also, consumption of large amount of fat caused increase in the glucose level, whereas during addition of medicinal plants to the diet, this parameter remained within the values of the norm. Activity of refence values, indicating somewhat damage to hepatocytes, while the (ne absolute weight of the organ, absence of macroscopic signs protein) were within the norm

Intake of lavender shoots stimulated notable increase in alkaline phosphatase (to $349.7 \%$ of the levels of the control group), concentration LDL cholesterol (to $227.7 \%$ ) and moderate significant increase in the Consumption of crumbled shoots of lemon balm caused great increase in 列 zyme in the control group), decrease in the concentration of urea nitrogen (to $79.0 \%$ ), total bilirubin (to $63.3 \%$ ) and triglycerides (to $63.1 \%$ ) in blood ing ince phosp(to $406.2 \%$ of the control group), index of aterogenecity (to $524.0 \%$ of the control group) first of all due to decrease in the concentration of HDL cholesterol (to $51.9 \%$ of the control group). Also, there was seen decreases in the concentration of triglycerides (to $56.4 \%$ of the control group) and glucose (to $80.9 \%$ of the control group, Table 3 ). 


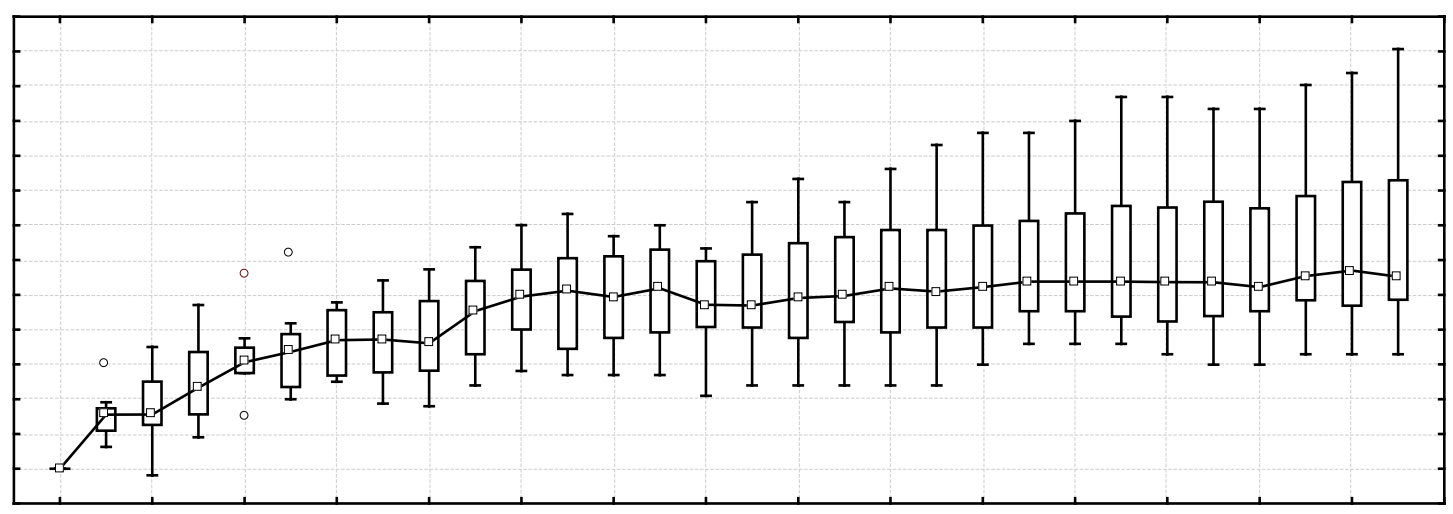

$a$

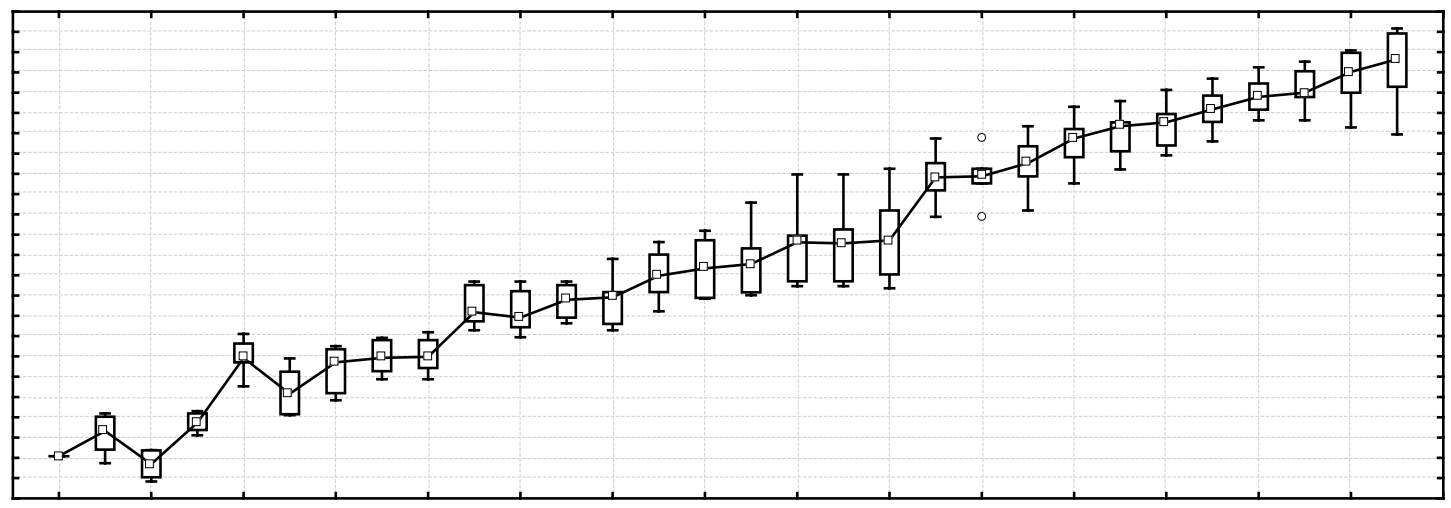

$b$

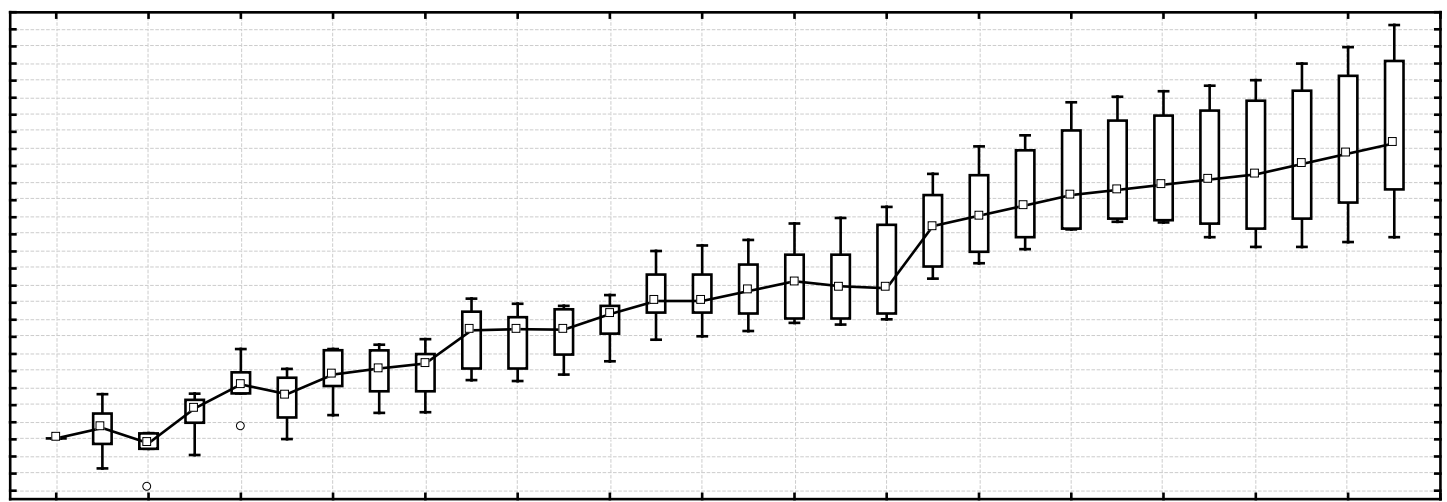

$c$

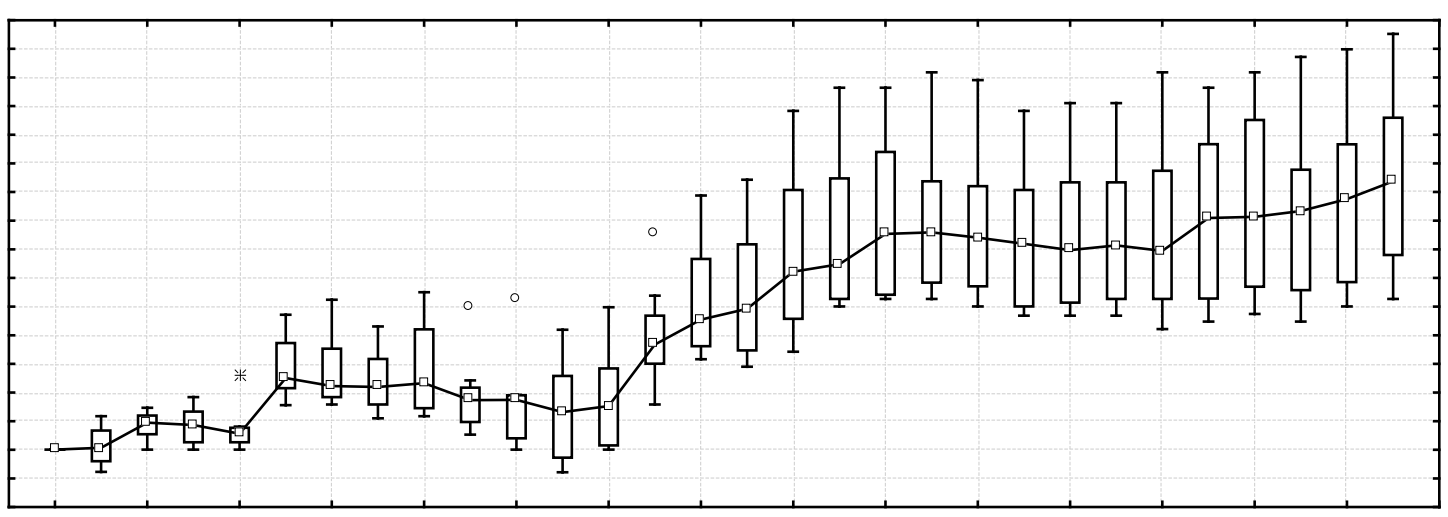

$d$

Fig. 2. Changes in the body weight of the rats in the control variant of the experiment (a) and when adding grined seeds of Lavandula angustifolia Mill. (b), Melissa officinalis L. (c) and Vitex angus-castus L. (d) into the diet: on the abscissa axis - $24 \mathrm{~h}$ of the experiment, on the ordinate axis - body weight of the animals ( $\%$ of the initial wody weight before the experiment, considered $100 \%$ for each experimental animal); small square - median, upper and lower borders of the square $-75 \%$ and $25 \%$ of quartiles, the upper line - minimum and maximum values, circles - emissions; $n=8$ 
Analysis of protein metabolism revealed that high-fat diet did not increase the concentration of the total protein. Addition of vitex and lemon balm to high-fat diet elevated the level of total protein beyond the limits of the normal values, while lavender has not. At the same time, in all groups, we observed slight increase in globuline fraction, especially noted at addition of Vitex.

High-fat diet did not significantly affect the morphological composition of blood of the experimental animals. Almost all the parameters were within the reference values. Exception was the level of monocytes in blood, which in all the groups was 1.5-2.0 times above the normal parameters. Intake of dry shoots of $L$. angustifolia and $M$. officinalis contributed to significant increase in the concentration of leukocytes in blood (to $165.4 \%$ and $199.9 \%$ of the concentration in the control group, respectively), but did not exceed the thresholds of the reference values (Table 4). Consumption of dry herbs of $V$. angus-castus stimulated decrease in con- centration of band neutrophils in blood of rats (four times lower than in the control group, Table 4). General analysis of blood and leukogram of male rats revealed no other significant changes.

Physical activity (Fig. 3a) of the animals was significantly reduced by the end of the experiment after consumption of $L$. angustifolia snd M. officinalis. Under the influence of these plants, orienting activity of the rats also decreased significantly (Fig. 3b). No significant changes in emotional status (Fig. 3c) were seen during the experiment when the animals were fed with all three species of medicinal plants. Addition of the shoots of $V$. angus-castus led to no changes in physical and oriented activity of animals (Fig. 3). Significant changes in the "open field" test at the beginning and the end of the experiment were observed between and inside the groups of rats (Table 5) that consumed the shoots of $L$. angustifolia and M. officinalis for the quantity of the attended peripheral squares and the number of stances in the peripheral squares.

\section{Table 3}

Change in biochemical parameters of blood of males of rats under effect of addition of crumbled shoots of Lavandula angustifolia Mill., Melissa officinalis $\mathrm{L}$. and Vitex angus-castus $\mathrm{L}$. $(\mathrm{x} \pm \mathrm{SD}, \mathrm{n}=8$, duration of experiment -30 days)

\begin{tabular}{|c|c|c|c|c|c|c|c|}
\hline Parameters & Control & L. angustifolia & $\begin{array}{l}\text { L. angustifolia } \\
\text { compared to the } \\
\text { control, } \%\end{array}$ & M. officinalis & $\begin{array}{l}\text { M. officinalis } \\
\text { compared to the } \\
\text { control, } \%\end{array}$ & V. angus-castus & $\begin{array}{l}V \text {. angus-castus } \\
\text { compared to the } \\
\text { control, } \%\end{array}$ \\
\hline Total protein, $\mathrm{g} / \mathrm{L}$ & $77.0 \pm 4.9$ & $76.0 \pm 4.0$ & 98.7 & $80.0 \pm 3.7$ & 103.9 & $86.4 \pm 4.7^{*}$ & 112.2 \\
\hline Albumins, $\mathrm{g} / \mathrm{L}$ & $39.6 \pm 2.6$ & $38.7 \pm 2.5$ & 97.8 & $41.3 \pm 2.2$ & 104.3 & $44.0 \pm 1.7$ & 111.2 \\
\hline Globulins, $\mathrm{g} / \mathrm{L}$ & $37.4 \pm 3.9$ & $37.3 \pm 3.3$ & 99.6 & $38.7 \pm 3.3$ & 103.4 & $42.4 \pm 3.8$ & 113.4 \\
\hline Protein coefficient, $U$ & $1.10 \pm 0.15$ & $1.06 \pm 0.12$ & 96.1 & $1.09 \pm 0.14$ & 98.7 & $1.04 \pm 0.09$ & 94.8 \\
\hline Urea, $\mathrm{mmol} / \mathrm{L}$ & $6.84 \pm 1.02$ & $6.00 \pm 0.74$ & 87.7 & $5.40 \pm 0.58$ & 78.9 & $5.13 \pm 1.48$ & 74.9 \\
\hline Urea nitrogen, $\mathrm{mg} / 100 \mathrm{~g}$ & $13.1 \pm 2.0$ & $11.5 \pm 1.4$ & 87.7 & $10.3 \pm 1.1^{*}$ & 79.0 & $10.6 \pm 1.4$ & 81.3 \\
\hline Creatinine, $\mu \mathrm{mol} / \mathrm{L}$ & $63.0 \pm 4.4$ & $61.0 \pm 7.4$ & 96.8 & $74.9 \pm 12.8$ & 118.8 & $67.0 \pm 11.5$ & 106.3 \\
\hline Aspartate aminotransferase (AST), U/L & $186 \pm 61$ & $160 \pm 48$ & 85.7 & $182 \pm 33$ & 97.8 & $191 \pm 39$ & 102.3 \\
\hline Alanine aminotransferase (ALT), U/L & $131 \pm 41$ & $129 \pm 39$ & 98.5 & $111 \pm 18$ & 85.2 & $179 \pm 46$ & 136.8 \\
\hline De Ritis ratio (AST/ALT), $U$ & $1.63 \pm 0.78$ & $1.37 \pm 0.45$ & 84.2 & $1.64 \pm 0.30$ & 100.9 & $0.94 \pm 0.43$ & 57.9 \\
\hline Alkaline phosphatase, $\mathrm{U} / \mathrm{L}$ & $129 \pm 64$ & $451 \pm 94 * * *$ & 349.7 & $601 \pm 149 * * *$ & 465.7 & $524 \pm 143^{* * * *}$ & 406.2 \\
\hline Total bilirubin, $\mu \mathrm{mol} / \mathrm{L}$ & $6.1 \pm 1.7$ & $4.1 \pm 2.8$ & 67.3 & $3.8 \pm 1.4^{*}$ & 63.3 & $5.7 \pm 1.5$ & 93.6 \\
\hline Glucose, $\mathrm{mmol} / \mathrm{L}$ & $7.39 \pm 1.04$ & $6.36 \pm 0.63$ & 86.1 & $6.40 \pm 0.55$ & 86.7 & $5.97 \pm 0.58^{*}$ & 80.9 \\
\hline Totalcalcium, $\mathrm{mmol} / \mathrm{L}$ & $2.53 \pm 0.09$ & $2.51 \pm 0.11$ & 99.4 & $2.59 \pm 0.14$ & 102.3 & $2.59 \pm 0.16$ & 102.3 \\
\hline Non-organic phosphorus, $\mathrm{mmol} / \mathrm{L}$ & $3.07 \pm 0.58$ & $3.67 \pm 0.40$ & 119.5 & $3.46 \pm 0.29$ & 112.6 & $3.13 \pm 0.57$ & 101.9 \\
\hline RatioofCa/P & $0.843 \pm 0.129$ & $0.686 \pm 0.099$ & 81.4 & $0.743 \pm 0.090$ & 88.1 & $0.857 \pm 0.192$ & 101.7 \\
\hline $\begin{array}{l}\text { Gamma-glutamyl transpeptidase } \\
\text { (GGT), units/L }\end{array}$ & $9.3 \pm 2.6$ & $9.1 \pm 4.4$ & 98.5 & $6.7 \pm 0.7$ & 72.3 & $6.4 \pm 1.2$ & 69.2 \\
\hline Cholesterol, $\mathrm{mmol} / \mathrm{L}$ & $1.27 \pm 0.13$ & $1.59 \pm 0.20^{*}$ & 124.7 & $1.43 \pm 0.18$ & 112.4 & $1.43 \pm 0.07$ & 112.4 \\
\hline Tryglicerides, $\mathrm{mmol} / \mathrm{L}$ & $2.13 \pm 0.55$ & $1.36 \pm 0.38$ & 63.8 & $1.34 \pm 0.31^{*}$ & 63.1 & $1.20 \pm 0.38^{* *}$ & 56.4 \\
\hline $\begin{array}{l}\text { High-dense lipoprotein cholesterol } \\
\text { (HDL cholesterol),mmol/L }\end{array}$ & $0.65 \pm 0.13$ & $0.66 \pm 0.19$ & 101.5 & $0.80 \pm 0.44$ & 122.6 & $0.34 \pm 0.24 *$ & 51.9 \\
\hline $\begin{array}{l}\text { Low-dense lipoprotein cholesterol } \\
\text { (LDL cholesterol), } \mathrm{mmol} / \mathrm{L}\end{array}$ & $0.52 \pm 0.29$ & $1.18 \pm 0.08^{* * *}$ & 227.7 & $0.51 \pm 0.11$ & 98.0 & $0.95 \pm 0.40$ & 184.3 \\
\hline C-reactive protein, $\mathrm{mg} / \mathrm{L}$ & $12.5 \pm 5.4$ & $13.2 \pm 5.2$ & 105.7 & $10.2 \pm 1.4$ & 81.7 & $12.6 \pm 3.0$ & 100.3 \\
\hline Aterogenecity index, units & $1.04 \pm 0.45$ & $1.85 \pm 1.41$ & 177.1 & $1.30 \pm 0.91$ & 124.5 & $5.57 \pm 3.32^{* * *}$ & 524.0 \\
\hline
\end{tabular}

Note: see Table 1.

\section{Table 4}

Change in general analysis of blood and leukogram of male rats under effect of intake of crumbled shoots of Lavandula angustifolia Mill., Melissa officinalis $\mathrm{L}$. and Vitex angus-castus $\mathrm{L} .(\mathrm{x} \pm \mathrm{SD}, \mathrm{n}=8$, duration of experiment-30 days)

\begin{tabular}{|c|c|c|c|c|c|c|c|}
\hline Parameter & Control & L. angustifolia & $\begin{array}{l}\text { L. angustifolia } \\
\text { compared to the } \\
\text { control, } \%\end{array}$ & M. officinalis & $\begin{array}{c}\text { M. officinalis com- } \\
\text { pared to the control, } \\
\%\end{array}$ & V. angus-castus & $\begin{array}{l}V . \text { angus-castus } \\
\text { compared to the } \\
\text { control, } \%\end{array}$ \\
\hline Hemoglobin, $g / L$ & $126.8 \pm 7.0$ & $119.3 \pm 7.1$ & 94.1 & $130.4 \pm 6.9$ & 102.8 & $126.7 \pm 11.8$ & 99.9 \\
\hline Hematocrit, $\%$ & $40.5 \pm 2.7$ & $38.6 \pm 2.4$ & 95.3 & $42.0 \pm 1.9$ & 103.6 & $40.3 \pm 4.0$ & 99.5 \\
\hline Erythrocytes, $10^{12} / \mathrm{L}$ & $6.93 \pm 0.29$ & $7.13 \pm 0.30$ & 102.8 & $7.03 \pm 0.91$ & 101.3 & $7.32 \pm 0.67$ & 105.6 \\
\hline $\begin{array}{l}\text { Erythrocyte sedimentation rate } \\
\text { (ESR), } \mathrm{mm} / \mathrm{h}\end{array}$ & $1.17 \pm 0.37$ & $1.33 \pm 0.47$ & 114.3 & $1.00 \pm 0.00$ & 85.7 & $1.00 \pm 0.00$ & 85.7 \\
\hline Thrombocytes, $10^{9} / \mathrm{L}$ & $339 \pm 66$ & $351 \pm 87$ & 103.7 & $336 \pm 66$ & 99.3 & $284 \pm 72$ & 83.7 \\
\hline Leukocytes, $10^{9} / \mathrm{L}$ & $8.6 \pm 1.6$ & $14.2 \pm 2.3^{* * *}$ & 165.4 & $17.1 \pm 5.9^{* * *}$ & 199.9 & $11.3 \pm 6.1$ & 131.6 \\
\hline \multicolumn{8}{|l|}{ Leukocytic formula } \\
\hline Basophils, $\%$ & $0.0 \pm 0.0$ & $0.0 \pm 0.0$ & 0.0 & $0.0 \pm 0.0$ & 0.0 & $0.0 \pm 0.0$ & 0.0 \\
\hline Eosinophils, \% & $1.50 \pm 0.76$ & $1.17 \pm 0.37$ & 77.8 & $1.57 \pm 0.73$ & 104.8 & $0.86 \pm 0.35$ & 57.1 \\
\hline Mielocits, \% & $0.0 \pm 0.0$ & $0.0 \pm 0.0$ & 0.0 & $0.0 \pm 0.0$ & 0.0 & $0.0 \pm 0.0$ & 0.0 \\
\hline Neutrophils, \%: & & & & & & & \\
\hline -young & $0.0 \pm 0.0$ & $0.0 \pm 0.0$ & 0.0 & $0.0 \pm 0.0$ & 0.0 & $0.0 \pm 0.0$ & 0.0 \\
\hline -band & $1.17 \pm 0.69$ & $1.17 \pm 1.07$ & 100.0 & $0.71 \pm 0.45$ & 61.2 & $0.29 \pm 0.45^{*}$ & 24.5 \\
\hline - with segmented nuclei & $23.0 \pm 8.2$ & $22.3 \pm 5.1$ & 97.1 & $25.6 \pm 6.4$ & 111.2 & $21.0 \pm 4.4$ & 91.3 \\
\hline Lymphocytes, \% & $68.8 \pm 8.6$ & $67.2 \pm 6.3$ & 97.6 & $65.9 \pm 6.9$ & 95.7 & $72.1 \pm 3.6$ & 104.8 \\
\hline Monocytes, \% & $5.5 \pm 1.3$ & $8.2 \pm 3.3$ & 148.5 & $6.3 \pm 2.3$ & 114.3 & $5.6 \pm 1.7$ & 101.3 \\
\hline
\end{tabular}

Note: see Table 1. 

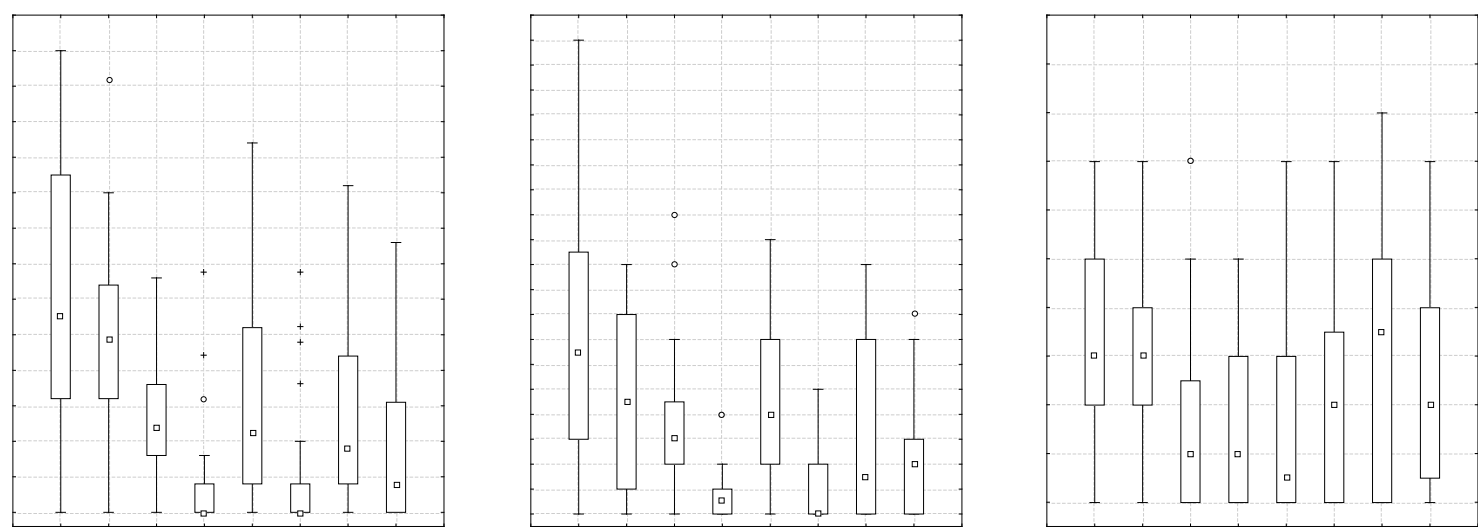

$a$

$b$

$c$

Fig. 3. Changes in the motor activity $(a)$, orienting activity $(b)$ and emotional status $(c)$ of male rats that in addition to their diet received crumbled shoots of Lavandula angustifolia Mill., Melissa officinalis L. and Vitex angus-castus L.: on abscissa axis - groups of animals $(\mathrm{n}=8)$ on the diet with excessive fat content and addition of grined shoots of the plants (in parentheses there are indicated day after the experiment: beginning - 1-4th or the end - 26-30th days), on ordinate axis - absolute number of markers of this type of behavior during 120 seconds of the experiment: for the motor activity - the number of attended squares of the "open field", for the orienting activity - number of stances, for the emotional status - number of acts of grooming, defecation and urination; small square - median, the upper and lower line of the rectangle $-75 \%$ and $25 \%$ quartiles, the upper line - minimum and maximum values, circles - emissions; different letters within each figure indicate significant differences between the groups $(\mathrm{P}<0.05)$ according to the results of Tukey test

\section{Table 5}

Changes in the behaviouristic characteristics of the three groups of rats during 120 seconds of the experiment when crumbled shoots of Lavandula angustifolia Mill., Melissa officinais L. and Vitex angus-castus $\mathrm{L}$. were added to the $\operatorname{diet}(\mathrm{x} \pm \mathrm{SD}, \mathrm{n}=32$, duration of the experiment was 30 days)

\begin{tabular}{|c|c|c|c|c|c|c|c|c|}
\hline Characteristic & $\begin{array}{l}\text { Control, } \\
\text { 1-4th days }\end{array}$ & $\begin{array}{c}\text { Control, } \\
\text { 26-30th days }\end{array}$ & $\begin{array}{l}\text { L. angustifolia, } \\
\text { 1-4th days }\end{array}$ & $\begin{array}{l}\text { L. angustifolia } \\
\text { 26-30th days }\end{array}$ & $\begin{array}{c}\text { M. officinalis, } \\
\text { 1-4th days }\end{array}$ & $\begin{array}{l}\text { M. officinalis, } \\
\text { 26-30th days }\end{array}$ & $\begin{array}{l}\text { V. angus- } \\
\text { castus, } \\
\text { 1-4th days }\end{array}$ & $\begin{array}{c}\text { V. angus- } \\
\text { castus, } \\
\text { 26-30th days }\end{array}$ \\
\hline $\begin{array}{l}\text { Number of attended periphery } \\
\text { squares }\end{array}$ & 8.13 & $24.33 \pm 14.4$ & & $71+$ & & & $13.54=$ & 8.96 \\
\hline Number of attended central squares & $1.00 \pm 2.341$ & $0.292 \pm 1.042$ & $0.00 \pm 0.00$ & $0.00 \pm 0.00$ & $0.821 \pm 1.887$ & $0.000 \pm 0.000$ & $0.107 \pm 0.416$ & $0.000 \pm 0.000$ \\
\hline $\begin{array}{l}\text { Number of stances in peripheral } \\
\text { squares }\end{array}$ & & & & & & & & \\
\hline $\begin{array}{l}\text { Number of stances in the central } \\
\text { squares }\end{array}$ & $1.292 \pm 1.429$ & $0.708 \pm 0.999$ & $0.607 \pm 0.994$ & $0.036 \pm 0.189$ & $0.750 \pm 1.602$ & $0.000 \pm 0.000$ & $0.222 \pm 0.641$ & $0.000 \pm 0.000$ \\
\hline Number of acts of groomin & & 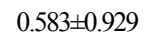 & $1.000 \pm 1.122$ & $0.536 \pm 0.744$ & & 4 & 0.393 & 0.393 \\
\hline Numb & & & & & & & 2.679 & $2.179 \pm 2.195$ \\
\hline Number of urinations & $0.333 \pm 0.482$ & $0.375 \pm 0.495$ & $0.107 \pm 0.416$ & $0.036 \pm 0.189$ & $0.036 \pm 0.189$ & $0.036 \pm 0.189$ & $0.000 \pm 0.000$ & $0.000 \pm 0.000$ \\
\hline
\end{tabular}

Notes: no significant differences between the groups were found according to most of the parameters; differences between the number of attended peripheral squares and the number of stances in the peripheral squares are indicated by different latin letters $(\mathrm{P}<0.05)$, according to Tukey test.

\section{Discussion}

Plant-based food supplements are currently gaining popularity, but the data about the risk they pose are rare and contravercial. Lamiaceae family contains herbs of high socio-economic significance, several horticultural and ornamental species, culinary herbs, having broad range of application because of richness in phenolic compounds (Trivellini et al., 2016). Natural phenols are less harmful to the environment and health than components used in cosmetics, pesticides and preservatives (Trivellini et al., 2016). Obesity and overating are some commonest health issues around the world, and many people see easy solution in the performance and image-enhancing drugs (PIEDs). Nonetheless, those preparations may exert toxicity and impair metabolism, despite the manufacturers' claims about safety of the natural receipes of their medicinal drugs (Bersani et al., 2015).

Identifying the composition of biologically active compounds in medicinal herbs is complicated because there are no unified methods for this purpose (Milevskaya et al., 2019). Therefore, in our study, we chose to add dry crumbled plants to granulated feed of animals.

In our study, addition of lavender and lemon balm to the diet was followed by more intense weight gain while consuming less food than the control group that received high-fat diet.
Valable medicinal plant $M$. officinalis is native to the eastern Mediterranean Region and Western Asia. Its main constituents are citral (geranial and neral), citronellal, geraniol. In the experiments, $M$. officinalis notably decreased body weight (Valizadeh et al., 2016); nonetheless, the review emphasizes that there are needed randomized trials of higher quality to confirm the results. Abilities to improve memory had been also demonstrated by some other plants like M. officinalis, and the mechanisms of action were determined (Shojaii et al., 2016), but for many medicinal herbs there is not a sufficient amount of studies on their efficiency in improving memory and learning (Shojaii et al., 2016).

Many pharmacological effects have been reported for crude extracts and pure compounds isolated from M. officinalis, but only anxiolytic, antiviral, antispasmodic activities, as well as effects on mood, cognition and memory were confirmed in the clinical experiments. The major mechanisms of this plant's neurological effects, which are the subject of discussion worldwide, are $\mathrm{AChE}$ inhibitory activity, stimulation of the acetylcholine and GABA(A) receptors, as well as inhibition of matrix metallo proteinase-2 (Shakeri et al., 2016). Lemon balm is applied during a number of health issues, particularly anxiety and some other disorders of the central nervous system, but substantiation of its effects needs trials in clinical settings (Shakeri et al., 2016). The most frequent clinical effects of application plant food supplements that contained M. officinalis were 
neurotoxicity and gastro-intestinal symptoms. The symptoms in most cases were mild (Lude et al., 2016).

High content of fat in diet is considered to inevitably cause increase in the parameters of lipid metabolism such as total cholesterol, level of triglycerides, content and proportion of lypoproteins of different density, which are expressed by such a parameter as aterogenecity index. In our experiments, in rats, the consumption of the diet with heightened content of fat during 30 days caused no elevation of the level of total cholesterol, which remained within the reference values. As known, the parameters of lipid metabolism in rats were lower than such in human due to production of specific bile acids $-\alpha$ - and $\beta$-muricholic acids, absent in humans (Thomas et al., 1984). Bile acids in particular are those considered responsible for fast removal of cholesterol from the rats' organisms. Difference lies in the fact that rats are very resistant to the level of serum cholesterol, unlike human. Moreover, the animals are hardly vulnerable to development of plaques in the arteries as a result of intake of cholesterol-rich food (Stehbens, 1986).

Gross et al. (2019) reported that $M$. officinalis was clinically effective against symptoms related to anxiety and displayed no signs of toxicity. The review by Swiader et al. (2019) analyzed the literature data on the chemical composition of $M$. officinalis and the possibilities of using it in medicine and food. Heshmati et al. (2020) indicated the relationship between consumption of $M$. officinalis and decreased total cholesterol and reduced systolic blood pressure. Intake of M. officinalis was not observed to be related to statistically significant changes in triglycerides, low-density lipoprotein, diastolic blood pressure, high sensitivity c-reactive protein levels, fasting blood sugar, $\mathrm{HbAlc}$, insulin or high-density lipoprotein levels. No serious side effects were reported. According to the study by Heshmati et al. (2020), M. officinalis is safe beneficial supplement. In our experiment, addition of lemon balm to high-fat diet of rats reduced the intensity of increase in the level of triglycerides and HDL cholesterol compared with the control, and at the same time the indicator of total cholesterol, LDL cholesterol, did not change significantly.

In a 21-day experiment on rats that received high-fat diet and various doses of extract of melissa, Zarei et al. (2014) observed significant decrease in the activity of hepatic enzymes. In our experiment, by the 30th day, the rats fed with fat diet were seen to AST, ALT and alkaline phosphatase exceeding the reference values, indicating damaged cellular membranes of hepatocytes. Adition of lemon balm to the diet led to decrease in only ALT activity, and AST activity remained the same as in the animals on high-fat diet, and the activity of alkaline phosphatase was significantly higher. This may be related to either longer duration of our experiment or lower dose of active agents.

Benny \& Thomas (2019) analyzed the literature reporting anti-amyloid, antioxidants, anticholinesterase, and memory-enhancement activities of essential oils from M. officinalis, L. angustifolia in preclinical and clinical studies of Alzheimers disease.

Treatment of neurodegenerative diseases with $M$. officinalis and rosmarinic acid - its major constituent - has been reported in many scientific and non-scientific articles, but clinical trial of ethanol extract from $M$. officinalis was only made so far toward Alzheimer disease (Mahboubi, 2019). Action mechanisms of $M$. officinalis comprise inhibitory effects against beta-amyloid, reactive oxygen species, and acetylcholine esterase.

M. officinalis can mitigate psychological symptoms in the patients undergoing operation (Shabanian et al., 2019). Use of medicinal herbs before and after surgery alleviates anxiety, depression, aggressive and impulsive behavior, stress, delirium and cognitive dysfunction. Trials on children with attention deficit hyperactivity disorder (ADHD) who consumed $M$. officinalis preparations showed low evidence for their effectiveness (Anheyer et al., 2017); but no concrete recommendations could be made while there is still a lack of sufficient numbers.

In many studies, $M$. officinalis exerted high antioxidant activity through flavonoids, rosmaric acid, gallic acid, phenolic contents. A number of studies confirmed the antioxidative action of M. officinalis, and its effect in preventing and treating oxidative stress-related diseases might be reliable (Miraj et al., 2017). Moradi et al. (2016) report that more comprehensive studies using more advanced methods are needed to develop promising anti-HSV drugs based on bioactive compounds isolated from M. officinalis.
Rosmarinic acid is considered to have notable pharmacological effects and was recently surveyed as a therapeutic drugs in treatment of diabetes (Ngo et al., 2018). Earlier researches confirmed that rosmarinic acid can control the plasma glucose level and heighten insulin sensitivity in hyperglycemia. Rosmarinic acid is quickly absorbed in the human body, but its mechanism remains unclear (Ngo et al., 2018). Against the background of high-fat diet, glucose level in blood plasma of the studied rats increased, whereas addition of medicinal plants to the diet decreased the glucose level to the normal values.

M. officinalis and $L$. angustifolia are commonly considered to take generally calming effect. Experimental pharmacology using L. angustifolia includes anesthetic, anticonvulsant, sedative, anti-inflammatory, antimicrobial, antispasmodic, antispasmodic, central nervous system depressant effects; clinical pharmacology includes anxiolytic, analgesic, and cardiovascular effects (Koriem, 2021). In the quantitative synthesis, inhalation of lavender decreased levels of anxiety, according to any validated scale and sign of anxiety (Donelli et al., 2019), but caused no reduction of blood pressure, a physiological parameter of anxiety. Investigation of effects of inhalation of lavender oil aroma in sleep needs more in-detail surveys (Fismer \& Pilkington, 2012). Some studies have shown the effiency of oral lavender supplements, but independent replications are needed to draw conclusions (Perry et al., 2012). In the "open field" method, addition of lavender and lemon balm perorally with food significantly decreased motor activity of animals, compared with the control group (high-fat diet). Also, these animals exhibited decrease in orienting activity. Despite some data on vitex manifesting calming effect (Mehlhorn, 2016), it exhibited no inhibition of motor and orienting activities in our experiment. Moreover, all the studied plants caused no changes in the emotional status of the experimental rats.

V. agnus-castus is rich in phytoestrogens and is traditionally applied in the treatment of premenstrual syndrome (Arzi et al., 2019). In the rat groups, no anti-anxiety effects were manifested by tamoxifen or a combination of tamoxifen and a high dose of $V$. angus-castus. Extract from $V$. agnus-castus displayed anti-anxiety activity and may be used to treat anxiety (Mehlhorn, 2016). Interaction between phytoestrogens from V. agnus-castus and estrogen receptors could be the mechanism that determines the plant's anxiolytic activity (Arzi et al., 2019).

Effects of the plants we tested on the organism of rats were both direct and indirect: by inhibiting certain species of microorganisms in the intestine of animals (Bilan et al., 2019). In our earlier experiments, ethanol extract from $M$. officinalis powerfully inhibited growth of colonies of bacteria of Salmonella typhimurium, poorly inhibited such of Escherichia coli, Klebsiella pneumonia and Corinebacterium xerosis, and caused no effect on Proteus mirabilis, Listeria monocytogenes and fungus of Candida albicans (Zazharskyi et al., 2019). Similar effects were observed for ethyl extract of the leaves of L. angustifolia: it notably inhibited growth of colonies of Salmonella typhimurium and Klebsiella pneumonia, weakly affected Escherichia coli, Proteus mirabilis and fungus of Candida albicans and inhibited no growth of cells of bacteria of Listeria monocytogenes and Corinebacterium xerosis (Zazharskyi et al., 2019). We seen broader range of antibacterial activity in in vitro experiments exhibited by ethyl extract from $V$. angus-castus that notably inhibited growth of Corinebacterium xerosis, Serratia marcescens, Salmonella typhimurium, Proteus mirabilis; weakly affected growth of colonies of Rhodococcus equi, Pseudomonas aeruginosa, Yersinia enterocolitica, Klebsiella pneumonia, Enterococcus faecalis, Escherichia coli, and took no inhibitory effect on growth of colonies of Enterobacter aerogenes, Listeria ivanovi, L. innocua, L. monocytogenes, Campylobacter jejuni and fungus of Candida albicans (Zazharskyi et al., 2020).

Also, in our previous studies, we determined that aqueous tincture of $V$. angus-castus in in vitro experiment had weak lethal effect on larvae of parasitic intestinal nematodes of Strongyloides papillosus (Wedl, 1856), though mortality of nematodes of Haemonchus contortus (Rudolphi, 1803) in aqueous tincture of this plants was no different from the control (Boyko et al., 2020). Essential oil from L. officinalis had similar effect on these species of nematodes, causing 4-fold increase in mortality of larvae of S. papillosus, but took no effect on larvae of $H$. contortus (Boyko \& Brygadyrenko, 2021). Thus, possible effect of medicinal plants of Lamiaceae family may likely occur through various species of parasitic nema- 
todes of Strongyloides genus, specific various species of model animals and human.

\section{Conclusion}

Against the background of high-fat diet, lemon balm and lavender manifested similar influences. Addition of these plants to the diet led to significant decrease in food intake, and at the same time the intensity of weight gain was greater than in the animals that consumed high-fat diet supplemented by vitex. Taking into account that during consumption of lavender and lemon balm, the motor and orienting activities of the animals decreased by the end of the experiment, we consider it as manifestation of calming effect taken by the plant, which was not observed in the control group and with addition of vitex. Also, lemon balm and lavender, by the end of the experiment, led to significant decrease in the relative weights of the brain and the thymus.

High-fat diet caused impairment of metabolism of animals. Addition of medicinal plants to the diet with high content of fat alleviates the disorders in the metabolisms of fat (increase in the level of triglycerides) and carbohydrates (increase in glucose level), but takes negative effect on protein metabolism (hyperproteinemia as a result of hyperglobulinemia).

Additional of medicinal plants to high-fat diet led to impaired activity of blood enzymes - alkaline phosphatase, AST and ALT; increase in triglycerides, LDL cholesterol against the background of decrease in HDL cholesterol and normal value of total cholysterol. Also, all the groups were characteristic of monocytosis, more notable at addition of lavender and lemon balm to the diet, which also caused leukocytosis compared with the control group and addition of vitex.

\section{References}

Akbarzadeh, M., Dehghani, M., Moshfeghy, Z., Emamghoreishi, M., Tavakoli, P., \& Zare, N. (2015). Effect of Melissa officinalis capsule on the intensity of premenstrual syndrome symptoms in high school girl students. Nursing and Midwifery Studies, 4(2), e27001.

Anheyer, D., Lauche, R., Schumann, D., Dobos, G., \& Cramer, H. (2017). Herbal medicines in children with attention deficit hyperactivity disorder (ADHD): A systematic review. Complementary Therapies in Medicine, 30, 14-23.

Aprotosoaie, A. C., Hancianu, M., Costache, I. I., \& Miron, A. (2014). Linalool: A review on a key odorant molecule with valuable biological properties. Flavour and Fragrance Journal, 29(4), 193-219.

Arika, W. M., Kibiti, C. M., Njagi, J. M., \& Ngugi, M. P. (2019). Effects of DCM leaf extract of Gnidia glauca (Fresen) on locomotor activity, anxiety, and exploration-like behaviors in high-fat diet-induced obese rats. Behavioural Neurology, 2019, 7359235 .

Artz, M. B. (2007). Vitex agnus-castus. In: Tracy, T. S., \& Kingston, R. L. (Eds.). Herbal products. Toxicology and clinical pharmacology. Forensic science and medicine. Humana Press. Pp. 245-258.

Arzi, A., Mojiri-Forushani, H., \& Karampour, N. S. (2019). Evaluation of the anxiolytic effect of Vitex agnus-castus on female mice and possible role of estrogen receptors. Jundishapur Journal of Natural Pharmaceutical Products, 14(2), e63570.

Ayaz, M., Sadiq, A., Junaid, M., Ullah, F., Subhan, F., \& Ahmed, J. (2017). Neuroprotective and anti-aging potentials of essential oils from aromatic and medicinal plants. Frontiers in Aging Neuroscience, 9, 168.

Bailly, C. (2020). Targets and pathways involved in the antitumor activity of citral and its stereo-isomers. European Journal of Pharmacology, 871, 172945.

Bayat, M., Azami Tameh, A., Hossein Ghahremani, M., Akbari, M., Mehr, S. E., Khanavi, M., \& Hassanzadeh, G. (2012). Neuroprotective properties of Melissa officinalis after hypoxic-ischemic injury both in vitro and in vivo. Daru: Journal of Faculty of Pharmacy, Tehran University of Medical Sciences, 20(1), 42.

Belova, M. M., Shipunova, V. O., Kotelnikova, P. A., Babenyshev, A. V., Rogozhin, E. A., Cherednichenko, M. Y., \& Deyev, S. M. (2019). "Green" synthesis of cytotoxic silver nanoparticles based on secondary metabolites of Lavandula angustifolia Mill. Acta Naturae, 11(2), 47-53.

Benny, A., \& Thomas, J. (2019). Essential oils as treatment strategy for Alzheimers disease: Current and future perspectives. Planta Medica, 85(3), 239-248.

Bersani, F. S., Coviello, M., Imperatori, C., Francesconi, M., Hough, C. M., Valeriani, G., De Stefano, G., Posocco, F. B. M., Santacroce, R., Minichino, A., \& Corazza, O. (2015). Adverse psychiatric effects associated with herbal weight-loss products. Biomed Research International, 2015, 120679.

Bilan, M. V., Lieshchova, M. A., Tishkina, N. M., \& Brygadyrenko, V. V. (2019). Combined effect of glyphosate, saccharin and sodium benzoate on the gut microbiota of rats. Regulatory Mechanisms in Biosystems, 10(2), 228-232.
Bojic, M., Males, Z., Antolic, A., Babic, I., \& Tomicic, M. (2019). Antithrombotic activity of flavonoids and polyphenols rich plant species. Acta Pharmaceutica, 69(4), 483-495.

Boukhatem, M. N., Sudha, T., Darwish, N., Chader, H., Belkadi, A., Rajabi, M., Houche, A., Benkebailli, F., Oudjida, F., \& Mousa, S. A. (2020). A new eucalyptol-rich lavender (Lavandula stoechas L.) essential oil: Emerging potential for therapy against inflammation and cancer. Molecules, 25(16), 3671.

Bounihi, A., Hajjaj, G., Alnamer, R., Cherrah, Y., \& Zellou, A. (2013). In vivo potential anti-inflammatory activity of Melissa officinalis L. essential oil. Advances in Pharmacological Sciences, 2013, 101759.

Boyko, O. O., Kabar, A. M., \& Brygadyrenko, V. V. (2020). Nematicidal activity of aqueous tinctures of medicinal plants against larvae of the nematodes Strongyloides papillosus and Haemonchus contortus. Biosystems Diversity, 28(1), 119-123.

Boyko, O., \& Brygadyrenko, V. (2021). Nematicidal activity of essential oils of medicinal plants. Folia Oecologica, 48(1), 42-48.

Brown, D., \& Murray, M. T. (2012). Vitex agnus castus (Chaste tree). In: Pizzorno, J., \& Murray, M. (Eds.). Textbook of natural medicine. Churchill Livingstone. Pp. 1135-1139.

Brygadyrenko, V. V., Lieshchova, M. A., Bilan, M. V., Tishkina, N. M., \& Horchanok, A. V. (2019). Effect of alcohol tincture of Aralia elata on the organism of rats and their gut microbiota against the background of excessive fat diet. Regulatory Mechanisms in Biosystems, 10(4), 497-506.

Bukvicki, D., Gottardi, D., Prasad, S., Novakovic, M., Marin, P. D., \& Tyagi, A. K (2020). The healing effects of spices in chronic diseases. Current Medicinal Chemistry, 27(26), 4401-4420.

Cardia, G., Silva-Filho, S. E., Silva, E. L., Uchida, N. S., Cavalcante, H., Cassarotti, L. L., Salvadego, V., Spironello, R. A., Bersani-Amado, C. A., \& Cuman, R. (2018). Effect of lavender (Lavandula angustifolia) essential oil on acute inflammatory response. Evidence-Based Complementary and Alternative Medicine, 2018, 1413940.

Cavanagh, H. M. A., \& Wilkinson, J. N. (2002). Biological activities of lavender essential oil. Phytotherapy Research, 16(4), 301-308.

Clifford, M. N. (1999). Chlorogenic acids and other cinnamates - nature, occurrence and dietary burden. Journal of the Science of Food and Agriculture, 79(3), 362372.

de Cássia da Silveira e Sá, R., Andrade, L. N., \& de Sousa, D. P. (2013). A review on anti-inflammatory activity of monoterpenes. Molecules, 18(1), 1227-1254.

Dobetsberger, C., \& Buchbauer, G. (2011). Actions of essential oils on the central nervous system: An updated review. Flavour and Fragrance Journal, 26(5), 300-316.

Dolatabadi, F., Abdolghaffari, A. H., Farzaei, M. H., Baeeri, M., Ziarani, F. S., Eslami, M., Abdollahi, M., \& Rahimi, R. (2018). The protective effect of Melissa officinalis L. in visceral hypersensitivity in rat using 2 models of acid-induced colitis and stress-induced irritable bowel syndrome: A possible role of nitric oxide pathway. Journal of Neurogastroenterology and Motility, 24(3), 490-501.

Donelli, D., Antonelli, M., Bellinazzi, C., Gensini, G. F., \& Firenzuoli, F. (2019). Effects of lavender on anxiety: A systematic review and meta-analysis. Phytomedicine, $65,153099$.

EFSA Panel on Additives and Products or Substances used in Animal Feed (FEEDAP), Bampidis, V., Azimonti, G., Bastos, M. L., Christensen, H., Kouba, M., Kos Durjava, M., López-Alonso, M., López Puente, S., Marcon, F., Mayo, B., Pechová, A., Petkova, M., Ramos, F., Sanz, Y., Villa, R. E., Woutersen, R., Brantom, P., Chesson, A., Westendorf, J., Gregoretti, L., Manini, P., \& Dusemund, B. (2020). Safety and efficacy of a dried aqueous ethanol extract of $\mathrm{Me}$ lissa officinalis L. leaves when used as a sensory additive for all animal species. EFSA Journal, 18(2), e06016.

Eivani, M., \& Khosronezhad, N. (2020). Melissa officinalis: A memory enhancer remedy. Physiology and Pharmacology, 24(3), 159-164.

Feliú-Hemmelmann, K., Monsalve, F., \& Rivera, C. (2013). Melissa officinalis and Passiflora caerulea infusion as physiological stress decreaser. International Journal of Clinical and Experimental Medicine, 6(6), $444-451$.

Fismer, K. L., \& Pilkington, K. (2012). Lavender and sleep: A systematic review of the evidence. European Journal of Integrative Medicine, 4(4), E436-E447.

Gangemi, S., Minciullo, P. L., Miroddi, M., Chinou, I., Calapai, G., \& Schmidt, R. J. (2015). Contact dermatitis as an adverse reaction to some topically used European herbal medicinal products - Part 2: Echinacea purpurea - Lavandula angustifolia. Contact Dermatitis, 72(4), 193-205.

Greff, B., Lakatos, E., Szigeti, J., \& Varga, L. (2020). Co-composting with herbal wastes: Potential effects of essential oil residues on microbial pathogens during composting. Critical Reviews in Environmental Science and Technology, 51(5), 457-511.

Gross, A. V., Stolz, E. D., Muller, L. G., Rates, S. M. K., \& Ritter, M. R. (2019). Medicinal plants for the "nerves": A review of ethnobotanical studies carried out in South Brazil. Acta Botanica Brasilica, 33(2), 269-282.

Hamza, A. A., Ahmed, M. M., Elwey, H. M., \& Amin, A. (2016). Melissa officinalis protects against doxorubicin-induced cardiotoxicity in rats and potentiates its anticancer activity on MCF-7 cells. PloS One, 11(11), e0167049. 
Hasanein, P., \& Riahi, H. (2015). Antinociceptive and antihyperglycemic effects of Melissa officinalis essential oil in an experimental model of diabetes. Medical Principles and Practice, 24(1), 47-52.

Häusler, E., Petersen, M., \& Alfermann, A. (1993). Isolation of protoplasts and vacuoles from cell suspension cultures of Coleus blumei Benth. Plant Cell Reports, 12(9), 510-512.

Heghes, S. C., Filip, L., Vostinaru, O., Mogosan, C., Miere, D., Iuga, C. A., \& Moldovan, M. (2020). Essential oil-bearing plants from Balkan Peninsula: Promising sources for new drug candidates for the prevention and treatment of diabetes mellitus and dyslipidemia. Frontiers in Pharmacology, 11, 989.

Heshmati, J., Morvaridzadeh, M., Sepidarkish, M., Fazelian, S., Rahimlou, M., Omidi, A., Palmowski, A., Asadi, A., \& Shidfar, F. (2020). Effects of Melissa officinalis (lemon balm) on cardio-metabolic outcomes: A systematic review and meta-analysis. Phytotherapy Research, 34(12), 3113-3123.

Hitl, M., Kladar, N., Gavaric, N., \& Bozin, B. (2021). Rosmarinic acid - human pharmacokinetics and health benefits. Planta Medica, 87(4), 273-282.

Hosseini, S. R., Kaka, G., Joghataei, M. T., Hooshmandi, M., Sadraie, S. H., Yaghoobi, K., Mansoori, K., \& Mohammadi, A. (2017). Coadministration of dexamethasone and Melissa officinalis has neuroprotective effects in rat animal mode with spinal cord injury. Cell Journal, 19(1), 102-116.

Iranshahy, M., \& Javadi, B. (2019). Diet therapy for the treatment of Alzheimer's disease in view of traditional Persian medicine: A review. Iranian Journal of Basic Medical Sciences, 22(10), 1102-1117.

Jeung, I. C., Jee, D., Rho, C. R., \& Kang, S. (2016). Melissa officinalis L. extracts protect human retinal pigment epithelial cells against oxidative stress-induced apoptosis. International Journal of Medical Sciences, 13(2), 139-146.

Joukar, S., \& Asadipour, H. (2015). Evaluation of Melissa officinalis (lemon balm) effects on heart electrical system. Research in Cardiovascular Medicine, 4(2) e27013.

Joukar, S., Zarisfi, Z., Sepehri, G., \& Bashiri, A. (2014). Efficacy of Melissa officinalis in suppressing ventricular arrhythmias following ischemia-reperfusion of the heart: A comparison with amiodarone. Medical Principles and Practice, 23(4), 340-345.

Kaka, G., Yaghoobi, K., Davoodi, S., Hosseini, S. R., Sadraie, S. H., \& Mansouri, K (2016). Assessment of the neuroprotective effects of Lavandula angustifolia extract on the contusive model of spinal cord injury in wistar rats. Frontiers in Neuroscience, 10,25 .

Karabagias, I. K., Karabagias, V. K., \& Riganakos, K. A. (2019). Physico-chemica parameters, phenolic profile, in vitro antioxidant activity and volatile compounds of ladastacho (Lavandula stoechas) from the region of Saidona. Antioxidants, 8(4), 80 .

Kennedy, D. O., \& Wightman, E. L. (2011). Herbal extracts and phytochemicals: Plant secondary metabolites and the enhancement of human brain function. Advances in Nutrition, 2(1), 32-50.

Kikuchi, H., Yuan, B., Yuhara, E., Imai, M., Furutani, R., Fukushima, S., Hazama, S., Hirobe, C., Ohyama, K., Takagi, N., \& Toyoda, H. (2014). Involvement of histone H3 phosphorylation via the activation of p38 MAPK pathway and intracellular redox status in cytotoxicity of HL-60 cells induced by Vitex agnuscastus fruit extract. International Journal of Oncology, 45(2), 843-852.

Kim, J., Lee, H., Lim, J., Oh, J., Shin, S. S., \& Yoon, M. (2017). The angiogenesis inhibitor ALS-L1023 from lemon-balm leaves attenuates high-fat diet-induced nonalcoholic fatty liver disease through regulating the visceral adipose-tissue function. International Journal of Molecular Sciences, 18(4), 846.

Koriem, K. M. M. (2021). Lavandulae aetheroleum oil: A review on phytochemica screening, medicinal applications, and pharmacological effects. Biointerface Research in Applied Chemistry, 11(3), 9836-9847.

Kubo, H., Shibato, J., Saito, T., Ogawa, T., Rakwal, R., \& Shioda, S. (2015). Unraveling the rat intestine, spleen and liver genome-wide transcriptome after the ora administration of lavender oil by a two-color dye-swap DNA microarray approach. PloS One, 10(7), e0129951.

Lee, E. K., Kim, Y. J., Kim, J. Y., Song, H. B., \& Yu, H. G. (2014). Melissa officinalis extract inhibits laser-induced choroidal neovascularization in a rat model. PloS One, 9(10), e110109.

Lesage-Meessen, L., Bou, M., Sigoillot, J. C., Faulds, C. B., \& Lomascolo, A (2015). Essential oils and distilled straws of lavender and lavandin: A review of current use and potential application in white biotechnology. Applied Microbiology and Biotechnology, 99(8), 3375-3385.

Lieshchova, M. A., Bilan, M. V., Bohomaz, A. A., Tishkina, N. M., \& Brygadyrenko, V. V. (2020). Effect of succinic acid on the organism of mice and their intestinal microbiota against the background of excessive fat consumption. Regulatory Mechanisms in Biosystems, 11(2), 153-161.

Lieshchova, M. A., Brygadyrenko, V. V., Tishkina, N. M., Gavrilin, P. M., \& Bohomaz, A. A. (2019). Impact of polyvinyl chloride, polystyrene, and polyethylene on the organism of mice. Regulatory Mechanisms in Biosystems, 10(1), 50-55.

Lieshchova, M. A., Tishkina, N. M., Bohomaz, A. A., Gavrilin, P. M., \& Brygadyrenko, V. V. (2018). Combined effect of glyphosphate, saccharin and sodium benzoate on rats. Regulatory Mechanisms in Biosystems, 9(4), 591-597.
Lude, S., Vecchio, S., Sinno-Tellier, S., Dopter, A., Mustonen, H., Vucinic, S., Jonsson, B., Muller, D., Fruchtengarten, L. V., Hruby, K., Nascimento, E. D., Di Lorenzo, C., Restani, P., Kupferschmidt, H., \& Ceschi, A. (2016). Adverse effects of plant food supplements and plants consumed as food: Results from the poisons centres-based plant Libra study. Phytotherapy Research, 30(6), 988-996.

Lundstrom, K., Pham, H. T., \& Dinh, L. D. (2017). Interaction of plant extracts with central nervous system receptors. Medicines, 4(1), 12

Mahboubi, M. (2019). Melissa officinalis and rosmarinic acid in management of memory functions and Alzheimer disease. Asian Pacific Journal of Tropica Biomedicine, 9(2), 47-52.

Maleki-Saghooni, N., Karimi, F. Z., Moghadam, Z. B., \& Najmabadi, K. M. (2018) The effectiveness and safety of Iranian herbal medicines for treatment of premenstrual syndrome: A systematic review. Avicenna Journal of Phytomedicine, $8(2), 96-113$

Martin, B. R. (2019). Complementary medicine therapies that may assist with weight loss: A narrative review. Journal of Chiropractic Medicine, 18(2), 115-126.

Martynov, V. O., Hladkyi, O. Y., Kolombar, T. M., \& Brygadyrenko, V. V. (2019a). Impact of essential oil from plants on migratory activity of Sitophilus granarius and Tenebrio molitor. Regulatory Mechanisms in Biosystems, 10(4), 359-371.

Martynov, V. O., Titov, O. G., Kolombar, T. M., \& Brygadyrenko, V. V. (2019b). Influence of essential oils of plants on themigration activity of Tribolium confusum (Coleoptera, Tenebrionidae). Biosystems Diversity, 27(2), 177-185.

Mehlhom, H. (2016). Vitex agnus castus. In: Mehlhorn, H. (Ed.). Encyclopedia of parasitology. Springer-Verlag, Berlin, Heidelberg. Pp. 3023-3023.

Mekonnen, A., Tesfaye, S., Christos, S. G., Dires, K., Zenebe, T., Zegeye, N., Shiferaw, Y., \& Lulekal, E. (2019). Evaluation of skin irritation and acute and subacute oral toxicity of Lavandula angustifolia essential oils in rabbit and mice. Journal of Toxicology, 2019, 5979546

Michel, J., Abd Rani, N. Z., \& Husain, K. (2020). A review on the potential use of medicinal plants from Asteraceae and Lamiaceae plant family in cardiovascular diseases. Frontiers in Pharmacology, 11, 852

Milevskaya, V. V., Prasad, S., \& Temerdashev, Z. A. (2019). Extraction and chromatographic determination of phenolic compounds from medicinal herbs in the Lamiaceae and Hypericaceae families: A review. Microchemical Journal, 145, $1036-1049$.

Miraj, S., Kopaei, R., \& Kiani, S. (2017). Melissa officinalis L.: A review study with an antioxidant prospective. Journal of Evidence-Based Integrative Medicine, 22(3), 385-394

Moradi, M. T., Rafieian-Kopaei, M., \& Karimi, A. (2016). A review study on the effect of Iranian herbal medicines against in vitro replication of herpes simplex virus. Avicenna Journal of Phytomedicine, 6(5), 506-515.

Moradkhani, H., Sargsyan, E., Bibak, H., Naseri, B., Sadat-Hosseini, M., FayaziBarjin, A., \& Meftahizade, H. (2010). Melissa officinalis L., a valuable medicine plant: A review. Journal of Medicinal Plants Research, 4(25), 2753-2759.

Naderi Dastjerdi, M., Darooneh, T., Nasiri, M., Moatar, F., Esmaeili, S., \& Ozgoli, G. (2019). Investigating the effect of Melissa officinalis on after-pains: A randomized single-blind clinical trial. Joumal of Caring Sciences, 8(3), 129-138.

Ngo, Y. L., Lau, C. H., \& Chua, L. S. (2018). Review on rosmarinic acid extraction, fractionation and its anti-diabetic potential. Food and Chemical Toxicology, $121,687-700$.

Noguchi-Shinohara, M., Ono, K., Hamaguchi, T., Iwasa, K., Nagai, T., Kobayashi, S., Nakamura, H., \& Yamada, M. (2015). Pharmacokinetics, safety and tolerability of Melissa officinalis extract which contained rosmarinic acid in healthy individuals: A randomized controlled trial. PloS One, 10(5), e0126422.

Oskouie, A. A., Yekta, R. F., Tavirani, M. R., Kashani, M. S., \& Goshadrou, F. (2018). Lavandula angustifolia effects on rat models of Alzheimer's disease through the investigation of serum metabolic features using NMR metabolomics. Avicenna Journal of Medical Biotechnology, 10(2), 83-92.

Ozarowski, M, Mikolajczak, P. L, Piasecka A, Kachlicki, P Kujawski, R, Bogacz, A., Bartkowiak-Wieczorek, J., Szulc, M., Kaminska, E., Kujawska, M., Jodynis-Liebert, J., Gryszczynska, A., Opala, B., Lowicki, Z., Seremak-Mrozikiewicz, A., \& Czerny, B. (2016). Influence of the Melissa officinalis leaf extract on long-term memory in scopolamine animal model with assessment of mechanism of action. Evidence-Based Complementary and Alternative Medicine, 2016, 9729818

Pal, M., Li, S. H., Tewari, S. K., \& Sun, H. D. (2013). Diterpenoid compounds from Vitex agnus-castus. Chemistry of Natural Compounds, 49(4), 635-638.

Park, B. Y., Lee, H., Woo, S., Yoon, M., Kim, J., Hong, Y., Lee, H. S., Park, E. K., Hahm, J. C., Kim, J. W., Shin, S. S., Kim, M. Y., \& Yoon, M. (2015). Reduction of adipose tissue mass by the angiogenesis inhibitor ALS-L1023 from $\mathrm{Me}$ lissa officinalis. PloS One, 10(11), e0141612.

Perry, R., Terry, R., Watson, L. K., \& Ernst, E. (2012). Is lavender an anxiolytic drug? A systematic review of randomised clinical trials. Phytomedicine, 19, 825-835.

Peterfalvi, A., Miko, E., Nagy, T., Reger, B., Simon, D., Miseta, A., Czéh, B., \& Szereday, L. (2019). Much more than a pleasant scent: A review on essential oils supporting the immune system. Molecules, 24(24), 4530. 
Raut, J. S., \& Karuppayil, S. M. (2014). A status review on the medicinal properties of essential oils. Industrial Crops and Products, 62, 250-264.

Ross, I. A. (2001). Vitex agnus-castus. In: Ross, I. A. Medicinal plants of the world Chemical constituents, traditional and modern medical uses. Humana Press, Totowa, NJ. Vol. 2. Pp. 427-435.

Saberi, A., Abbasloo, E., Sepehri, G., Yazdanpanah, M., Mirkamandari, E., Sheibani, V., \& Safi, Z. (2016). The effects of methanolic extract of Melissa officinalis on experimental gastric ulcers in rats. Iranian Red Crescent Medical Journal, 18(7), e24271.

Sadeghzadeh, J., Vakili, A., Bandegi, A. R., Sameni, H. R., Zahedi Khorasani, M., \& Darabian, M. (2017). Lavandula reduces heart injury via attenuating tumor necrosis factor-alpha and oxidative stress in a rat model of infarct-like myocardial injury. Cell Journal, 19(1), 84-93.

Safaeian, L., Sajjadi, S. E., Javanmard, S. H., Montazeri, H., \& Samani, F. (2016). Protective effect of Melissa officinalis extract against $\mathrm{H}_{2} \mathrm{O}_{2}$-induced oxidative stress in human vascular endothelial cells. Research in Pharmaceutical Sciences, 11(5), 383-389.

Safarabadi, A. M., Abbaszadeh, S., Sepahvand, H., \& Ebrahimi, F. (2018). An overview of the important analgesic herbs in Iran. Anaesthesia Pain and Intensive Care, 22(4), 522-528.

Saljoughian, S., Roohinejad, S., Bekhit, A. E. A., Greiner, R., Omidizadeh, A., Nikmaram, N., \& Khaneghah, A. M. (2018). The effects of food essential oils on cardiovascular diseases: A review. Critical Reviews in Food Science and Nutrition, 58(10), 1688-1705.

Samarth, R. M., Samarth, M., \& Matsumoto, Y. (2017). Medicinally important aromatic plants with radioprotective activity. Future Science OA, 3(4), FSO247.

Sammar, M., Abu-Farich, B., Rayan, I., Falah, M., \& Rayan, A. (2019). Correlation between cytotoxicity in cancer cells and free radical-scavenging activity: In vitro evaluation of 57 medicinal and edible plant extracts. Oncology Letters, 18(6), 6563-6571.

Samuelson, R., Lobl, M., Higgins, S., Clarey, D., \& Wysong, A. (2020). The effects of lavender essential oil on wound healing: A review of the current evidence. Journal of Alternative and Complementary Medicine, 26(8), 680-690.

Sedighi, M., Faghihi, M., Rafieian-Kopaei, M., Rasoulian, B., \& Nazari, A. (2019). Cardioprotective effect of ethanolic leaf extract of Melissa officinalis L. against regional ischemia-induced arrhythmia and heart injury after five days of reperfusion in rats. Iranian Journal of Pharmaceutical Research, 18(3), 1530-1542.

Seol, G. H., Lee, Y. H., Kang, P., You, J. H., Park, M., \& Min, S. S. (2013). Randomized controlled trial for Salvia sclarea or Lavandula angustifolia: Differential effects on blood pressure in female patients with urinary incontinence undergoing urodynamic examination. Journal of Alternative and Complementary Medicine, 19(7), 664-670.

Setzer, W. N. (2009). Essential oils and anxiolytic aromatherapy. Natural Product Communications, 4(9), 1305-1316.

Shabanian, G., Heidari-Soureshjani, S., \& Salcher, J. (2019). Effectiveness of medicinal herbs on psychological indices before and after surgeries. Plant Science Today, 6(3), 321-327.

Shakeri, A., Sahebkar, A., \& Javadi, B. (2016). Melissa officinalis L. - A review of its traditional uses, phytochemistry and pharmacology. Journal of Ethnopharmacology, 188, $204-228$.

Shin, S. S., \& Yoon, M. (2020). Regulation of obesity by antiangiogenic herbal medicines. Molecules, 25(19), 4549.

Shinjyo, N., \& Green, J. (2017). Are sage, rosemary and lemon balm effective interventions in dementia? A narrative review of the clinical evidence. European Journal of Integrative Medicine, 15, 83-96.

Shojaii, A., Ghods, R., \& Fard, M. A. (2016). Medicinal herbs in Iranian traditional medicine for learning and memory. African Journal of Traditional Complementary and Alternative Medicines, 13(2), 199-209.

Shokri, A., Saeedi, M., Fakhar, M., Morteza-Semnani, K., Keighobadi, M., Hosseini Teshnizi, S., Kelidari, H. R., \& Sadjadi, S. (2017). Antileishmanial activity of Lavandula angustifolia and Rosmarinus officinalis essential oils and nanoemulsions on Leishmania major (MRHO/IR/75/ER). Iranian Journal of Parasitology, 12(4), 622-631.

Sik, B., Kapcsandi, V., Szekelyhidi, R., Hanczne, E. L., \& Ajtony, Z. (2019). Recent advances in the analysis of rosmarinic acid from herbs in the Lamiaceae family. Natural Product Communications, 14(7), 1934578X19864216.
Stehbens, W. E. (1986). An appraisal of cholesterol feeding in experimental atherogenesis. Progress in Cardiovascular Diseases, 29(2), 107-128.

Stojković, D., Soković, M., Glamočlija, J., Džamić, A., Ćirić, A., Ristić, M., \& Grubišić, D. (2011). Chemical composition and antimicrobial activity of Vitex agnus-castus L. fruits and leaves essential oils. Food Chemistry, 128(4), 10171022.

Swiader, K., Startek, K., \& Wijaya, C. H. (2019). The therapeutic properties of lemon balm (Melissa officinalis L.): Reviewing novel findings and medical indications. Journal of Applied Botany and Food Quality, 92, 327-335.

Thomas, J. N., Kelley, M. J., \& Story, J. A. (1984). Alteration of regression of cholesterol accumulation in rats by dietary pectin. British Journal of Nutrition, 51(3), 339-345.

Todorov, D., Hinkov, A., Shishkova, K., \& Shishkov, S. (2014). Antiviral potential of Bulgarian medicinal plants. Phytochemistry Reviews, 13(2), 525-538.

Torki, M., Mohebbifar, A., \& Mohammadi, H. (2021). Effects of supplementing hen diet with Lavandula angustifolia and/or Mentha spicata essential oils on production performance, egg quality and blood variables of laying hens. Veterinary Medicine and Science, 7(1), 184-193.

Trivellini, A., Lucchesini, M., Maggini, R., Mosadegh, H., Villamarin, T. S. S., Vernieri, P., Mensuali-Sodi, A., \& Pardossi, A. (2016). Lamiaceae phenols as multifaceted compounds: Bioactivity, industrial prospects and role of "positivestress". Industrial Crops and Products, 83, 241-254.

Uritu, C. M., Mihai, C. T., Stanciu, G. D., Dodi, G., Alexa-Stratulat, T., Luca, A., Leon-Constantin, M. M., Stefanescu, R., Bild, V., Melnic, S., \& Tamba, B. I. (2018). Medicinal plants of the family Lamiaceae in pain therapy: A review. Pain Research and Management, 2018, 7801543.

Valizadeh, E., Ghalichi, F., \& Ostadrahimi, A. (2016). Traditional herbal medicine for weight management: A review. International Journal of Medical Research and Health Sciences, 5(11), 393-399.

Wang, D., Yuan, X., Liu, T., Liu, L., Hu, Y., Wang, Z., \& Zheng, Q. (2012). Neuroprotective activity of lavender oil on transient focal cerebral ischemia in mice. Molecules, 17(8), 9803-9817.

Woronuk, G., Demissie, Z., Rheault, M., \& Mahmoud, S. (2011). Biosynthesis and therapeutic properties of Lavandula essential oil constituents. Planta Medica, 77(1), 7-15.

Wynn, S. G., \& Fougère, B. J. (2007). Veterinary herbal medicine: A systems-based approach. Veterinary Herbal Medicine, 291-409.

Xu, P., Wang, K., Lu, C., Dong, L., Gao, L., Yan, M., Aibai, S., Yang, Y., \& Liu, X. (2017). The protective effect of lavender essential oil and its main component linalool against the cognitive deficits induced by d-galactose and aluminum trichloride in mice. Evidence-Based Complementary and Alternative Medicine, 2017,7426538

Yu, S. H., \& Seol, G. H. (2017). Lavandula angustifolia Mill. oil and its active constituent linalyl acetate alleviate pain and urinary residual sense after colorectal cancer surgery: A randomised controlled trial. Evidence-Based Complementary and Alternative Medicine, 2017, 3954181.

Zarei, A., Changizi Ashtiyani, S., Taheri, S., \& Rasekh, F. (2014). Comparison between effects of different doses of Melissa officinalis and atorvastatin on the activity of liver enzymes in hypercholesterolemia rats. Avicenna Journal of Phytomedicine, 4(1), 15-23.

Zazharskyi, V. V., Davydenko, P. O., Kulishenko, O. M., Borovik, I. V., \& Brygadyrenko, V. V. (2019). Antimicrobial activity of 50 plant extracts. Biosystems Diversity, 27(2), 163-169.

Zazharskyi, V. V., Davydenko, P. O., Kulishenko, O. M., Borovik, I. V., Zazharska, N. M., \& Brygadyrenko, V. V. (2020). Antibacterial and fungicidal activities of ethanol extracts of 38 species of plants. Biosystems Diversity, 28(3), 281-289.

Ziaee, M., Khorrami, A., Ebrahimi, M., Nourafcan, H., Amiraslanzadeh, M., Rameshrad, M., Garjani, M., \& Garjani, A. (2015). Cardioprotective effects of essential oil of Lavandula angustifolia on isoproterenol-induced acute myocardial infarction in rat. Iranian Journal of Pharmaceutical Research, 14(1), 279-289.

Zvezdina, E. V., Dayronas, J. V., Bochkareva, I. I., Zilfikarov, I. N., Babaeva, E. Y., Ferubko, E. V., Guseynova, Z. A., Serebryanaya, F. K., Kaibova, S. R., \& Ibragimov, T. A. (2020). Members of the family Lamiaceae Lindl. as sources of medicinal plant raw materials to obtain neurotropic drugs. Pharmacy and Pharmacology, 8(1), 4-28. 


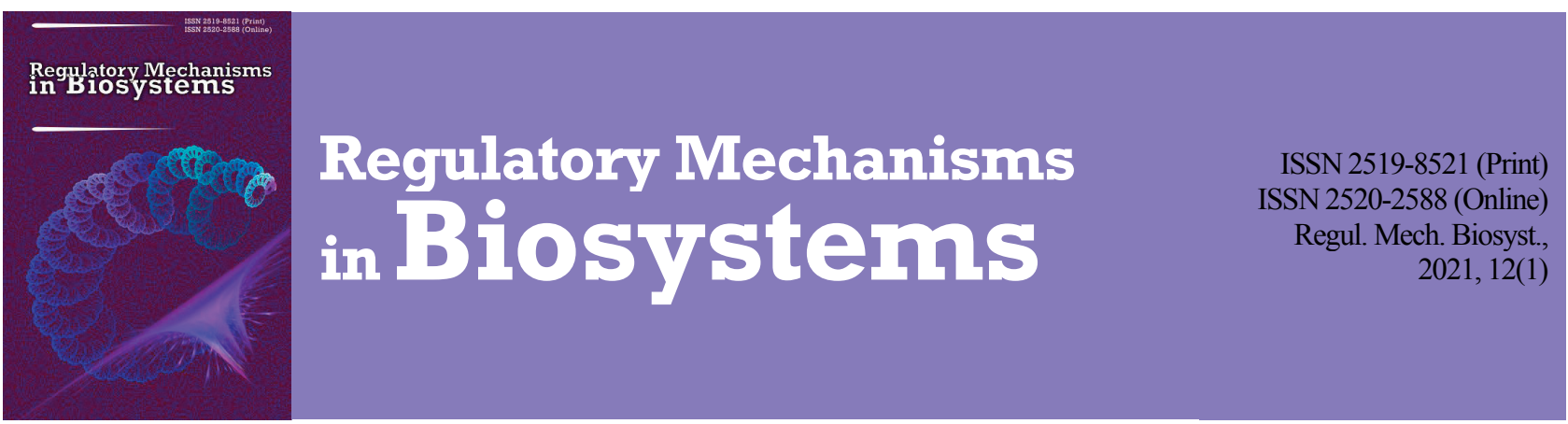

\section{Table of Contents}

Kushch, M. M., Makhotyna, D. S., Fesenko, I. A., Savenko, M. M., \& Ulianytska, A. Y. Microstructure of the nerve plexus of the muscular membrane of the gut of domestic ducks (Anas platyrhynchos domesticus) of different ages ....................................................................................

Shevchenko, L. V., Davydovych, V. A., Midyk, S. V., \& Bezusa, O. O. Enrichment of chicken table eggs with lycopene and astaxanthin ................. 9

Zhurba, M. Y., Klymenko, S. V., \& Szot, I. Quality variation of fruits of species of the genus Lycium in Ukraine: A comparative morphological analysis

Samoiliuk, V. V., Koziy, M. S., Bilyi, D. D., Maslikov, S. M., Spitsina, T. L., \& Galuzina, L. I. Effect of immunological castration of male pigs on morphological and functional condition of the testicles

Borysevych, B. V., Dukhnytskyj, V. B., Tyshkivska, A. M., Tyshkivsky, M. Y., \& Tyshkivska, N. V. Microscopic changes in the organs of broiler chickens with Ornithobacterium rhinotracheale infection

Suprovych, T. M., Suprovych, M. P., Mokhnachova, N. B., Biriukova, O. D., Strojanovska, L. V., \& Chepurna, V. A. Genetic variability and biodiversity of Gray Ukrainian cattle by BoLA-DRB3 gene

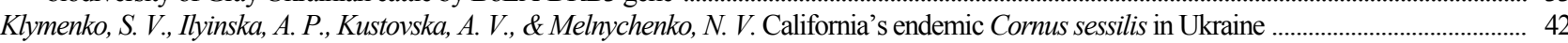

Sliusarenko, D. V., Ilnitskiy, M. G., Bilyi, D. D., Bobrytska, O. M., \& Kovalova, L. O. Regional anesthesiological support for the implementation of surgical interventions in the abdomen of dogs

Galyk, G. V., Fedorovych, Z. Y., Lychkovsky, E. I., \& Vorobets, Z. D. Mathematical model of transmembrane potential dynamics of loach early embryogenesis .

Yevstafieva, V., Horb, K., Melnychuk, V., \& Gorb, O. Differential characters of fleas of the genus Ctenocephalides (Siphonaptera, Pulicidae) obtained from dogs

Zhurba, M., Vergun, O., Klymenko, S., \& Szot, I. Biochemical characterization of fruits of Lycium spp. in Ukraine ................................................. 7

Yuskiv, L. L., \& Yuskiv, I. D. The synthesis of lipids and proteins in vitro in tissues of Cyprinus carpio infected with Bothriocephalus acheilognathi .

Savchuk, I., Skydan, O., Stepanenko, V., Kryvyi, M., \& Kovalova, S. Safety of livestock products of bulls on various diets during fattening in the conditions of radioactive contamination

Syrovatko, K.M. \& Vuhliar, V. S. The effect of additives withe

Flerova, E. A. Structural features of the mesonephros of semianadromous fish on the example of the European smelt (Osmerus eperlanus)

Zaprudnova, R. A. Level of natremia as an index of the condition of the organism of animals under stress .............................................................. 103

Litonina, A. S., Smirnova, Y. M., Platonov, A. V., Laptev, G. Y., Dunyashev, T. P., \& Butakova, M. V. Application of enzyme probiotic drug

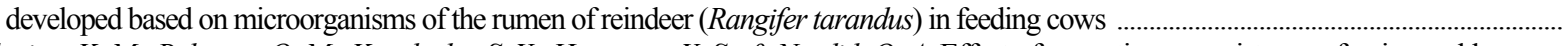

Holovina, K. M., Bobrova, O. M., Kovalenko, S. Y., Hovorova, Y. S., \& Nardid, O. A. Effect of ozonation on resistance of ovine and human erythrocytes to hypothermic storage

Melnychuk, V., Yevstafieva, V., Pishchalenko, M., Reshetylo, O., \& Antipov, A. Morphological identification of Nematodirus spathiger nematodes (Nematoda, Molineidae) obtained from the small intestine of sheep

Snegin, E. A., Kramarenko, A. S., Artemchuk, O. Y., \& Kramarenko, S. S. Intra- and interbreed genetic heterogeneity and divergence in four commercial pig breeds based on microsatellite markers

Drobakhin, O. O., Magro, V. I., Kosharnyi, V. V., Rutgaizer, V. H., \& Abdul-Ohly, L. V. The influence of microwave electromagnetic radiation on rat heart morphogenesis during thyroidectomy

mets, H. V., Iskra, R. Y., \& Svarchevska, O. Z. Hematological parameters and protein metabolism in the blood of pregnant rats under the effect of vanadium citrate

Pirych, A. V., Yurchenko, T. V., Hudzenko, V. M., Demydov, O. A., Kovalyshyna, H. M., Humeniuk, O. V., Kyrylenko, V. V. Features of modern winter wheat varieties in terms of winter hardiness components under conditions of the Ukrainian Forest-Steppe

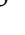

